$$
\begin{gathered}
\text { Universidade de São Paulo } \\
\text { Instituto de Física de São Carlos }
\end{gathered}
$$

Departamento de Física e Ciências dos Materiais Grupo de Computação Interdisciplinar

\author{
VILSON VIEIRA
}

\title{
Um estudo quantitativo sobre a evolução de movimentos artísticos
}

São Carlos

2014 

VILSON VIEIRA

\title{
Um estudo quantitativo sobre a evolução de movimentos artísticos
}

\author{
Dissertação apresentada ao Programa de Pós- \\ Graduação em Física do Instituto de Física de \\ São Carlos da Universidade de São Paulo, para a \\ obtenção do título de Mestre em Ciências. \\ Área de Concentração: Física Aplicada \\ Opção: Física Computacional \\ Orientador: Prof. Dr. Gonzalo Travieso \\ Colaborador: Prof. Dr. Luciano da Fontoura Costa
}

\author{
Versão Corrigida \\ (versão original disponível na Unidade que aloja o Programa) \\ São Carlos \\ 2014
}


AUTORIZO A REPRODUÇÃO E DIVULGAÇÃO TOTAL OU PARCIAL DESTE TRABALHO, POR QUALQÜER MEIO CONVENCIONAL OU ELETRÔNICO PARA FINS DE ESTUDO E PESQUISA, DESDE QUE CITADA A FONTE.

Ficha catalográfica elaborada pelo Serviço de Biblioteca e Informação do IFSC, com os dados fornecidos pelo(a) autor(a)

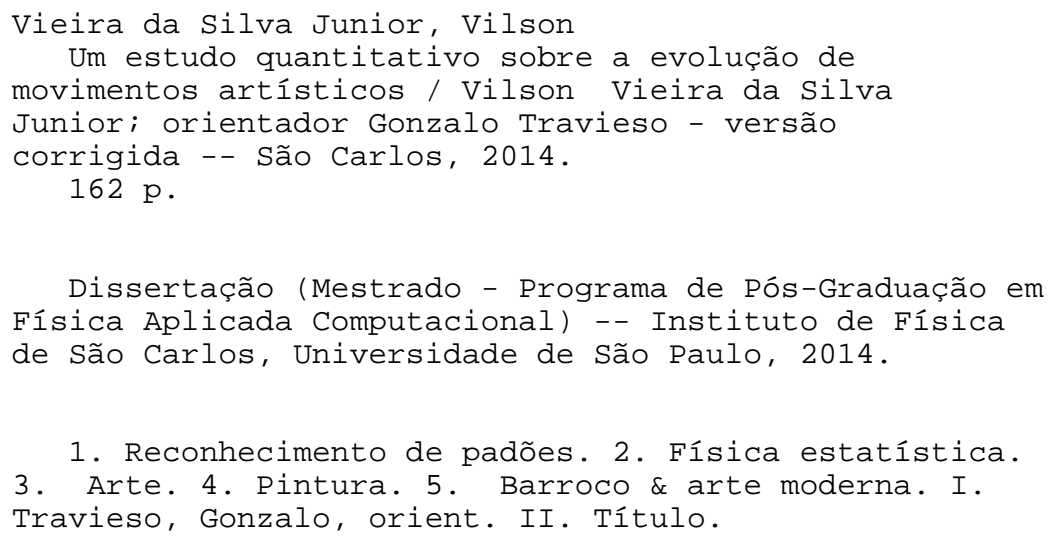




\section{AGRADECIMENTOS}

Sinceros agradecimentos ao Prof. Gonzalo Travieso e ao Prof. Luciano da Fontoura Costa. Tenham certeza que foi com vocês que aprendi o que é fazer pesquisa. Foram ensinamentos que guardarei para toda a vida. Além da orientação de excelência, ficará para sempre a amizade.

Aos meus queridos pais, Vilson e Salete, sabem que devo tudo o que sou a vocês. Encontro sempre suas palavras de conforto e sabedoria em cada esquina que cruzo, em cada caminho que percorro. Amo muito vocês.

À minha amada, Gabriela, que esteve ao meu lado em cada momento, bom ou ruim, por seu amparo, carinho e cumplicidade. Te amo.

À Paulo e Lourdes pelas conversas sempre animadas, e à Isabela pelas risadas sempre prontas às minhas piadas :-D

Aos meus irmãos Renato e Ricardo Fabbri, que me acolhem com tanto carinho e com quem espero viver ainda ótimas passagens. Renato, obrigado por ser um verdadeiro mentor.

Ao bom amigo e conselheiro Pedro Kroeger, continuas sendo a quem sigo os passos. 
A todos do LabMacambira.sf.net, por todas as colaborações e aprendizados, seja artisticamente, cientificamente, socialmente, em software, em tinta, em notas ou em espírito.

À Mozilla Foundation e seus colaboradores, em especial ao bom amigo Forrest Oliphant, que me mentorou enquanto participante do Google Summer of Code 2012 e 2014, e com quem continuo compartilhando ótimas conversas e desenvolvimentos. Thank you, Fo!

A todos os amigos que fiz no IFSC/USP, em especial Carlos Doro Neto (valeu pelo Doro's method!), David Sbrissa (bit******!), prof. Osvaldo "Chu”, prof. Rodrigo Guido, profa. Yvonne Mascarenhas, Débora Correa, Mauro Miazaki, Diego, César, Thomás, Filipi. Aos parceiros do hacklab do velho, tenho grande carinho por todos vocês.

Não sei se conseguirei lembrar de todos, mas meu especial agradecimento e grande carinho a Danivel Penalva, Caleb Luporini, Guilherme Lunhani, Geraldo Magela Rocha, Glerm Soares, Chico e Fábio Simões, Daniel Marostegan, prof. Rogério “Zeco" Silva, Gilson Beck, Marcos Mendonça, Danilo Shiga, Edson Corrêa, Vanessa Ferreira, prof. Luis Castelões, Luis Fernando Muniz Cirne, Marília Pisani, prof. Massimo Canevacci. À Teia Casa de Criação e Pontão Nós Digitais, ao MuSA, aos amigos da Udesc, à galera do AVAV, do Crânio Sonante, a todos que tive contato real e virtualmente, nas listas de email, AA, IRC e outras redes e canais.

Agradeço às comunidades de cultura e software livre e aberto por todos os conhecimentos e tecnologias repassados e que compõem esta contribuição.

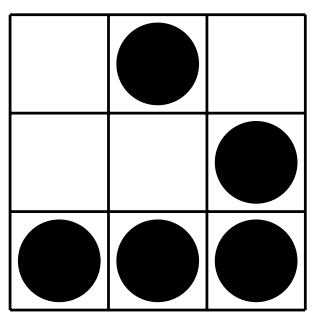


"A arte é feita para perturbar. A ciência tranquiliza. Na arte só uma coisa importa: aquilo que não se pode explicar." - Goerges Braque

"A ciência é tudo aquilo que conseguimos explicar a um computador. Todo o resto é arte." - Donald KNUTH

"Todos querem entender de arte. Por que não tentam entender o canto de um pássaro?"

- Pablo Picasso 



\section{RESUMO}

VIEIRA, V. Um estudo quantitativo sobre a evolução de movimentos artísticos. 2014. 162p. Dissertação (Mestrado) - Instituto de Física de São Carlos, Universidade de São Paulo, São Carlos, 2014.

Enquanto muitos estudos são feitos para a análise e classificação de pinturas e outros ramos das Artes, este estudo não se detém somente à classificação. Estende-se aqui um método de análise já aplicado à Música e Filosofia (1), representando a evolução da Pintura como uma série temporal onde relações como oposição, inovação e dialética são medidas quantitativamente. Para isso, um corpus de pinturas de 12 artistas reconhecidos do período Barroco e de movimentos da Arte Moderna foram analisadas. Um conjunto de 100 atributos foi extraído e os atributos que mais contribuíram para a classificação das pinturas foram selecionados. $\mathrm{O}$ espaço de projeção obtido a partir desses atributos criou a base para a análise de medidas. Essas medidas quantitativas revelaram observações sobre a evolução dos estilos artísticos, especialmente quando comparados com outras áreas do conhecimento humano já analisados. A Música parece ter evoluído com a influência de uma tradição mestre-aprendiz (i.e. por apresentar alta dialética entre os músicos estudados). A Filosofia apresenta valores altos de oposição entre os representantes escolhidos (1), sugerindo que sua evolução apresenta constante oposição de ideias. Já na Pintura nota-se um outro padrão: aumento constante da inovação, baixa oposição entre membros do mesmo período artístico e picos de oposição no momento de transição entre estes períodos. Uma diferença entre os movimentos Barroco e movimentos da Arte Moderna foi também percebido no espaço projetado: enquanto as pinturas barrocas aparecem formando um agrupamento sobreposto, as pinturas modernas apresentam quase nenhuma sobreposição e estão dispostas espalhadas ao longo da projeção, mais que as barrocas. Essa observação encontra base na história da Arte onde os pintores barrocos compartilham características estéticas de suas pinturas, enquanto os modernos tendem a desenvolver seus próprios estilos e, por conseguinte, suas próprias estéticas.

Palavras-chave: Reconhecimento de padrões. Física estatística. Arte. Pintura. Barroco \& arte moderna. 



\section{ABSTRACT}

VIEIRA, V. A quantitative study about the evolution of artistic movements. 2014. 162p. Dissertação (Mestrado) - Instituto de Física de São Carlos, Universidade de São Paulo, São Carlos, 2014.

While many studies were performed for the analysis and classification of paintings and other art venues, this study does not stop in the classification step. It extends an analysis method already applied to music and philosophy, representing the evolution of painting as a time-series where relations like opposition, skewness and dialectics were measured quantitatively. For that, a corpus of paintings of 12 well-known artists from Baroque and Modern art was analyzed. A set of 100 features was extracted and the features which most contributed to the classification of painters were selected. The projection space obtained from the features provided the basis to the analysis of measurements. This quantitative measures underlie revealing observations about the evolution of art styles, even when compared with other humanity fields already analyzed. (1) While music seems to evolve guided by a master-apprentice tradition (i.e. presenting high dialectics between composers) and philosophy by opposition, painting presents another pattern: constant increasing skewness, low opposition between members of the same movement and opposition peaks in the transition between movements. A difference between Baroque and Modern movements are also observed in the projected space: while Baroque paintings are presented as an overlapped cluster, the Modern paintings present minor overlapping and are disposed more scattered in the projection than baroques. This finds basis in arts history where Baroque painters share aesthetic characteristics while Modern painters tend to develop their own style and aesthetics.

Keywords: Pattern recognition. Statistical physics. Arts. Painting. Barroque \& modern art. 



\section{LISTA DE FIGURAS}

Figura 1.1 -

Figura 2.1 -

Figura 2.2 -

Figura 2.3 -

Figura 2.4

Figura $2.5-$
A imagem superior é a ilustração "Reconstrução do Templo de Jerusalém" (1200-1300) para o livro "Histoire d'Outremer", de Guilherme de Tiro. Esta pintura antecede o método de perspectiva de Brunelleschi e portanto é possível notar a ausência de linhas que convirjam para um só ponto, embora haja a intenção da representação de profundidade, pela sobreposição dos elementos. Já a imagem inferior, um afresco de Pietro Perugino (1481-1482), apresenta o estilo de perspectiva, com todas as linhas convergindo para o centro da imagem, em seu horizonte. As imagens ilustram como o estilo pode influenciar mudanças nas características das obras ao longo da história. . . . . . . . 31

Judite e Holoferne (Caravaggio), c. 1599 . . . . . . . . . . . . . 39

Retrato de Isaak Abrahamsz Massa (Frans Hals), c. 1626 . . . . 40

Uma Dança para a Música do Tempo (Nicolas Poussin), c. 1634-

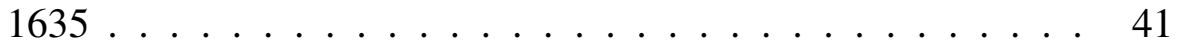

Velha Fritando Ovos (Diego Velázquez), c. 1618 . . . . . . . . 41

A Tempestade no Mar da Galiléia (Rembrandt van Rijn), c. 1633 
a) Dialética: um argumento chamado tese, até então tomado como verdade, é confrontado por um argumento oposto, chamado antítese. O resultado do confronto destas duas ideias é a síntese, que poderá gerar uma nova ideia ou argumento. A linha pontilhada simboliza a sintese ótima entre tese e antítese. Portanto, um argumento que se aproxime dessa linha terá alta dialética; $b$ ) Oposição: é um argumento que se opõe a um argumento original, afasta-se da linha pontilhada de referência. Esta linha de referência é necessária, pois não trata-se apenas de um argumento anterior, mas um conjunto deles. Ela simboliza, no diagrama, um estado médio considerando todos os argumentos originais que antecedem o argumento de posição. Assim, um argumento que se afasta da linha de referência estaria se opondo a tal argumento, e vice-versa; c) Inovação: um movimento de inovação é aquele que se afasta do argumento original, inovando: toma uma nova direção quando comparada à linha pontilhada de referência. Esta linha de referência também demarca o estado médio dos argumentos originais. Portanto, argumentos que tomam uma direção diferente da referência estariam inovando. Nota-se também que há uma ordem temporal dos argumentos, representada pelos números. Para a dialética: primeiro há a tese, em seguida a antítese e, por fim, a síntese. Para a oposição, há o argumento original seguido do argumento de oposição. Para a inovação, há o argumento original seguido do argumento de inovação. . . . . . . . . . . . . . . . 52 
Figura 2.15 - $\quad$ Etapas canônicas utilizadas neste estudo para o processamento de imagens. ....................... 55

Figura 2.16 - Coordenadas das vizinhanças-4 e 8 para um dado pixel $I_{(x, y)}$ qualquer. .................... 56

Figura 2.17 - $\quad$ Espaço de cor CIELAB. Uma cor qualquer é representada como um ponto no espaço $(L *, a *, b *) . \ldots \ldots 61$

Figura 2.18 - $\quad$ a) Rotulação das regiões após aplicação de algoritmo de segmentação segundo vizinhança-4: os rótulos identificam segmentos encontrados pela segmentação, porém não revelam necessariamente regiões conexas; $b$ ) Rotulação das regiões (ou componentes) conexas após aplicação de algoritmo para identificação de regiões conexas: esta é a rotulação desejada quando o que se pretende é identificar formas em uma imagem qualquer. . . . . . 64

Figura 2.19 - $\quad$ a) Imagina da pintura original. $b$ ) Imagem em escala de cinza $I$. c) A entropia $H$ da imagem $I$ mapeada em uma escala de cores. É interessante notar como regiões de borda possuem entropia

Figura $2.21-$ a) Imagem da pintura original. b) Uma região segmentada da pintura. c) A curvatura extraída a partir da região segmentada. d) A curva paramétrica $k(t)$ dado um limiar em particular, com os picos em destaque. . . . . . . . . . . . . . 7 
Figura 2.23 - Esquema representando uma matriz de confusão. Deseja-se que a diagonal principal possua valores próximos ao número máximo de elementos em cada classe $C_{i}$, caracterizando assim uma boa classificação. $C_{i}$ é uma classe do conjunto de treino e $\hat{C}_{i}$ uma classe do conjunto de teste. . . . . . . . . . . . . . . 85

Figura 3.3 - $\quad$ Pré-processamento para recorte das imagens originais em janelas de dimensão $800 \times 800$. a) a imagem original, $b$ ) a janela em destaque, $c$ ) a imagem de dimensões $800 \times 800$ utilizada neste estudo. Embora se percam detalhes da imagem original, o janelamento é necessário para facilitar o processamento ao se utilizar uma dimensão única para as imagens. . . . . . . . . . . . . . . 90

Figura 3.4 - $\quad$ Pré-processamento utilizando equalização de histograma e filtro por mediana com janela de vizinhança-8. a) a imagem original em escala de cinza, $b$ ) a imagem equalizada, $c$ ) a imagem filtrada através do filtro de mediana. Pode-se perceber que a luminosidade da imagem está homogênea. Seus detalhes de borda foram suavizados, porém ainda estão presentes, dada a natureza do filtro por mediana. . . . . . . . . . . . . . . . . 91

Figura 3.5 - $\quad$ Tipos de imagens utilizadas no estudo. a) imagem colorida em formato RGB, $b$ ) imagem em escala de cinza, e $c$ ) imagem binária. 92 
Figura 3.6 - $\quad$ Experimentos realizados para segmentação de pinturas, considerando ambas pinturas barrocas e modernas. $a$ ) a imagem original, $b$ ) segmentação por Watershed, c) Felzenswald, d) SLIC $\operatorname{com} k=10$ e $e$ ) SLIC com $k=20$. O método SLIC com $k=10$ foi escolhido por apresentar, visualmente, melhor separação dos segmentos, e os parâmetros escolhidos contribuíram para a segmentação apresentada. . . . . . . . . . . . . . . 93

Figura 3.7 - $\quad$ Pós-processamento através da rotulação dos componentes conexos e sua filtragem, removendo as regiões com áreas menores que um dado limiar. a) Detalhe de regiões segmentadas através do algoritmo SLIC, $b$ ) objetos rotulados, $c$ ) objetos com área menor que limiar removidos. É a partir desta última imagem que se realizou a extração de características. . . . . . . . . . . . . 99

Figura 3.8 - $\quad$ Regiões segmentadas e suas respectivas curvaturas. Os marcadores em vermelho identificam os picos de curvatura no perfil e sua localização na região segmentada. O cálculo de curvatura demonstra desempenho esperado na identificação dos picos de

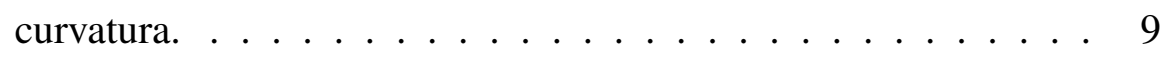

Figura 3.9 - Diagrama com todos os passos tomados, desde o processamento das imagens das pinturas até a extração de características, assim como a obtenção da série temporal onde foram calculadas as medidas de oposição, inovação e dialética. . . . . . . . . . . . 96

Figura 3.11 - $\quad$ Matrizes de espalhamento para cada $i$-ézimo par de atributos, listadas na tabela 3.10 em ordem decrescente de $\alpha$. A primeira projeção (par 1) foi utilizada nesse estudo. . . . . . . . . . . . . 99 
Figura 3.12 - Cálculo dos índices de oposição $W_{i, j}$ - com base no deslocamento $\overrightarrow{D_{j}}$ e inovação $s_{i, j}$ dados dois estados consecutivos $\vec{p}_{i}$ e

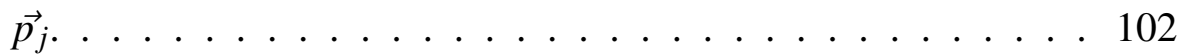

Figura 3.13 - Cálculo da contra-dialética $d_{i \rightarrow k}$ dados os estados consecutivos de tese $\overrightarrow{p_{i}}$, antítese $\overrightarrow{p_{j}}$ e síntese $\overrightarrow{p_{k}}$. Quanto maior o valor da distância $d_{i \rightarrow k}$ de $\overrightarrow{p_{k}}$ à síntese ideal formada pela mediatriz $B_{i, j}$ entre $\overrightarrow{p_{i}}$ e $\overrightarrow{p_{j}}$, menor a dialética. . . . . . . . . 103

Figura 3.14 - $\quad$ Projeção do espaço criativo considerando o melhor par de atributos média de picos da curvatura e média do número de segmentos. ..................... 105

Figura 3.15 - Série temporal considerando o melhor par de atributos média de picos da curvatura e média do número de segmentos. . . . . . . 106

Figura 3.16 - Histogramas dos níveis médios de cinza para todos os pintores barrocos. Vermeer e Velázquez mostram maior similaridade com Caravaggio do que os outros pintores barrocos: a proximidade em contraste encontra fundamento na história (seção 2.1.3), tendo sido ambos pintores influenciados por Caravaggio. . . . . 109

Figura 3.17 - Histogramas nos níveis médios de cinza para os pintores modernos. Há baixa similaridade entre os pintores modernos, diferente do que ocorre para os pintores barrocos. . . . . . . . . 110

Figura 3.19 - $\quad$ Valores de oposição $W_{i, j}$ e inovação $s_{i, j}$ considerando os dois melhores atributos. . . . . . . . . . . . 111

Figura 3.22 - Valores de contra-dialética considerando os dois melhores atri-

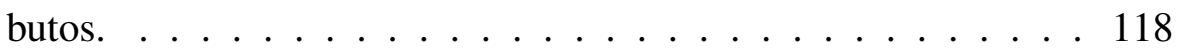


Figura 3.24 - $\quad$ Série temporal resultante da projeção em 2 dimensões do espaço criativo considerando os dois primeiros componentes com maiores autovalores obtidos a partir da transformação LDA na matriz de $N=100$ atributos. . . . . . . . . . . . . . 120

Figura 3.26 - Valores de oposição e inovação considerando a série temporal para todos os $N=100$ atributos refletidos nos dois primeiros componentes obtidos pelo método LDA. Os mesmos padrões observados quando considerando os dois melhores atributos ainda permanecem nessa observação, como esperado. . . . . . . . . . 121

Figura 3.28 - Contra-dialética (valores altos indicam baixa incidência de dialética) calculada para os componentes principais obtidos por LDA. O padrão observado anteriormente para o melhor par de atributos apresenta-se ainda mais visível aqui: é possível observar claramente que o maior valor está no ponto de transição dos movimentos artísticos (Van Gogh e Kandinsky). . . . . . . . . . 123 

100 iterações. Metade das pinturas de cada artista é usada como conjunto de treino e a metade restante como conjunto de teste. Os elementos da diagonal principal mostram o número de amostras da classe esperada que correspondem com a classe obtida pelo método. Dada a grande quantidade de valores na diagonal principal, a validação sugere que o método LDA foi suficiente para a classificação das pinturas. Além disso, detalhes já observados nos resultados desse estudo são novamente observados na matriz: separação entre os pintores antecessores e sucessores à Van Gogh e similaridade entre pintores do mesmo período, principalmente Barroco. A função de acurácia também foi calculada, equivalendo em média a 58\% para as repetições consideradas. . 124

Figura B.1 Caravaggio ..................... 140

Figura B.2 Frans Hals . . . . . . . . . . . . . . . . . . . . 141

Figura B.3 Nicolas Poussin . . . . . . . . . . . . . . . 142

Figura B.4 Diego Velázquez . . . . . . . . . . . . . . . . . 143

Figura B.5 - Rembrandt Harmenszoon van Rijn . . . . . . . . . . . . . . . 144

Figura B.6 - Johannes Vermeer . . . . . . . . . . . . . . . . . . . . 145

Figura B.7 - Vincent van Gogh . . . . . . . . . . . . . . . . 146

Figura B.8 - Wassilly Kandinsky . . . . . . . . . . . . . . . . . 147

Figura B.9 $-\quad$ Henri Matisse . . . . . . . . . . . . . . . . . . . 148

Figura B.10 - Pablo Picasso . . . . . . . . . . . . . . . . . . . . . 149 
Figura C.1 - Visualização alternativa das projeções das figuras3.14 e 3.15. É possível perceber detalhes de contraste e cor e sua influência no agrupamento e separação dos grupos de pintores. . . . . . . . . 15

Figura C.2 - $\quad$ Detalhe da figura C.1 do grupo onde há maior concentração de pintores. Nota-se que alguns pintores, como van Gogh, apresentam uma classificação com nenhuma sobreposição, enquanto outros, principalmente aqueles do grupo Barroco, apresentam grande sobreposição.

Figura C.3 - Detalhe da figura C.1 do grupo de pinturas pertencentes exclusivamente à Jackson Pollock. Por este pintor ter características que foge aos demais artistas, suas pinturas apresentam-se distribuídas afastadas consideravelmente dos outros pintores.

Figura D.1 - $\quad$ Pintura generativa, criada a partir de tesselação de Delaunay da obra original de Frans Hals. . . . . . . . . . . . . . . . . . 159

Figura D.2 - $\quad$ Pintura generativa, criada a partir de tesselação de Delaunay da obra original de Picasso.

Figura D.3 - $\quad$ Fotos da exposição realizada no SIFISC 2013, no espaço “Obra Artística" com imagens geradas por algoritmo desenvolvido em paralelo a este estudo. . . . . . . . . . . . . . . . 161

Figura D.4 - $\quad$ Prévia do conteúdo da publicação impressa intitulada "Pinturas generativas \& Freakcoding" prevista para 2014, através da Editora independente Quiosque. . . . . . . . . . . . . . 162 


\section{LISTA DE TABELAS}

Tabela 2.13 - Sumário de características do período Barroco e de cada artista dos movimentos da Arte Moderna estudados. . . . . . . . . . 50

Tabela 2.20 - Os 14 atributos de textura de Haralick, considerando: $p(i, j)=$ $P_{\bar{d}}(i, j), p_{x}(i)=\sum_{j=1}^{N_{g}} p(i, j), p_{y}(j)=\sum_{i=1}^{N_{g}} p(i, j), p_{x+y}(k=i+j)=$ $\sum_{i=1}^{N_{g}} \sum_{j=1}^{N_{g}} p(i, j), p_{x-y}(k=|i-j|)=\sum_{i=1}^{N_{g}} \sum_{j=1}^{N_{g}} p(i, j)$. Ainda, $H(X)$

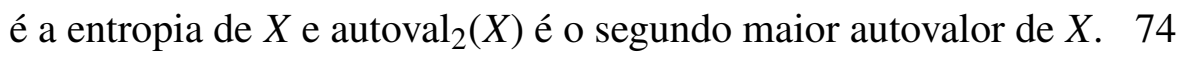

Tabela 2.22 - Sumário de todos os 100 atributos utilizados neste estudo, considerando detalhes de contraste, textura (descritas pelas medidas de entropias e energias, assim como as medidas de Haralick) e forma (descritas pelas medidas de curvatura e medidas geométricas como perímetro, área e sua razão). . . . . . . . . 80

Tabela 3.1 - $\quad$ Pintores escolhidos para a análise, exibidos em ordem cronológica, juntamente com o estilo artístico que melhor representa. Divididos em dois grupos: 6 pintores barrocos e 6 pintores modernos. ......................... 88 
Tabela 3.2 -

Tabela 3.10 -

Tabela 3.20

Tabela $3.21-$

Tabela 3.23 -

Tabela 3.25 -
Algumas das 240 pinturas juntamente com a data de sua criação. Todas as pinturas usadas no estudo estão apresentadas em forma de galeria no apêndice B. . . . . . . . . . . . . . . 8

Pares de atributos $F_{N, a}$ e $F_{N, b}$ ordenados por $\alpha$. Pares com valores maiores de $\alpha$ mostram maior dispersão interclasse enquanto menor dispersão intraclasse (maior agrupamento). O melhor par de atributos: média dos picos de curvatura e média do número de segmentos foram selecionados para a análise e cálculo das medidas de oposição, inovação e dialética. . . . . . . . . . . . . 98

Índice de oposição $W_{i, j}$ e inovação $s_{i, j}$ para cada um dos 11 deslocamentos de um pintor a outro. . . . . . . . . . . . . . 110

Possível interpretação, com base na história da Arte e características estéticas, para cada valor de oposição e inovação calculado. Consideram-se os dois melhores atributos: média do número de segmentos e média da quantidade de picos de curva-

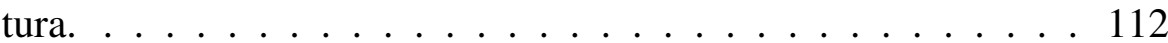

Índices de contra-dialética para cada um dos 10 deslocamentos entre tese, antítese e síntese, considerando os dois melhores atributos: média do número de segmentos e média da quantidade de picos de curvatura. . . . . . . . . . . . . . . . 115

Possível interpretação, com base na história da Arte e características estéticas, para cada valor de contra-dialética calculado. 115

Índices de oposição e inovação para cada um dos 11 deslocamentos de um pintor ao outro. 
Tabela 3.27 - Índices de contra-dialética para cada um dos deslocamentos para os dois melhores componentes do LDA. . . . . . . . . . . . 122 



\section{SUMÁRIO}

1 Introdução 29

1.1 Motivação . . . . . . . . . . . . . . . . . . . . . . . 34

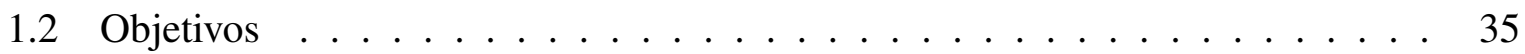

1.3 Organização . . . . . . . . . . . . . . . . . . . 35

$\begin{array}{lll}2 & \text { Fundamentos } & 37\end{array}$

2.1 Uma breve introdução ao Barroco e Arte Moderna . . . . . . . . . . . . . . . . 38

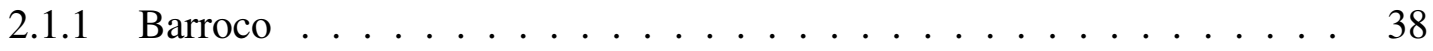

2.1 .2 Arte Moderna . . . . . . . . . . . . . . . . . . . 43

2.1.3 Sumário de características do período Barroco e de movimentos da Arte Moderna . . . . . . . . . . . . . . . . . . . . 48

2.2 Conceitos básicos em Filosofia $\ldots \ldots \ldots$. . . . . . . . . . . 50

2.3 Momentos estatísticos . . . . . . . . . . . . . . . . . . . 53

2.4 Processamento e análise de imagens digitais $\ldots \ldots \ldots$. . . . . . . . . . . 54

2.4.1 Vizinhança e operadores espaciais . . . . . . . . . . . . . 56 
2.4 .2 Pré-processamento ......................... 58

2.4 .3 Segmentação . . . . . . . . . . . . . . . . . . . 60

2.4.4 Pós-processamento . . . . . . . . . . . . . . . . . . 64

2.5 Extração de atributos . . . . . . . . . . . . . . . . . 66

2.5.1 Atributo de complexidade . . . . . . . . . . . . . 67

2.5.2 Atributos espectrais . . . . . . . . . . . . . 69

2.5.3 Atributos de textura . . . . . . . . . . . . . . 72

2.5.4 Atributos de contorno e forma . . . . . . . . . . . . . 73

2.6 Análise de atributos e redução de dimensionalidade . . . . . . . . . . . . . 81

2.6.1 Validação cruzada . . . . . . . . . . . . . . . . . . . 84

$\begin{array}{llr}3 & \text { Desenvolvimentos e resultados } & 87\end{array}$

3.1 Pintores escolhidos $\ldots \ldots \ldots \ldots \ldots$. . . . . . . . . . . . 87

3.2 Corpus de pinturas $\ldots \ldots \ldots \ldots \ldots \ldots$

3.3 Análise de imagens para extração de atributos . . . . . . . . . . . . 88

3.4 Seleção de atributos . . . . . . . . . . . . . . . . . . . . . . . 97

3.5 Medidas de dialética, oposição e inovação . . . . . . . . . . . . . . . 100

3.6 Análise das pinturas para atributos com maior dispersão . . . . . . . . . . . . . 104

3.7 Análise por LDA de todos os atributos . . . . . . . . . . . . . . . 119 
Apêndice A - Tutorial para execução dos scripts Python desenvolvidos para análise

Apêndice B - Galeria de imagens das 240 pinturas analisadas

Apêndice C - Visualizações complementares

Apêndice D - Contribuições artísticas 



\section{Capítulo 1}

\section{Introdução}

A História da Arte costuma ser dividida em períodos, tendências, escolas, estilos e mais recentemente, em movimentos artísticos. (2) Um período compreende o limite de tempo onde certas características predominam entre as obras. Também, em um dado período, há o desenvolvimento de tendências: características na linguagem artística (i.e. cores, texturas, materiais, composições) que tornaram-se marcantes e serão transmitidas para as próximas gerações, seja por sua afirmação ou refutação. Essas tendências, ao se consolidarem, compõem escolas ou estilos. Os movimentos artísticos também apresentam ideias e características comuns, mas costumam ter bem definidos: sua data de criação, local, participantes, assim como um manifesto.

Seja qual for a classificação tomada para a história da Arte e de seus artistas em termos de movimentos e períodos, é possível perceber algo latente: as características de suas obras estão em constante transformação, definindo os diferentes períodos ou escolas. A história da Arte é portanto permeada por uma sucessão de similaridades e oposições destas características ou ideias. A Pintura oferece inúmeros exemplos. Brunelleschi e Alberti inauguraram um estilo de pintura $(3,4)$ onde conseguiam representar a profundidade visível de uma cena utilizando um método geométrico: linhas paralelas convergindo em um ou mais pontos no horizonte. 
(figura 1.1). Até então as pinturas, afrescos, mosaicos e desenhos não tinham noção alguma de profundidade - os elementos que compunham a pintura eram distribuídos segundo sua importância espiritual ou temática, (5) utilizando, por exemplo, a simples sobreposição dos elementos na tela. Esse estilo acabaria por fazer parte das características da grande maioria das pinturas a partir do século XV. (6) Porém, ela não foi suficiente para Cézanne nem seus contemporâneos da Arte Moderna, que estavam descontentes com essa "equação matemática" e usaram gradações de cores para representar a profundidade, rompendo com a tradição iniciada por Brunelleschi e Alberti. (7)

A "Monalisa" de Leonardo da Vinci $(9,10)$ é um dos principais exemplos do estilo sfumato, onde as pinceladas que definem bordas e linhas são removidas com verniz de madeira, comum nas pinturas renascentistas. Outros estilos de pintura como as cores da Escola de Viena, (11) o movimento e a expressão, $(6,12)$ foram criados por cada geração de artistas em uma tentativa de expressar as características que desejavam. A cada geração, estes mesmos artistas descobriram que continuavam existindo convenções que os obrigavam a aplicar o que haviam aprendido ao invés de pintarem o que realmente viam. Os "rebeldes" da Arte Moderna acabaram por negar essas convenções, criando novos meios. Van Gogh não estava interessado em seguir estritamente as regras da perspectiva e profundidade, ao invés disso, deformava a imagem para ressaltar detalhes que lhe eram relevantes. Picasso não se importava que o resultado final de sua obra parecesse distante do modelo original, e desta forma sentia-se livre para retratar verdadeiras colagens das várias perspectivas possíveis do modelo, todas sobrepostas na mesma pintura. Miró pintava símbolos baseando-se em um dicionário que criara, sendo um dos primeiros a utilizar a pintura automática. O século XX presencia a passagem de uma geração de experimentadores, inventores, que davam maior preferência à originalidade do que à tradição. Não queriam mais a "fidelidade" de Caravaggio ou a "beleza ideal" de Poussin, buscavam "expressividade intensa, clareza de estrutura e uma simplicidade linear na técnica.” (6) No modernismo não existiam estilos predominantes — como no caso do período Barroco - mas existiam sim 
Figura 1.1 - A imagem superior é a ilustração "Reconstrução do Templo de Jerusalém" (1200-1300) para o livro "Histoire d'Outremer", de Guilherme de Tiro. Esta pintura antecede o método de perspectiva de Brunelleschi e portanto é possivel notar a ausência de linhas que convirjam para um só ponto, embora haja a intenção da representação de profundidade, pela sobreposição dos elementos. Já a imagem inferior, um afresco de Pietro Perugino (14811482), apresenta o estilo de perspectiva, com todas as linhas convergindo para o centro da imagem, em seu horizonte. As imagens ilustram como o estilo pode influenciar mudanças nas características das obras ao longo da história.
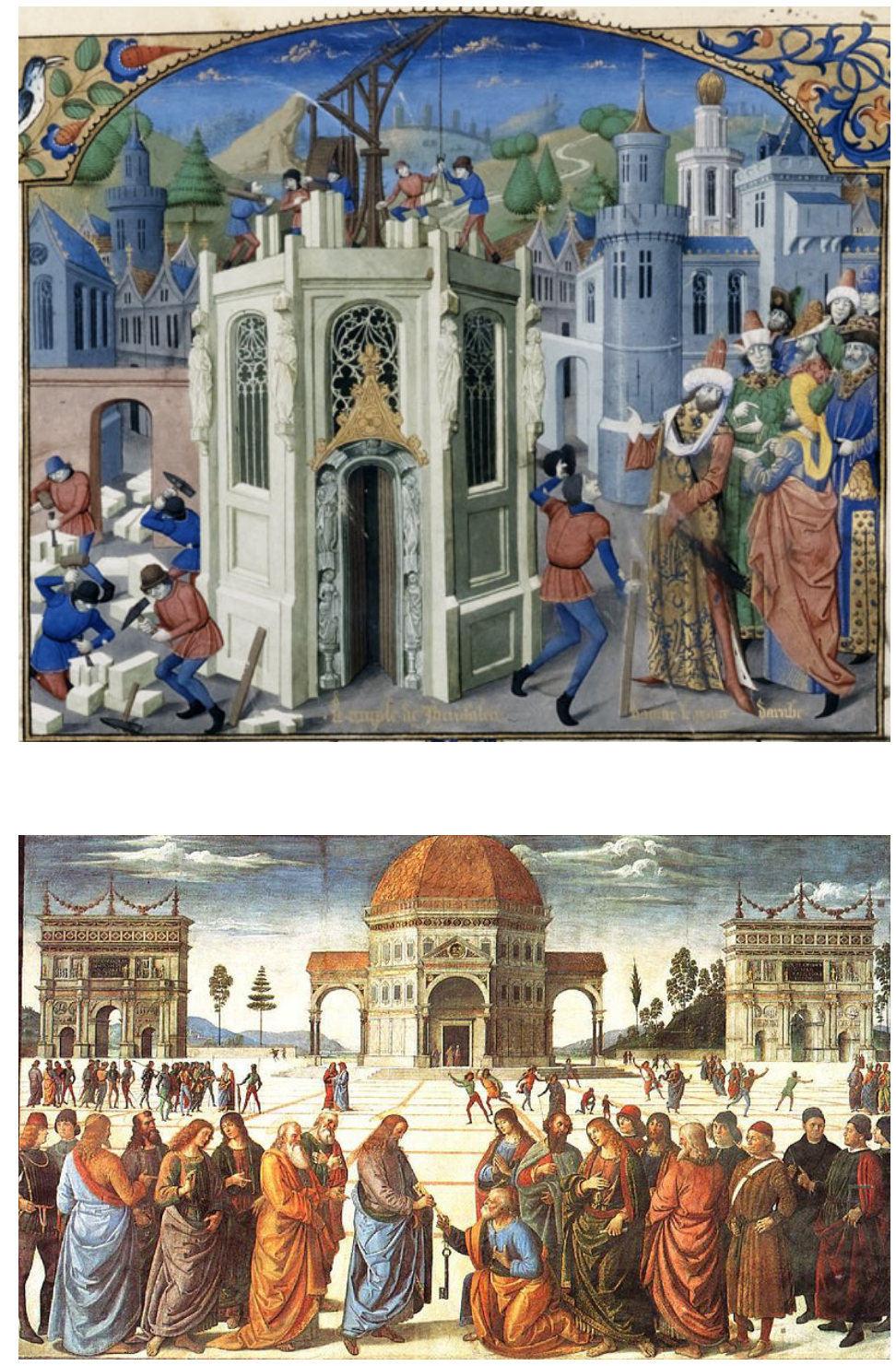

Fonte: PERSPECTIVE...(8) 
várias abordagens, criadas ou desenvolvidas por cada artista. Como bem dito por Gombrich: (6) "Qualquer afastamento da tradição que interessasse à crítica e atraísse um seguidor era saudado como um novo ismo ao qual o futuro pertenceria”. Essa inquietação moderna é avistada nas linhas retas e arquitetura funcional das casas e prédios do outro lado da rua, apenas para citar uma das influências que a Arte Moderna acabou por tornar presente no dia-a-dia.

É justamente essa sucessão de oposições e similaridades entre características nas obras artísticas que torna este estudo possível. Nele, busca-se entender essa evolução de uma maneira quantitativa, através de medidas geométricas. Estas medidas têm como base conceitos centrais no estudo da Filosofia: oposição, inovação e dialética. (13-15) A dialética por exemplo é definida como um método de argumentação onde busca-se a síntese entre dois argumentos contraditórios: a tese e a antítese. São conceitos originalmente qualitativos. Neste estudo, aqui apresentado, promove-se um ponto de vista alternativo: tese, antítese e síntese são definidas como estados em uma série temporal. A dialética torna-se uma medida quantitativa: o inverso da distância entre o estado da síntese e a mediatriz formada pelos estados de tese e antítese. Quanto menor a distância, maior a dialética, pois o estado de síntese se aproxima da mediatriz, que representa no espaço vetorial o que seria a síntese ideal entre as ideias de tese e antítese. Pode-se, assim, medir quanto um argumento apresenta de dialética. Ou se um dado argumento possui dialética maior ou menor que outro, apresentando para isso, valores numéricos. Essas medidas são discutidas de maneira extensiva na seção 3.5.

Para ser possível tal análise, é necessária a representação dos agentes envolvidos — nesse caso, pintores e suas obras - em um espaço vetorial onde as medidas são então realizadas. Esse mapeamento, das imagens de pinturas para o espaço vetorial, começa com a seleção de imagens das pinturas. Para os resultados obtidos no estudo aqui apresentado, foi selecionado um grupo de 12 pintores: 6 do período Barroco e outros 6 de movimentos da Arte Moderna. A escolha de grupos com tamanha disparidade cronológica tem seu motivo: a História da Arte 
reconhece diferenças contrastantes entre o período Barroco e os vários movimentos da Arte Moderna, porém tais afirmações são qualitativas. Neste estudo, busca-se afirmar ou refutar estas afirmações com base em medidas quantitativas. Um total de 20 pinturas de cada autor foi escolhido aleatoriamente, formando um conjunto de 240 pinturas analisadas. Métodos de processamento de imagens foram aplicados para extrair atributos que caracterizam cada pintura. Através da análise de matriz de espalhamento e LDA (Linear Discriminant Analysis), $(16,17)$ os atributos que melhor classificaram as pinturas em seus respectivos pintores foram selecionados. Esses vetores de atributos, agora com dimensões reduzidas, formam então o espaço vetorial pretendido. Considerando tais vetores em ordem cronológica, tem-se uma série temporal e é nessa série que se dá o cálculo das medidas sugeridas para a oposição, inovação e dialética.

Enquanto valores numéricos, tais medidas revelam padrões que encontram paralelo na história da Arte. Um exemplo marcante é o contraste entre pintores barrocos e modernos. Enquanto todo o grupo Barroco apresenta sobreposição entre seus pintores, o grupo de pintores modernos apresenta quase nenhuma sobreposição. Essa observação encontra base na história da Arte, onde os pintores barrocos, reconhecidamente, compartilham técnicas uns com os outros e portanto, compartilham também características estéticas em suas pinturas - enquanto os modernos são marcados pelo individualismo, cada qual definindo seu próprio estilo.

As medidas, assim como o método de análise de séries temporais, são independentes de domínio, o que possibilita sua aplicação para a análise de outras áreas além da Pintura. Até então, Filosofia, Música (1) e Pintura foram avaliadas. Aplicações em Cinema, Literatura e Arquitetura, por exemplo, são possíveis. Tal flexibilidade permite também a comparação entre as medidas obtidas para cada área de conhecimento. Por exemplo, é possível notar que na Música há predomínio de valores altos para a dialética, enquanto na Filosofia, a oposição é o caráter predominante. (1) Já na Pintura, há constante inovação, e ambas oposição e dialética possuem maior valor no momento de transição de um movimento artístico ao outro. Novamente, cada 
um desses resultados encontra fundamento na história e nas características de cada um de seus autores e obras. Tais resultados, sugerem evidências quantitativas da tradição mestre-aprendiz encontrada na Música e tradição de oposição encontrada na Filosofia. Estas tradições são plenamente reconhecidas nas áreas de Música e Filosofia. (1) Na Pintura, verifica-se constante inovação, enquanto oposição e dialética são fortes somente no momento de transição entre períodos artísticos, o que pode vir a acrescentar à compreensão histórica das Artes Plásticas.

\subsection{Motivação}

A subjetividade da história das artes sugere métodos mais objetivos de análise. É importante ressaltar que o método aqui apresentado não pretende esgotar ou suplantar a análise subjetiva, humana, mas sim complementá-la, somar ao ferramental metodológico já existente. Da mesma forma, conceitos como a dialética possuem grande importância nas Ciências Humanas, mas são comumente tratados de maneira qualitativa.

Ainda, o cálculo automático dos atributos usados para análise também motivou esse estudo. No estudo anterior, (1) os atributos eram fornecidos por críticos (os próprios autores) através de notas dadas a uma determinada característica de uma obra. No caso da Música, complexidade rítmica, número de vozes e harmoniosidade dos timbres, são exemplos de características consideradas. Na Filosofia, exemplos de características que foram consideradas são: reducionismo/holismo, teocentrismo/antropocentrismo e racionalismo/empirismo. Na busca pela automatização, fez-se uso do processamento de imagens para extrair atributos das pinturas. Procura-se assim investigar se na Pintura haveriam similaridades com as áreas já analisadas (Música e Filosofia). 


\subsection{Objetivos}

O objetivo principal deste trabalho é modelar artefatos produzidos por artistas como um conjunto de características projetadas em um espaço vetorial. Assim, é oferecida uma forma complementar à interpretação da história artística. Conceitos subjetivos — antes apenas de domínio das Ciências Humanas - como dialética, oposição e inovação podem ser calculados como medidas quantitativas.

\subsection{Organização}

No capítulo 2 são descritos os fundamentos, algoritmos, métodos canônicos e detalhes históricos sobre os quais se construiu este estudo, assim como trabalhos relacionados e de interessante leitura. No capítulo 3 são apresentados os desenvolvimentos realizados nesse estudo: o processamento de imagens para obtenção das características, a representação da evolução artística em um espaço vetorial e a interpretação das medidas de dialética, oposição e inovação. Os resultados são confirmados pelo cálculo dos componentes que mais separam os grupos de pintores, através do método LDA. Este, por sua vez, é validado por uma matriz de confusão. Por fim, no capítulo 4 há uma revisão do que foi discutido e são apontadas as principais contribuições e conclusões desse estudo, além de refletir sobre desenvolvimentos futuros e que já estão em andamento. No apêndice A é apresentado um tutorial para download e execução dos scripts em linguagem de programação Python que implementam os algoritmos desenvolvidos para essa análise. No apêndice B há uma galeria com as 240 imagens das pinturas usadas no estudo. No apêndice $C$ é apresentada uma visualização alternativa da série temporal resultante, que também pode ser explorada através de um aplicativo Web interativo. No apêndice D são descritas as contribuições artísticas deste estudo: uma exposição realizada em 2013 no IFSC/USP com imagens geradas a partir de um algoritmo desenvolvido para pintura generativa. 



\section{Capítulo 2}

\section{Fundamentos}

Neste capítulo são descritos os fundamentos, algoritmos e métodos canônicos, com os quais se realizou esta pesquisa. A seção 2.1 apresenta um resumo sobre características encontradas em ambos períodos Barroco e Moderno, assim como uma pequena biografia de cada artista selecionado para este estudo. A seção 2.2 revisa os conceitos de oposição, inovação e dialética. Estes conceitos foram emprestados da Filosofia e tornados medidas quantitativas, discutidas na seção 3.5.

Os momentos estatísticos básicos, usados ao longo de todo o estudo, são revisados na seção 2.3. A seção 2.4 apresenta os métodos de processamento de imagens usados neste estudo para extrair vetores de características das pinturas, definidos na seção 2.5. A seção 2.6 encerra este capítulo com a discussão do método de espalhamento de matrizes, usado para identificar quais vetores de atributos mais contribuíram para a clusterização das pinturas, assim como o método LDA, que foi aplicado para a redução das dimensões da matriz de atributos. O método LDA confirmou os resultados obtidos para o melhor par de atributos. 


\subsection{Uma breve introdução ao Barroco e Arte Moderna}

É interessante levantar aqui algumas características sobre a história e estética do período Barroco e de movimentos da Arte Moderna. Tais pontos, relacionados diretamente às Artes Plásticas, estão sumarizados na seção 2.1.3 e serão confrontados com observações obtidas pela análise das medidas quantitativas, discutidas na seção 3.6. O resumo biográfico de cada artista considerado, auxilia na avaliação de tais resultados.

\subsubsection{Barroco}

O Barroco na pintura é marcado pela tradição, pelo desejo de retratar a verdade (encontrado nas obras de Caravaggio, Frans Hals e Velázquez), a beleza (em Poussin, Vermeer), o sagrado (Caravaggio, Rembrandt). Esteticamente, é notável o uso do contraste de luz para dar destaque a um determinado local da pintura enquanto escurece regiões menos importantes, como na técnica do chiaroscuro de Caravaggio. Há também a preferência por oposições complexas e desprezo pelo equilíbrio simplista na composição dos elementos em uma pintura. Tais estéticas objetivam causar emoções em quem contempla os quadros, geralmente de caráter sagrado, retratando passagens bíblicas com grande fidelidade aos detalhes. A transmissão dessas técnicas ou estéticas de um pintor para o outro é comum no Barroco. Espera-se, portanto, que pintores barrocos apresentem uma grande similaridade estética em suas obras. $(6,11,18)$ Para o presente estudo, os seguintes pintores foram escolhidos por representarem, reconhecidamente, características do período Barroco:

Miguel Ângelo da Caravaggio, Itália, 1573-1610. Após a Renascença, foram Annibale Carracci e Miguel Ângelo da Caravaggio (19) que, mesmo tendo métodos completamente opostos, amplificaram as ideias já apresentadas em Tintoretto e El Greco durante o chamado Maneirismo: (20) ênfase sobre luz e cor, desprezo pelo simples equilíbrio, preferência por oposições 
complexas. Tais ideias foram apresentadas de uma nova maneira e inauguraram o que viria a ser o período Barroco. (18) Caravaggio - diferente de Carracci que se preocupava em retratar o belo - queria retratar a verdade, como a via, em detalhes. Essa busca pela verdade pode ser vista em Judite e Holoferne (figura 2.1). (21, 22)

O uso da luz, contrastando rigidamente com o Figura 2.1 - Judite e Holoferne (Caravaggio), c. negro fundo, colabora para ressaltar a jovialidade de Judite, que demonstra ter convicção do que faz: cortar a cabeça de Holoferne. Sua serva por outro lado, demonstra nervosismo, esperando que o pedaço de carne morta encha o saco de pano que segura. É possível sentir o horror, a surpresa e impotência de Holoferne enquanto é arrancado de seu sono por sua própria espada. Caravaggio fornece assim 1599

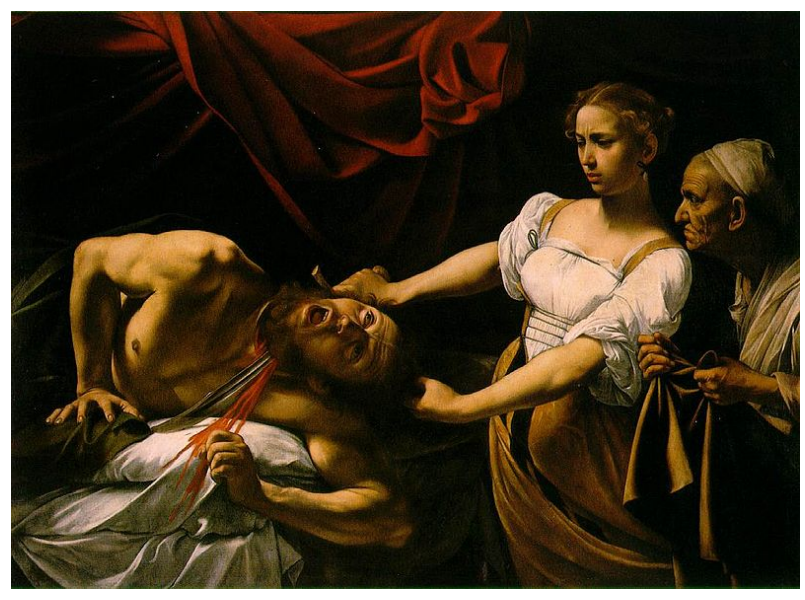

Fonte: CHRONOLOGY...(23)

uma interpretação de notável detalhismo da passagem bíblica: "Então Judite se aproximou da coluna da cama, que ficava junto à cabeça de Holoferne, e pegou a espada dele. Depois chegou perto da cama, agarrou a cabeleira de Holoferne, e pediu: Dá-me força agora, Senhor Deus de Israel. E com toda a força, deu dois golpes no pescoço de Holoferne e lhe cortou a cabeça. Rolou o corpo do leito e tirou o mosquiteiro das colunas. Depois saiu, entregou a cabeça de Holoferne para a serva, que a colocou na sacola de alimentos." (Judite 13, 6)

Frans Hals, Holanda, 1580(?)-1666. Ao mesmo tempo que o Barroco era iniciado na Itália, que compreendia a metade católica da Europa, em regiões protestantes como a Holanda, não havia espaço para pintar o sagrado. (6) Sobravam os retratos como fonte de renda e Frans Hals (24) soube bem como pintá-los, embora recebendo pouco em retorno. Sua obra é constituída em grande parte por retratos de burgueses e mercadores Holandeses, como o Retrato de 
Isaak Abrahamsz Massa (figura 2.2), mercador e amigo próximo de Hals. (Frans Hals), c. 1626

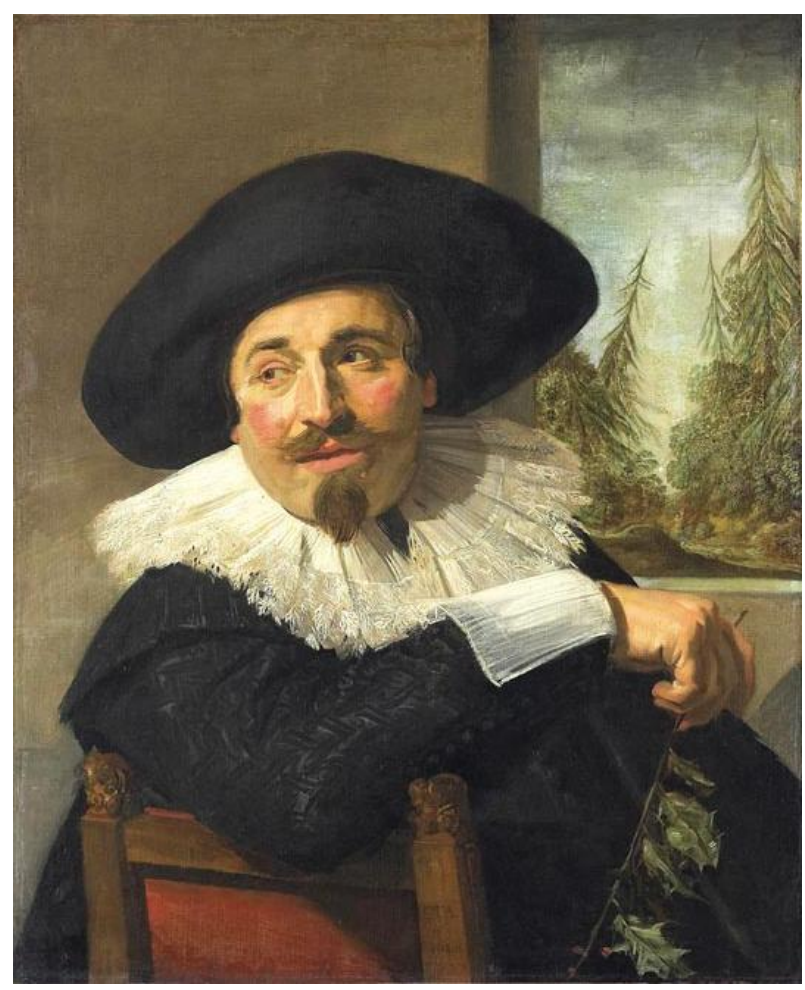

Fonte: LIST...(25)
Figura 2.2 - Retrato de Isaak Abrahamsz Massa

Embora na época a maioria dos pintores e estudantes estivessem influenciados pela técnica do chiaroscuro de Caravaggio, isso não se observa em Frans Hals: o fundo possui detalhes, complementa a composição e existem variações de sombra na face do modelo (o lado direito é iluminado por uma luz direta, enquanto o lado esquerdo apresenta uma sombra de luz natural). Em Caravaggio, a luz é outra, ela é direta, penetrante, artificial. (6) Ao mesmo tempo, os retratos de Frans Hals diferiam dos retratos de até então. Sua pincelada rápida permitia capturar não o modelo, mas o momento, o instante. (26) Outra diferença é a pose alternativa para a época. Diferente dos retratos com olhares perdidos, Frans Hals usa os olhos do modelo para expressar e compor o momento. Ao invés de um olhar perdido, Massa olha para algo que lhe chama atenção, a ponto de virar-se na cadeira.

Nicolas Poussin, França, 1594-1665. Carracci, Reni e seus seguidores retratavam uma versão “embelezada" da natureza, que imitava as estátuas clássicas. Este programa ficou conhecido como neoclássico ou "acadêmico." (6) Poussin foi um dos grandes mestres "acadêmicos", influenciado pelo pintor que representa a oposição a Caravaggio: Carracci. Suas pinturas querem retratar a beleza, a inocência, a pureza de épocas antigas, seus mitos e histórias. (27) É possível notar essa intenção na figura 2.3 que retrata sua obra Uma Dança para a Música do Tempo. 
É interessante apontar a diferença com a obra de Caravaggio e a proximidade com as pinturas de Carracci ou Reni. Ao invés do fundo escuro, da luz artificial, encontra-se uma paisagem iluminada, que se preocupa em retratar o belo. Não há espaço para o horror, para a rigidez da verdade, como acontece com Caravaggio.

Diego Velázquez, Espanha, 1599-1660.

Mesmo ainda não tendo visitado Roma,
Figura 2.3 - Uma Dança para a Música do Tempo (Nicolas Poussin), c. 1634-1635

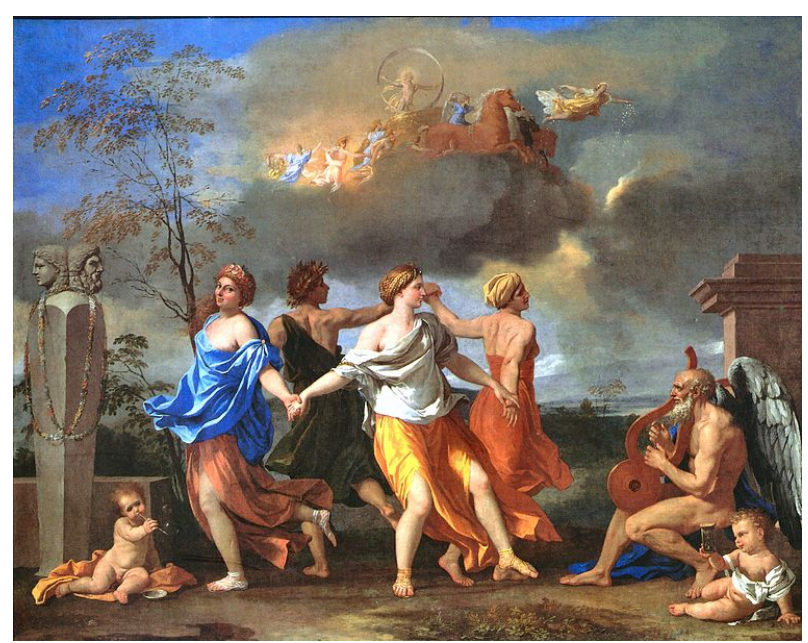

Fonte: LIST. . (28)

Velázquez havia conhecido e se impressionado pelos trabalhos de Caravaggio. Há grande semelhança entre suas obras e as pinturas do mestre italiano, como é possível observar na figura 2.4 da obra Velha Fritando Ovos.
Figura 2.4 - Velha Fritando Ovos (Diego Velázquez), c. 1618

Assim como Caravaggio, retrata a natureza como ela é, sua verdade é mais importante do que sua aparente beleza. Na pintura em destaque, há uma grande preocupação com os detalhes: os ovos, as mãos, as feições dos modelos, os utensílios de cozinha, o vidro que o menino segura, todos representados com precisão fotográfica. A técnica do chiaroscuro de Caravaggio foi aplicada, onde uma luz intensa à esquerda da pintura ilumina com

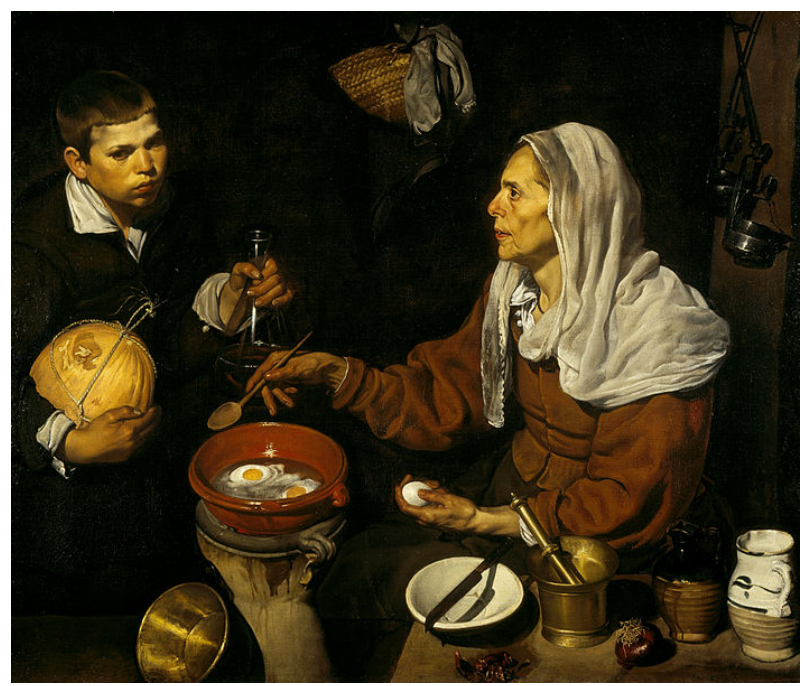

Fonte: LIST...(29) grande contraste os detalhes que Velázquez queria propositalmente ressaltar. Ao mesmo tempo, o fundo é tão negro que não se pode mais observar as paredes do ambiente. (6) 
Rembrandt van Rijn, Holanda, 1606-69. É reconhe- Figura 2.5 - A Tempestade no Mar da cido como o maior pintor da Holanda, dono de uma Galiléia (Rembrandt van Rijn), c. 1633

série de autorretratos que contam de forma biográfica toda a sua vida. $(6,31)$ Rembrandt usava a técnica do chiaroscuro porém de maneira diferente, como é possível ver em A Tempestade no Mar da Galiléia (figura 2.5). Há grande contraste, mas o fundo não está mergulhado em negro, ao contrário, o céu complementa a composição, o mesmo pode se dizer do mar. Essa mesma abordagem está presente nos retratos e outras cenas sagradas que pintou. (32) Rembrandt aproveita técnicas de seus antecessores, mas ao mesmo tempo, se contrapõe a eles, adicionando nuances de seu próprio

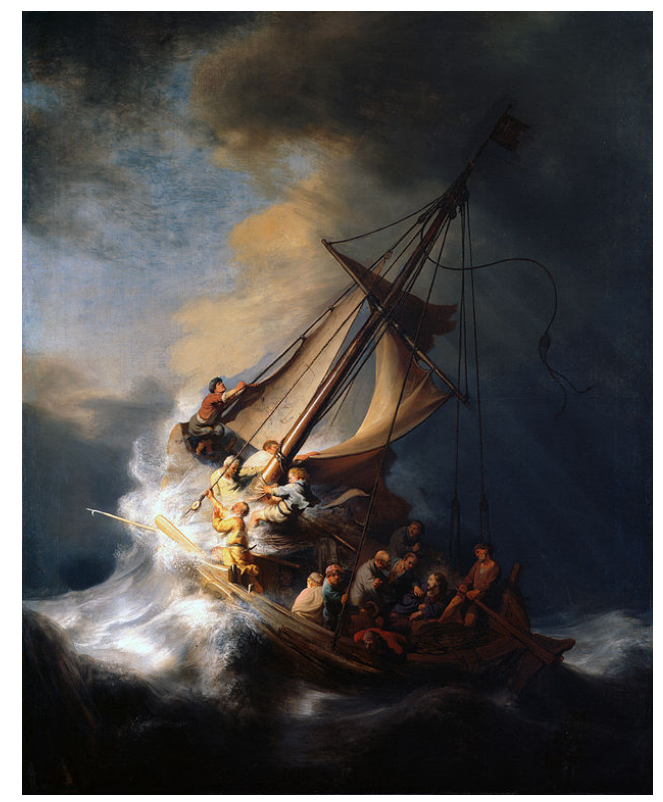

Fonte: LIST...(30) estilo.

Figura 2.6 - A Garota com Brinco de Pérola (Johannes Vermeer), c. 1665

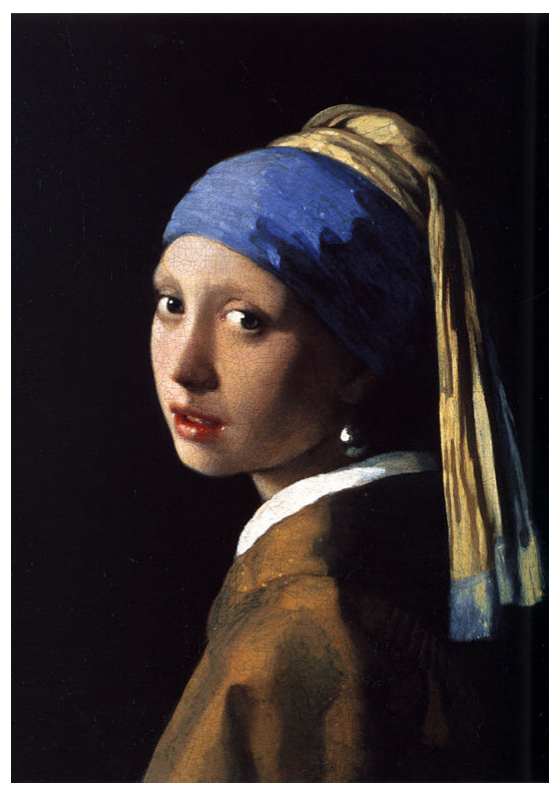

Fonte: LIST...(33)
Johannes Vermeer, Holanda, 1632-1675. Uma das grandes realizações dos pintores holandeses é a retratação da natureza-morta com incrível detalhismo. (34) Vermeer é considerado o grande mestre deste estilo, mas ao invés de objetos, incluía pessoas em sua "natureza-morta". (6) Vermeer parece procurar a melhor vestimenta, a melhor pose do modelo e a melhor posição para o ponto de luz. Parece experimentar com os objetos da cena até encontrar o que deseja. É interessante também perceber a diferença de sua pin- 
tura comparada a dos outros pintores aqui discutidos: todas são feitas praticamente no mesmo local — sempre um cômodo doméstico - e com um número limitado de modelos, geralmente com a luz vindo de uma janela. (34) Em suas pinturas há, a exemplo de Velázquez, uso extensivo do chiaroscuro de Caravaggio, como em A Garota com Brinco de Pérola (figura 2.6). Vermeer desconhecia a perspectiva geométrica: a profundidade em seus quadros era obtida através do reconhecido detalhismo deste pintor e outros holandeses.

\subsubsection{Arte Moderna}

Cada época de uma civilização cria uma arte que lhe é própria e que jamais se verá renascer. Tentar revivificar os princípios artísticos de séculos passados só pode levar à produção de obras natimortas. Assim como é impossível fazer reviver em nós o espírito e as maneiras de sentir dos antigos gregos, também os esforços tentados para aplicar seus princípios [...] só levarão à criação de formas semelhantes às formas gregas. A obra assim produzida será sem alma para sempre.

Wassily Kandinsky (35)

De Vermeer à Van Gogh, passam-se por volta de 150 anos: o Rococó, o Neoclassicismo, o Realismo, chegando aos movimentos da Arte Moderna. Ao contrário do Barroco, a Arte Moderna parece não compartilhar estéticas ou técnicas. (2) Cada pintor aplica ou cria novas formas de representar o que vê ou sente. Como dito por Gombrich: (6) "[os pintores modernos] ansiavam por uma arte que não consistisse de truques que poderiam ser aprendidos, por um estilo que não é meramente um estilo, mas algo forte e poderoso como a paixão humana". Van Gogh procurou por essa arte através do uso intenso de cores e aspecto caricato de suas pinturas. (36) Paul Gauguin buscou no "primitivismo" (37) encontrar as raízes da representação da natureza. Outros como Seurat (4) usaram da observação de propriedades físicas da visão cromática para pintar a natureza como uma coleção de pontos coloridos e dessa forma acabou criando o pontilhismo. 
Os pintores modernos criam seu próprio estilo de maneira individualista, sem a influência de seus contemporâneos ou predecessores. (6)

A Arte Moderna é representada nesse estudo pelos seguintes pintores, que inclui representantes dos movimentos Pós-impressionista, Expressionista, Cubista, Surrealista, Dada e Abstrato:

Vincent van Gogh, Holanda, 1853-1890. Figura 2.7-Quarto em Arles (Vincent van Gogh), Junto com Cezánne e Gaugin, Van Gogh c. 1889

antecede o que veio a ser conhecido como “Arte Moderna.” (6) Cada pincelada de Van Gogh revela sua sensação ao estar pintando, sua emoção; e garantem movimento à composição. Não estava interessado em respeitar regras de perspectiva, de composição, ou sombra. (36) É possível perceber essa

oposição ao clássico em sua obra Quarto em Fonte: LIST...(38)

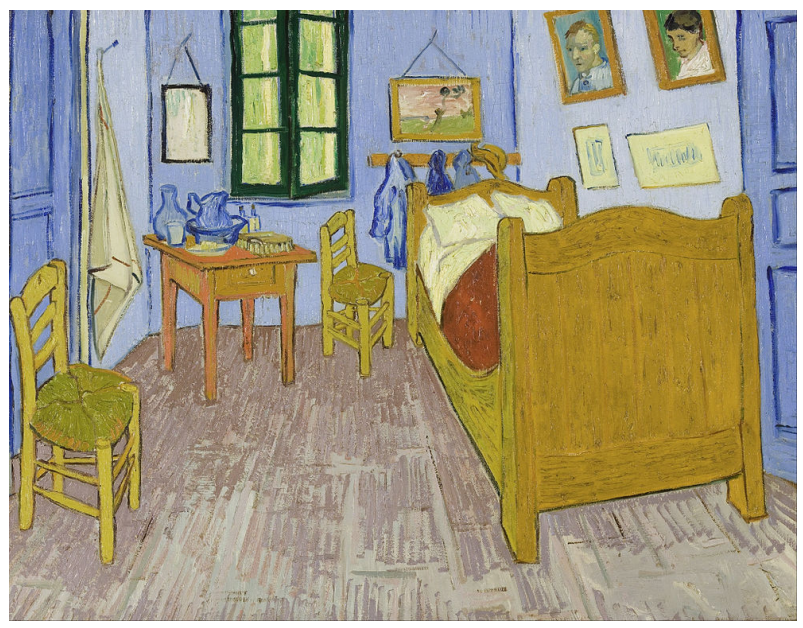
Arles (figura 2.7). Os móveis não apresentam a perspectiva esperada, muito menos dimensões corretas. Não há sombra na pintura. Propunha usar as cores de maneira franca, sem se render às técnicas de sombreado. As pinceladas são todas aparentes, formam a própria textura. Nada têm de parecido com as obras barrocas, ou mesmo às impressionistas. Usava a distorção dos objetos para expressar o que sentia. Vale complementar tal figura com as palavras do próprio Van Gogh em uma de suas inúmeras cartas: "Lamentavelmente, meu caríssimo amigo, o público apenas verá nesse exagero uma caricatura — mas o que nos importa isso?”. (39) Mesmo sem perceber, acabara por desempenhar um papel revolucionário para as artes, e se opõe assim a todos os pintores conhecidos até então.

Wassily Kandinsky, Rússia, 1866-1944. Possivelmente inaugurou o que veio a ser conhecido como "Arte Abstrata" onde nenhum objeto é reconhecível na pintura. (40) 
Figura 2.8 - Em Branco (Wassily Kandinsky), c. Suas pinturas encontram ressonância com a 1923

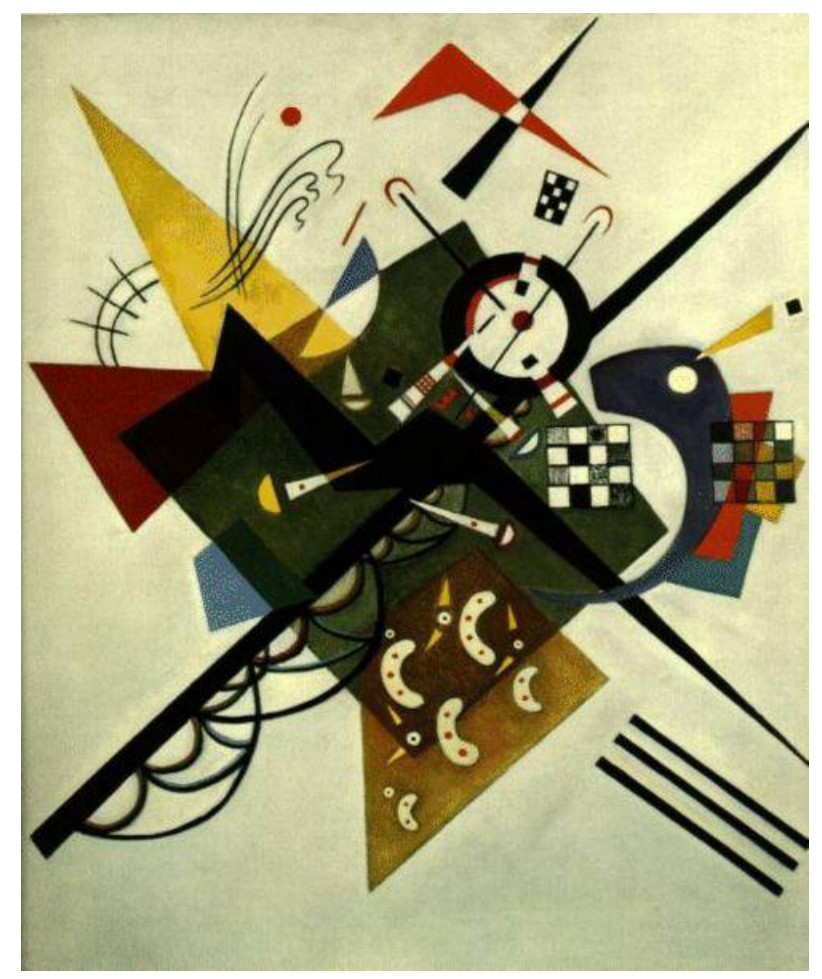

Fonte: WASSILY...(41) música cromática (encontrada já em Bach em seu "Cravo Bem Temperado", tornandose elemento expressivo no fim do período romântico, com Lizt, Mahler e Wagner, e acabando por impulsionar o atonalismo da música serial dodecafônica, já no século XX) no sentido do uso de toda a escala cromática em uma composição. (6) Kandinsky estava interessado no efeito perceptivo da cor pura, na interpretação psicológica das cores. (42) Assim, formas que lembrassem objetos da natureza não eram necessárias, como visível na figura 2.8. Esse uso das cores de maneira direta e franca já tinha sido anunciado por Van Gogh, que negava o uso de sombras para tornar as cores ainda mais aparentes e expressivas, algo visto também em Kandinsky e Matisse.

Henri Matisse, França, 1869-1954. Foi o mais famoso pintor do grupo parisiense conhecido como Lez Fauves, ou "os selvagens", os Fauvistas. $(43,44)$ Tal grupo foi assim chamado pelo desprezo às formas encontradas na natureza e pelo uso de cores "violentas" em suas pinturas. Dedicou-se à "simplificação decorativa" ao estudar os esquemas de cores de tapetes orientais e transpor estes esquemas para seus quadros. (6) Como visto na figura 2.9 há harmonia entre todos os elementos da pintura, fazendo com que pareçam formar um único padrão, como em um tapete. Até mesmo a paisagem vista da janela parece integrar-se com a sala. Os desenhos do papel de parede são encontrados também na toalha da mesa. 
Os contornos simples desses desenhos estão presentes também na figura humana e em todos os utensílios da sala. Por esses motivos, o pintor a chamou de "harmonia em vermelho", ressaltando a importância da cor na obra. (46)

Pablo Picasso, Espanha, 1881-1973. Estava interessado no problema de representar uma imagem através de objetos simples, mas sem perder suas características de solidez e profundidade. $(6,47)$

Influenciado por Cézanne, (49) emprega de forma literal seu conselho de observar a natureza como um conjunto de esferas, cones e cilindros. Procura então representar o que vê como um complexo de peças uniformes, cada uma representando uma faceta do que está sendo retratado. Cria assim o movimento cubista. $(50,51)$ Essa colagem geométrica é vista em Violino (figura 2.10). De certa forma, relembra os desenhos "primitivos" que retratam o objeto a partir do ponto de vista que mais lhe representa. As formas do violino repetem-se por toda a pintura: como as curvas da voluta, dos efes e do corpo. O mesmo grupo de 4 cordas aparece diversas vezes, como que querendo representá-las de vários pontos de vista. Essa colagem de pontos de vista
Figura 2.9 - A mesa de jantar: harmonia em vermelho (Henri Matisse), c. 1908

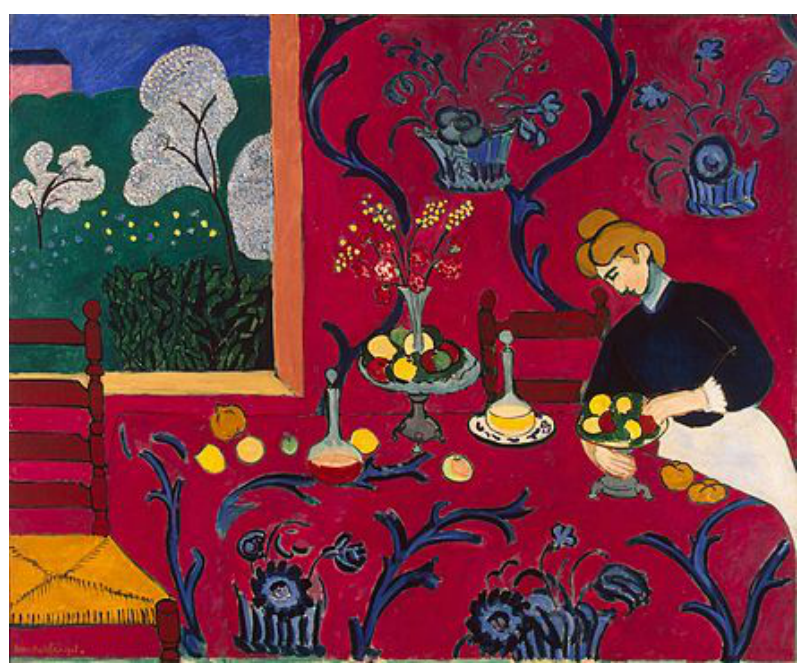

Fonte: LIST...(45)

Figura 2.10 - Violino (Pablo Picasso), c. 1911-12

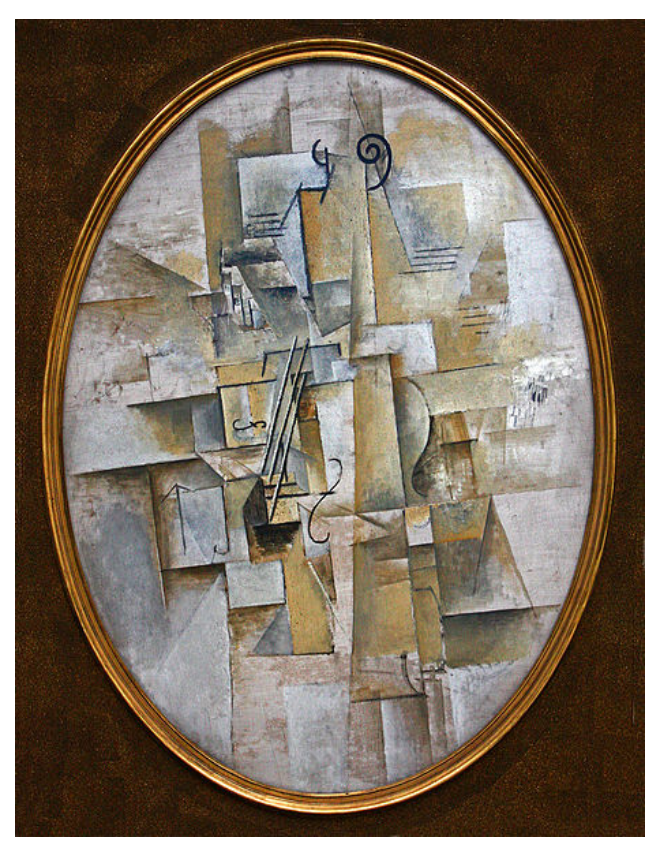

Fonte: PABLO...(48) 
remete ao que acontece quando tenta-se resgatar um objeto da memória. Quando imagina-se um violino, sua forma é exagerada. Não se imagina um violino específico, mas um conjunto de detalhes de todos os violinos que já foram vistos algum dia. Embora seja uma colagem de formas desconexas, a pintura aparenta organização, como se seu todo desse sentido ao objeto já conhecido. (6)

Joan Miró, Espanha, 1893-1983. Inicial- Figura 2.11 - O Campo Cultivado (Joan Miró), c. mente teve sua fase fauvista mas tornou-se reconhecidamente um surrealista. Miró foi um dos primeiros artistas a desenvolver a "escrita automática", uma técnica onde o artista deixa sua mão mover-se livremente pelo papel, transferindo o desenho, em seguida, para a tela. (53) Queria com isso se desfazer das técnicas de pintura já estabelecidas. Utilizou 1923-24

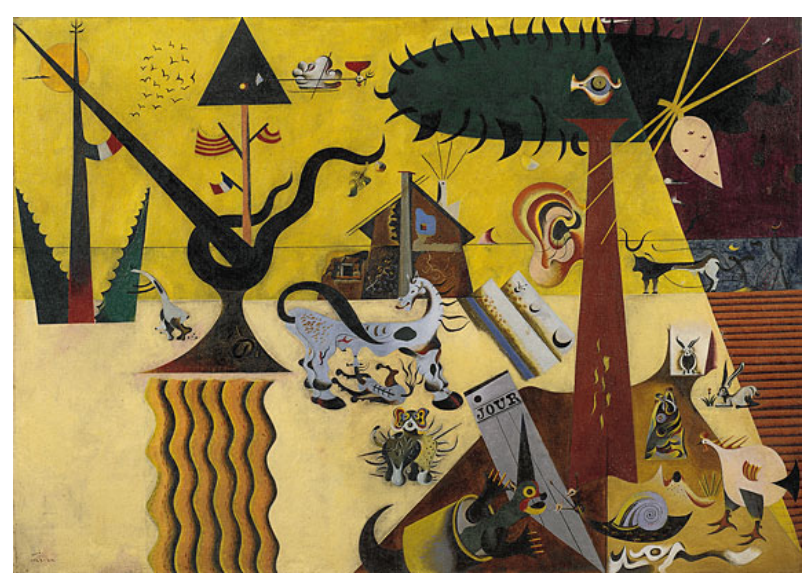

Fonte: JOAN...(52) também um dicionário de símbolos abstratos para representar objetos reais (e.g. um triângulo para a cabeça, linhas curvas para um bigode) como é visto na figura 2.11, onde sua obra acaba por se tornar uma colagem destes símbolos. (54)

Jackson Pollock, Estados Unidos, 1912-1956. Abandonou as imagens fantásticas do Surrealismo e os métodos convencionais de pintura. Pintava com as telas jogadas no chão, gotejando ou arremessando suas tintas, em pé, sobre as telas. O complexo de linhas (visto na figura 2.12) reflete o desejo de simplificação dos artistas modernos assim como sua busca por uma "pintura pura." (6)

Pollock trilhou essa busca através do que ficou conhecido como "pintura de ação": uma pintura não premeditada, criada por impulso espontâneo. Isso é afirmado pelo próprio pintor: "Não tra- 
Figura 2.12 - Ritmo de Outono (Jackson Pollock), c. 1950

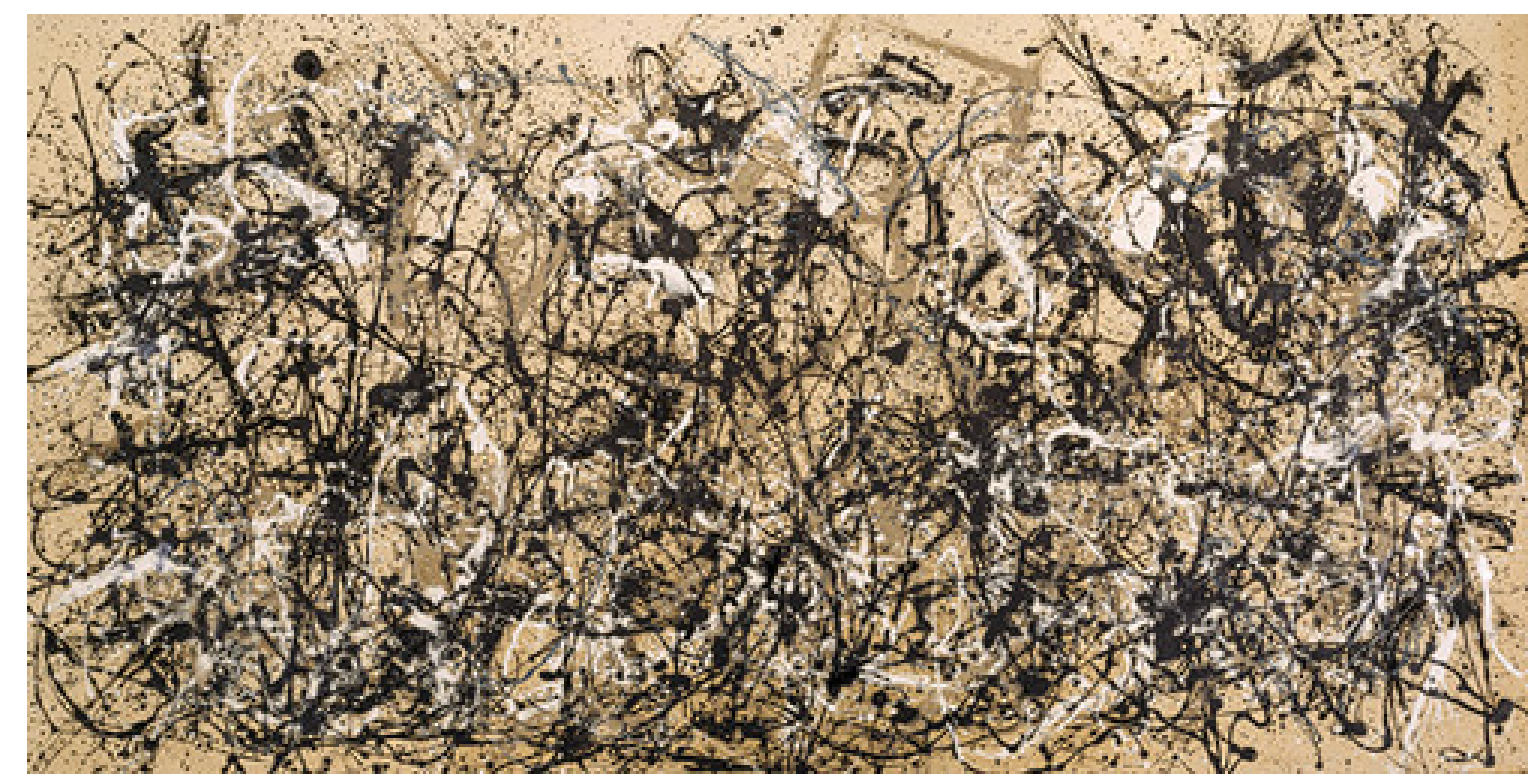

Fonte: JACKSON...(55)

balho a partir de desenhos ou esboços em cores. Minha pintura é direta. [...] O método de pintar é o resultado natural de uma necessidade. Quero expressar meus sentimentos, e não ilustrá-los. A técnica é apenas um meio de chegar a uma declaração. Quando estou pintando, tenho uma ideia geral do que estou fazendo. Posso controlar o fluxo da pintura: não há acidentes, assim como não há começo nem fim. Eu não tenho medo de fazer mudanças, de destruir a imagem, porquê a pintura tem vida própria. Eu tento deixar ela viver.”. (56)

\subsubsection{Sumário de características do período Barroco e de movimentos da} Arte Moderna

Dadas as características presentes nas obras dos pintores escolhidos, pode-se sumarizar um conjunto de afirmações que serão confrontadas no Capítulo 3 de resultados:

- Os pintores da Arte Moderna são caracterizados por sua independência em estilo: há 
pouca similaridade entre suas obras e de suas obras com àquelas do período Barroco. Já os pintores do período Barroco apresentam semelhanças, por compartilharem estilos tradicionais. Embora hajam também oposições, como entre Poussin e Caravaggio.

- Há uma diferença cronológica considerável entre o Barroco e os movimentos da Arte Moderna, assim como diferenças estéticas marcantes entre estes dois períodos;

- Pollock apresenta pinturas que diferem de todos os outros pintores escolhidos. Suas pinturas chegam a sugerir aleatoriedade, contrastando até mesmo com pintores também surrealistas como Miró e afastando-se por completo dos artistas barrocos;

- Velázquez e Vermeer se assemelham com Caravaggio pois ambos utilizavam chiaroscuro. Velázquez chegou a estudar as pinturas de Caravaggio e a semelhança de suas obras é notável;

- Caravaggio é expoente no uso da técnica do chiaroscuro, apresentando pinturas com predominância de cores escuras. Portanto há grande diferença de contraste entre suas pinturas e àquelas mais modernas, sendo estas mais claras;

- Poussin se opõe à Caravaggio: ele não deseja retratar a verdade, mas sim o belo. A técnica do chiaroscuro não é encontrada em Poussin, suas pinturas são mais claras, lembrando as pinturas de Carracci, Reni ou mesmo Rafael.

- O Barroco tem como objetivo principal retratar emoções, movimento. É possível perceber que pinturas como as de Caravaggio tinham o intuito de chocar, principalmente por se tratarem de retratações sagradas.

A tabela 2.13 resume de maneira pontual as características que marcam as obras da grande maioria dos pintores do período Barroco, assim como aquelas que fazem parte das obras de cada pintor moderno: 
Tabela 2.13 - Sumário de características do periodo Barroco e de cada artista dos movimentos da Arte Moderna estudados.

\begin{tabular}{|c|c|c|}
\hline Barroco & \multicolumn{2}{|c|}{ Arte Moderna } \\
\hline \multirow{6}{*}{$\begin{array}{l}\text { Contraste (e.g. claro-escuro); } \\
\text { emoção ao invés da razão; movimento; } \\
\text { dramaticidade; sensualidade; } \\
\text { beleza; fantasia; } \\
\text { a verdade; o sagrado }\end{array}$} & Van Gogh & $\begin{array}{l}\text { Sensação; movimento; textura; cores; } \\
\text { uso da perspectiva e profundidade de uma } \\
\text { nova maneira; distorção }\end{array}$ \\
\hline & Kandinsky & $\begin{array}{l}\text { Abstrato; cromatismo; } \\
\text { interpretação psicológica; } \\
\text { formas geométricas, puras }\end{array}$ \\
\hline & Matisse & $\begin{array}{l}\text { Cores "violentas"; desprezo às formas } \\
\text { naturais; decoração; simplicidade }\end{array}$ \\
\hline & Picasso & $\begin{array}{l}\text { Solidez; simplicidade; formas geométricas; } \\
\text { colagem de várias perspectivas }\end{array}$ \\
\hline & Miró & $\begin{array}{l}\text { Surreal; automatismo; símbolos e seus } \\
\text { significados; negação das técnicas de } \\
\text { pintura existentes }\end{array}$ \\
\hline & Pollock & Abstrato; pintura de ação, pura, espontânea \\
\hline
\end{tabular}

Fonte: Elaborado pelo autor.

\subsection{Conceitos básicos em Filosofia}

Dialética, oposição e inovação são conceitos essenciais nas discussões filosóficas. A dialética é vista como método filosófico para argumentação, central na Filosofia ocidental e oriental. (1315) Para Platão, o método dialético era o próprio método científico, onde se investiga racionalmente um determinado conceito. (14) Cada conceito deve ser confrontado com outras teorias e situações para se chegar a uma nova teoria. Hegel sumariza o método dialético (15) em três momentos bem definidos: a tese, um argumento ou ideia tomado como verdadeiro; a antítese, a contradição ou negação da tese; e a síntese, o resultado do confronto da tese com a antítese. A solução dialética — a síntese - é uma nova ideia que busca pelo equilíbrio entre tese e antítese, ilustrado na figura 2.14 .

Como a tradução literal sugere, "o caminho entre as ideias" é o diálogo entre ideias que leva a outras ideias, ou teorias. Zenão de Eleia, Aristóteles, Platão e Sócrates foram pioneiros em seu 
uso. A dialética também está presente no método dialético de Hegel e na dialética materialista de Marx, que propõe utilizar a dialética como um método propriamente científico, aplicando-a diretamente à realidade. (57)

A oposição de ideias está intimamente relacionada à dialética. Frequentemente, há grande oposição entre a tese e a antítese (figura 2.14, detalhe $b$ ), sendo ideias essencialmente contraditórias. A inovação, por sua vez, relaciona-se com a oposição: uma ideia não necessariamente estará destinada a opor uma outra ideia, pois não participa apenas de um "jogo de oposição". Uma ideia pode também "buscar" um movimento novo, alternativo. Desta forma, estará inovando, contrastando com a oposição, indo em uma nova direção (figura 2.14, detalhe c). É importante notar que há uma ordem temporal nos argumentos, simbolizados na figura por números. No caso da dialética, há primeiramente a tese, seguida da antítese e, por fim, a síntese. Portanto, compreende três estados temporais. O mesmo ocorre para a oposição e inovação, porém compreendendo apenas dois estados no tempo.

Uma proposta de quantificar os conceitos básicos de dialética, oposição e inovação foi iniciado em um estudo aplicado à Filosofia e Música. (1) A partir de uma matriz de atributos que descreve pesos (ou notas) dadas em conjunto pelos autores à certas características de filósofos e músicos, tem-se um espaço vetorial onde os conceitos são quantificados. Esse estudo está sendo aqui expandido. As mesmas medidas são aplicadas, mas não mais à notas que poderiam ser julgadas como subjetivas - já que atribuídas por humanos. Ao invés disso, as notas são substituídas por vetores de atributos, extraídos através do processamento de imagens (discutido nas seções 2.4 e 3.5). 
Figura 2.14 - a) Dialética: um argumento chamado tese, até então tomado como verdade, é confrontado por um argumento oposto, chamado antítese. $O$ resultado do confronto destas duas ideias é a síntese, que poderá gerar uma nova ideia ou argumento. A linha pontilhada simboliza a sintese ótima entre tese e antítese. Portanto, um argumento que se aproxime dessa linha terá alta dialética; b) Oposição: é um argumento que se opõe a um argumento original, afasta-se da linha pontilhada de referência. Esta linha de referência é necessária, pois não trata-se apenas de um argumento anterior, mas um conjunto deles. Ela simboliza, no diagrama, um estado médio considerando todos os argumentos originais que antecedem o argumento de posição. Assim, um argumento que se afasta da linha de referência estaria se opondo a tal argumento, e vice-versa; c) Inovação: um movimento de inovação é aquele que se afasta do argumento original, inovando: toma uma nova direção quando comparada à linha pontilhada de referência. Esta linha de referência também demarca o estado médio dos argumentos originais. Portanto, argumentos que tomam uma direção diferente da referência estariam inovando. Nota-se também que há uma ordem temporal dos argumentos, representada pelos números. Para a dialética: primeiro há a tese, em seguida a antítese e, por fim, a síntese. Para a oposição, há o argumento original seguido do argumento de oposição. Para a inovação, há o argumento original seguido do argumento de inovação.

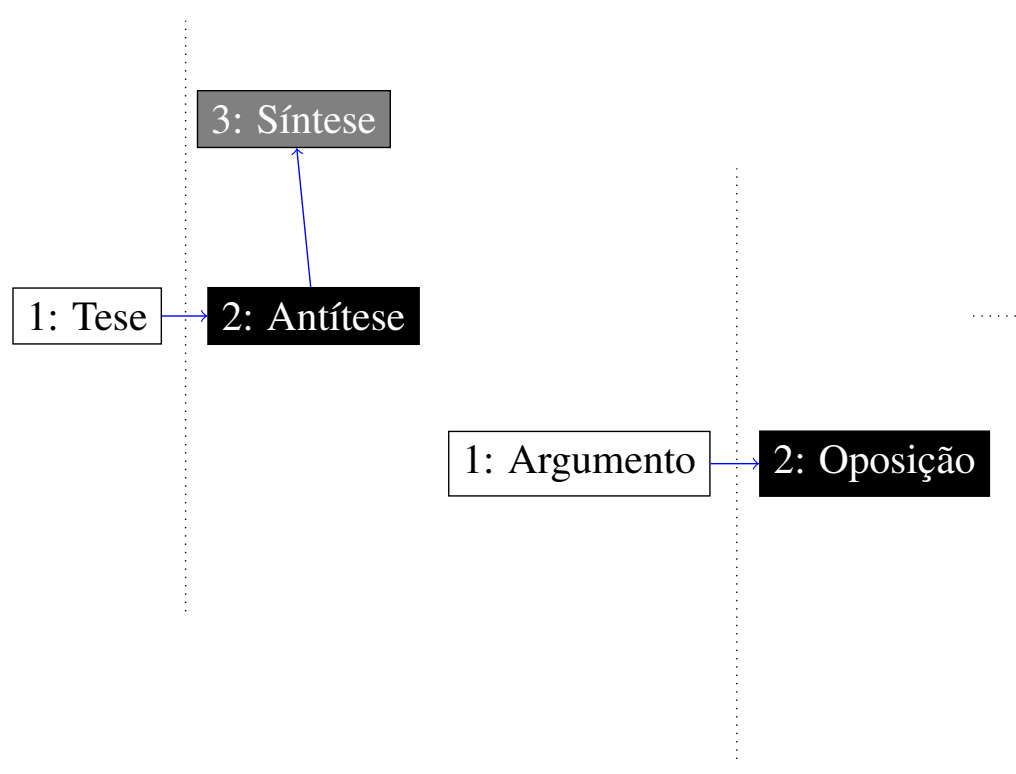

a) Dialética

b) Oposição

c) Inovação

Fonte: Elaborado pelo autor. 


\subsection{Momentos estatísticos}

Alguns momentos de distribuição da Estatística Descritiva ou Teoria de Probabilidades são utilizados durante todo este estudo e cabe aqui uma rápida revisão. Primeiramente, os momentos estatísticos centrais, úteis quando se observa uma tendência central nas variáveis aleatórias ou seja, quando os dados tendem a agruparem-se em torno de um valor específico. Considerando a variável aleatória $X$, sua média é definida como (58)

$$
\operatorname{média}(X)=m_{x}=\mu_{x}=\bar{x}=\frac{\sum_{i=1}^{n} X_{i}}{n}
$$

e estima o valor central, em volta do qual os valores $X_{i}$ agrupam-se. Um outro momento usado para estimar a centralidade é a mediana, definida como

$$
\operatorname{mediana}(X)=\tilde{\mathrm{x}}=\mu_{1 / 2}=\left\{\begin{array}{ll}
X_{(n+1) / 2} & n \text { ímpar } \\
\operatorname{média}\left(X_{n / 2}, X_{n / 2+1}\right) & n \text { par }
\end{array} \quad \text { (estando } X\right. \text { ordenado). }
$$

Após ter-se definido o valor central, pode-se estimar o espalhamento ou quanto os valores variam em torno do valor central. A variância é geralmente utilizada para este fim:

$$
\operatorname{variância}(X)=\operatorname{var}_{x}=\sigma_{x}^{2}=s_{x}^{2}=\frac{\sum_{i=1}^{n}\left(X_{i}-\mu_{x}\right)^{2}}{n-1}
$$

assim como o desvio padrão, que corresponde à raiz quadrada da variância:

$$
\text { desvio padrão }(X)=\operatorname{std}(X)=\sigma_{x}=s_{x}=\sqrt{\frac{\sum_{i=1}^{n}\left(X_{i}-\mu_{x}\right)^{2}}{n}} \text {. }
$$

Ao se considerar duas variáveis aleatórias $X$ e $Y$, pode-se estender o cálculo da variância para 
estimar-se o grau de interdependência entre as duas variáveis aleatórias:

$$
\operatorname{covariância}(X, Y)=\operatorname{cov}(X, Y)=c_{X, Y}=\frac{\sum_{i=1}^{n}\left(X_{i}-\mu_{x}\right)\left(Y_{i}-\mu_{y}\right)}{n}
$$

É interessante notar que variáveis independentes terão covariância igual a zero.

\subsection{Processamento e análise de imagens digitais}

O processamento e análise de imagens digitais compreende operações para adquirir, manipular e representar imagens digitais em um sistema computacional. (59) Este processamento envolve uma série de etapas canônicas (16) e a figura 2.15 apresenta as etapas utilizadas neste estudo. Estas operações são necessárias para extrair os vetores de características de uma imagem. $\mathrm{Na}$ presente seção são discutidas as etapas utilizadas neste estudo.

Cada imagem, após ser digitalizada, é representada como uma matriz de valores onde cada elemento armazena a intensidade luminosa de uma região amostrada da imagem analógica. Uma imagem colorida $I$ representada no formato digital conhecido como RGB (as bandas de cores primárias vermelha, verde e azul) é definida como a matriz $I$ de valores discretos $I_{(x, y)}$ com dimensão $N_{x} \times N_{y} \times N_{z}$. Os valores $N_{x}$ e $N_{y}$ são, respectivamente, a quantidade de pixels das linhas e colunas de $I$, e $N_{z}$ determina a quantidade de bandas de cores da imagem - e.g. para uma imagem RGB de $800 \times 800$ pixels, a dimensão de sua representação matricial é $800 \times$ $800 \times 3$. Cada elemento $I_{(x, y)}$ da matriz corresponde a uma tripla $(R, G, B)$ de valores inteiros compreendidos entre 0 e 255 , onde 0 é a intensidade de cor mais escura, e 255 a mais clara. A combinação destas três intensidades resulta na cor do pixel.

As imagens também podem ser representadas em escala de cinza (ou monocromática), por uma matriz I com dimensão $N_{x} \times N_{y} \times N_{z}$, com $N_{z}=1$, onde cada pixel $I_{(x, y)}$ é descrito por um único 
Figura 2.15 - Etapas canônicas utilizadas neste estudo para o processamento de imagens.

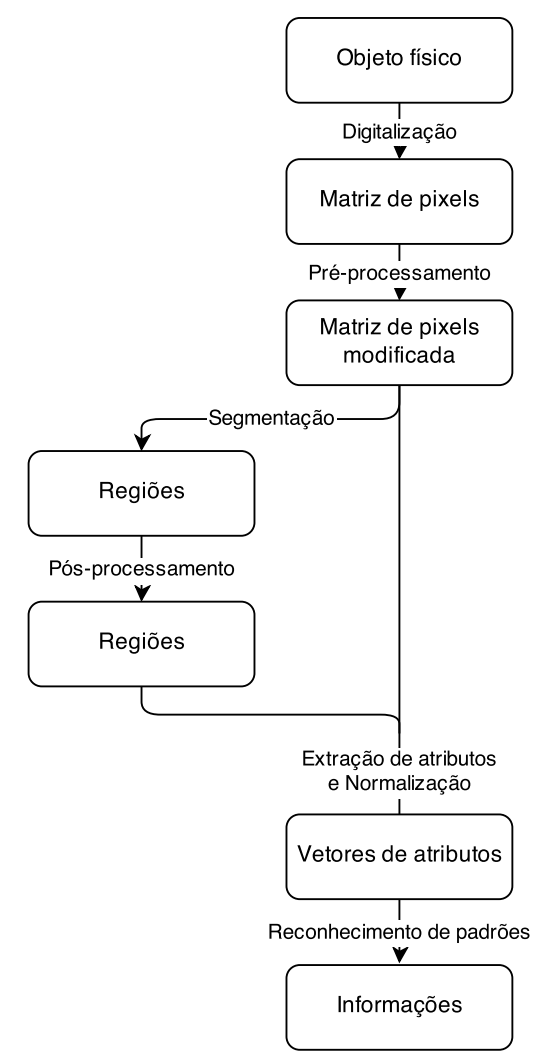

Fonte: Elaborado pelo autor.

valor de intensidade. Nota-se que cada banda de cor de uma imagem RGB corresponde a uma imagem monocromática.

Alguns algoritmos utilizam a imagem representada com apenas dois valores: preto e branco. Por exemplo, em uma imagem segmentada, os elementos conexos podem ser representados com a cor branca e fundo preto. A matriz para esta representação binária é definida como I tendo dimensão $N_{x} \times N_{y}$. Cada um de seus elementos $I_{(x, y)}$ pode assumir apenas dois valores, 0 ou 255. Convenciona-se usar também os valores 0 ou 1, dado o aspecto binário da matriz e para facilitar a aplicação de operações lógicas sobre elas. (59)

Uma imagem $I$ é também definida como uma função $f(x, y)$ que mapeia os índices matriciais $(x, y)$ de um pixel em seu valor $v$ de intensidade. Sendo $S_{x}=\left\{0,1, \ldots, N_{x}-1\right\}$ e $S_{y}=\left\{0,1, \ldots, N_{y}-\right.$ 
1 o domínio espacial da imagem e $S_{v}=\{0,1, \ldots, 255\}$ o domínio de $v$, tem-se a função

$$
f: S_{x} \times S_{y} \rightarrow S_{v}
$$

para imagens binárias o domínio será $S_{v}=\{0,255\}$ ou $S_{v}=\{0,1\}$, representando assim os possíveis níveis de intensidade da imagem. (59)

\subsubsection{Vizinhança e operadores espaciais}

As relações locais entre pixels de uma imagem são realizadas entre um determinado pixel $I_{(x, y)} \mathrm{e}$ seus vizinhos. Algoritmos para pré-processamento (e.g. equalização por histograma, ou filtro de medianas) e até mesmo para extração de características (e.g. algoritmo de curvatura ou cálculo de entropia local) utilizam esta relação. (59) Os vizinhos de um pixel $I_{(x, y)}$ são os $N_{V}$ pixels $V_{i}$ que o circundam, e costuma-se chamar este conjunto de vizinhança- $N_{V} \operatorname{com} 0 \leq i \leq N_{V}$. Duas vizinhanças são comuns: a vizinhança-4 e vizinhança-8, ilustradas na figura 2.16 .

Figura 2.16 - Coordenadas das vizinhanças-4 e 8 para um dado pixel $I_{(x, y)}$ qualquer.

\begin{tabular}{|l|l|l|}
\hline & $V_{1}$ & \\
\hline$V_{2}$ & $I_{(x, y)}$ & $V_{0}$ \\
\hline & $V_{3}$ & \\
\hline
\end{tabular}

vizinhança-4

\begin{tabular}{|l|l|l|}
\hline$V_{3}$ & $V_{2}$ & $V_{1}$ \\
\hline$V_{4}$ & $I_{(x, y)}$ & $V_{0}$ \\
\hline$V_{5}$ & $V_{6}$ & $V_{7}$ \\
\hline
\end{tabular}

vizinhança-8

Fonte: Elaborado pelo autor.

Dado um pixel $I_{(x, y)}$, sua vizinhança-4 corresponde aos seguintes conjuntos: 


$$
\begin{aligned}
& V_{0}=(x, y+1) \\
& V_{1}=(x-1, y) \\
& V_{2}=(x, y-1) \\
& V_{3}=(x+1, y)
\end{aligned}
$$

e sua vizinhança-8 é definida por:

$$
\begin{aligned}
& V_{0}=(x, y+1) \\
& V_{1}=(x-1, y+1) \\
& V_{2}=(x-1, y) \\
& V_{3}=(x-1, y-1) \\
& V_{4}=(x, y-1) \\
& V_{5}=(x+1, y-1) \\
& V_{6}=(x+1, y) \\
& V_{7}=(x+1, y+1)
\end{aligned}
$$

A partir da definição de vizinhança, pode-se definir uma função de processamento no domínio espacial da imagem como

$$
g(x, y)=T[f(x, y)]
$$

sendo $f(x, y)$ a imagem de entrada, $g(x, y)$ a imagem processada e $T$ um operador de $f$ definido sobre uma vizinhança- $N_{V}$ do ponto $(x, y)$. Este processo consiste em mover o centro da 
vizinhança- $N_{V}$ de pixel a pixel e aplicar o operador $T$ aos pixels da vizinhança, obtendo-se o valor de $g(x, y)$ para cada posição. Isso corresponde a alterar os valores $f(x, y)$ pelo valor obtido ao aplicar $T$ à sua vizinhança. Apesar de ser possível utilizar várias formas para a vizinhança (e.g. círculos ou elipses), as formas quadradas são mais comuns por serem de fácil implementação. (59)

Pode-se também aplicar o operador $T$ diretamente em um pixel $(x, y)$. Para isso utiliza-se uma janela de dimensões $1 \times 1$ centrada no próprio pixel. Assim, $g$ depende apenas do valor de $f$ em um único ponto. Neste caso, $T$ é definido como uma função de transformação de intensidade:

$$
s=T(r)
$$

onde $s$ e $r$ representam a intensidade de $g$ e $f$ em qualquer pixel $(x, y)$. Ou seja, os níveis de intensidade da imagem processada dependerão da operação definida em $T$. A equalização de uma imagem de entrada a partir de um operador $T$ baseado no histograma de tons de cinza da imagem é um exemplo de aplicação, discutido em detalhes na subseção 2.4.2.

\subsubsection{Pré-processamento}

A etapa de pré-processamento tem como objetivo melhorar certos aspectos de uma imagem

digital. É possível então corrigir falhas ocorridas durante a aquisição da imagem ou realçar certos detalhes de interesse. Caso não aplicado o pré-processamento, o resultado de um posterior processamento pode ser comprometido, já que as características naturais da imagem podem ter sido degradadas. $(16,59)$

As operações de pré-processamento podem ser realizadas no domínio real e das frequências. No domínio real, os próprios elementos da matriz I são alterados diretamente. Já o domínio das frequências envolve a transformada de Fourier da matriz para manipular bandas de valores, 
necessitando da transformada inversa para levar a matriz ao espaço real novamente.

Uma operação recorrente de pré-processamento no domínio real, por ser computacionalmente barata e eficiente, é a equalização por histograma. O objetivo é ajustar o nível de contraste da imagem baseando-se em seu histograma de valores. O histograma de uma imagem em escala de cinza $I$ é dado pela função

$$
\operatorname{hist}(I)=p\left(R_{k}\right)=\frac{N_{k}}{N_{I}}
$$

onde $R_{k}$ é um nível de cinza $k$ específico, com $k \in\{0,1, \ldots, 255\}, N_{k}$ é a quantidade de pixels da imagem $I$ que possuem nível de cinza $k$ e $N_{I}$ é a quantidade total de pixels da imagem $I$. Ou seja, $p\left(R_{k}\right)$ corresponde à probabilidade de ocorrência de um nível de cinza $R_{k}$ na imagem. O gráfico de $p\left(R_{k}\right)$ é denominado histograma. Essa informação é interessante quando se deseja realçar o contraste da imagem, visto que pode-se mensurar a quantidade de pixels em regiões mais claras, mais escuras e com níveis de cinza medianos. Assim, pode-se definir uma operação $T$ (eq. 2.19) que equalize os níveis de cinza $R_{k}$ de $f$, gerando uma imagem equalizada $g$ de $N_{g}$ pixels:

$$
s=T\left(R_{k}\right)=\sum_{j=0}^{k} \frac{N_{j}}{N_{g}}=\sum_{j=0}^{k} p\left(R_{j}\right)
$$

à essa operação $T$ se dá o nome de equalização de histograma ou linearização de histograma. (59) Ao se mapear os níveis de cinza $R_{k}$ de $f$ nos níveis $s$ de $g$, tem-se a imagem equalizada em contraste.

Após equalizar os níveis de contraste da imagem, é comum suavizá-la e remover ruído através de filtros, como por exemplo, o filtro de mediana. Esse efeito de suavização e remoção de ruídos ocorre pois cada pixel terá como seu valor a mediana de seus vizinhos. Assim, quanto maior o tamanho da vizinhança, maior a suavização em relação à imagem. O filtro de média também 
pode ser utilizado. Porém, o filtro de mediana preserva detalhes de bordas que são borrados pelo filtro de média. (59) Portanto o uso do filtro de mediana é mais interessante para a análise de pinturas, já que detalhes de formas são características que devem ser extraídas. O que se quer é a eliminação de ruído sem borrar detalhes de borda.

Para implementar o filtro por mediana, troca-se o valor do nível de cinza $R_{k}$ em $f$ pela mediana dos níveis de cinza da vizinhança- $N_{V}$ desse pixel. Essa operação (eq. 2.19) pode ser definida como

$$
T[f(x, y)]=\operatorname{mediana}\left(V_{N}(f(x, y))\right)
$$

onde $V_{N}(f(x, y))$ é o conjunto de pixels na vizinhança- $N_{V}$ com centro em $(x, y)$ na imagem $f$.

\subsubsection{Segmentação}

Embora a visão humana seja capaz de distinguir formas com relativa precisão, é preciso aplicar um procedimento conhecido como segmentação para identificar formas da imagem em um sistema computacional. Assim, o processo de segmentação tem como objetivo particionar uma imagem em múltiplos segmentos que são na realidade grupos de pixels.

Há um grande número de algoritmos de segmentação, sendo uma área de pesquisa rica e em constante desenvolvimento. Portanto, não há como esgotar todo o conjunto de algoritmos existentes em via de testá-los para a segmentação das pinturas. Uma prática comum é selecionar um grupo de algoritmos e aplicá-los exaustivamente ao conjunto de imagens e, de maneira experimental, escolher o algoritmo que mais contribui para a segmentação pretendida. O algoritmo SLIC (Simple Linear Iterative Clustering) (60) é baseado em superpixels e aplicado em matrizes coloridas de imagens. Portanto, para pinturas coloridas, seu uso é incentivado e demonstrou segmentação esperada - como pode ser visto na seção 3.3. 
Algoritmos baseados em superpixels como o SLIC agrupam pixels em regiões que tenham maior significado do que a simples malha de pixels. Essas regiões mais significativas são chamadas superpixels. O algoritmo SLIC agrupa os pixels em superpixels através de uma adaptação do algoritmo de clusterização k-means. Apesar de ser uma ideia simples, se mostra comparável aos algoritmos de superpixel considerados "estado da arte" atualmente, chegando a superá-los para a segmentação. (60)

O algoritmo 1 lista os passos do procedimento SLIC. Primeiramente, uma imagem RGB I precisa ter seus elementos convertidos para o padrão CIE $1976 L * a * b *$ (ou simplesmente CIELAB), (61) que representa uma determinada cor em função de um espaço definido pela base $(L *, a *, b *)$, ilustrado na figura 2.17. $L *$ determina a quantidade de luminosidade da cor enquanto o eixo $a *$ determina a matiz entre verde e vermelho, e $b *$ a matiz entre azul e amarelo. A conversão do formato RGB para CIELAB é discutida em detalhes por Hoffmann(62).

Figura 2.17 - Espaço de cor CIELAB. Uma cor qualquer é representada como um ponto no espaço $(L *, a *, b *)$.

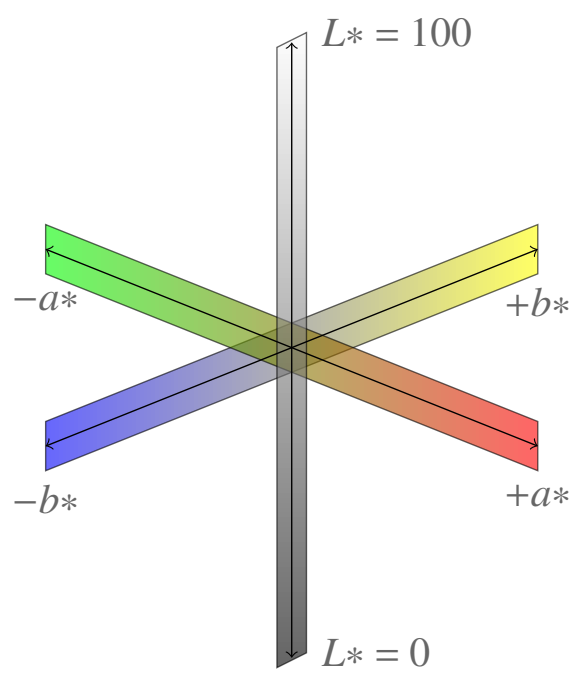

Fonte: Elaborado pelo autor.

Desta forma, cada pixel $I_{(x, y)}$ passa a ser representado por uma quíntupla $\left(L_{i}, a_{i}, b_{i}, x_{i}, y_{i}\right)$, sendo $L_{i}, a_{i}$ e $b_{i}$ as componentes da cor em formato CIELAB e $x_{i}, y_{i}$ as coordenadas em linha e coluna 
do pixel. O único parâmetro do algoritmo é $k$, sendo o número máximo de clusters. Em um passo inicial, $k$ clusters são amostrados tendo seus centroides $C_{k}=\left(L_{k}, a_{k}, b_{k}, x_{k}, y_{k}\right)$ distribuídos em uma malha regular de espaçamento $S=\sqrt{N_{I} / k}$, sendo $N_{I}$ o número de pixels da imagem. No passo de atribuição, cada pixel $I_{(x, y)}$ é associado à uma região limitada em torno de $C_{k}$. Isso acaba por reduzir a complexidade desse algoritmo, pois essa atribuição de cada pixel ao seu cluster não é feita considerando-se todos os $N_{I}$ pixels da imagem, mas apenas aqueles pixels dentro dessa região. Como a região de um superpixel tem como tamanho aproximadamente $S \times S$, o tamanho da região de busca pelo novo centroide do cluster (i.e. $k$-means) é $2 S \times 2 S$ em torno do centroide $C_{k}$ atual — este tamanho é definido por convenção do método SLIC. (60) Tendo todos os pixels $I_{(x, y)}$ da região em torno do centroide, calcula-se a distância $D_{I, C}$ de cada pixel $I_{(x, y)}$ ao seu centroide $C_{k}$ :

$$
\begin{aligned}
d_{c} & =\sqrt{\left(L_{k}-l_{i}\right)^{2}+\left(a_{k}-a_{i}\right)^{2}+\left(b_{k}-b_{i}\right)^{2}} \\
d_{s} & =\sqrt{\left(x_{k}-x_{i}\right)^{2}+\left(y_{k}-y_{i}\right)^{2}} \\
D_{I, C}^{\prime} & =\sqrt{\left(\frac{d_{c}}{N_{C}}\right)^{2}+\left(\frac{d_{s}}{N_{S}}\right)^{2}} \\
D_{I, C} & =\sqrt{d_{c}^{2}+\left(\frac{d_{s}}{S}\right)^{2} m^{2}}
\end{aligned}
$$

onde $d_{c}$ e $d_{s}$ são as distâncias do pixel $I_{(x, y)}=\left(L_{i}, a_{i}, b_{i}, x_{i}, y_{i}\right)$ até um centroide qualquer $C_{k}=$ $\left(L_{k}, a_{k}, b_{k}, x_{k}, y_{k}\right)$, considerando o espaço de cor e o espaço vetorial, respectivamente. Em $D_{I, C}^{\prime}$ essas duas medidas são combinadas e também normalizadas segundo as distâncias máximas em cor e espaço, dadas por $N_{C}$ e $N_{S}$. Como os centroides ficam espaçados a uma distância regular $S$, pode-se fazer $N_{S}=S$. O máximo valor de cor é especificado através do parâmetro $m$ do algoritmo. Esse parâmetro acaba por permitir o controle do peso das medidas de cor e espacial: quanto maior o valor de $m$, maior o peso da proximidade espacial e os superpixels 
serão mais compactos pois sua razão área por perímetro será menor. Quando $m$ é menor, os superpixels irão aderir mais às bordas (i.e. mais espalhados) de cada região e ao mesmo tempo terão tamanho e forma irregular. Como o algoritmo usa nativamente o formato CIELAB para cores, tem-se que $m \in[1,40]$. Cada pixel $I_{(x, y)}$ tem sua distância e rótulo atualizados, caso sua distância atual seja menor que a distância antiga. Por fim, no passo de atualização do algoritmo, os novos centroides $C_{k}$ são calculados como a média de todos os pixels pertencentes ao cluster e uma nova iteração se inicia. O algoritmo para dado um máximo especificado de iterações ou se o erro residual da distância dos centroides atuais e anteriormente calculados forem menores ou iguais a um dado limiar.

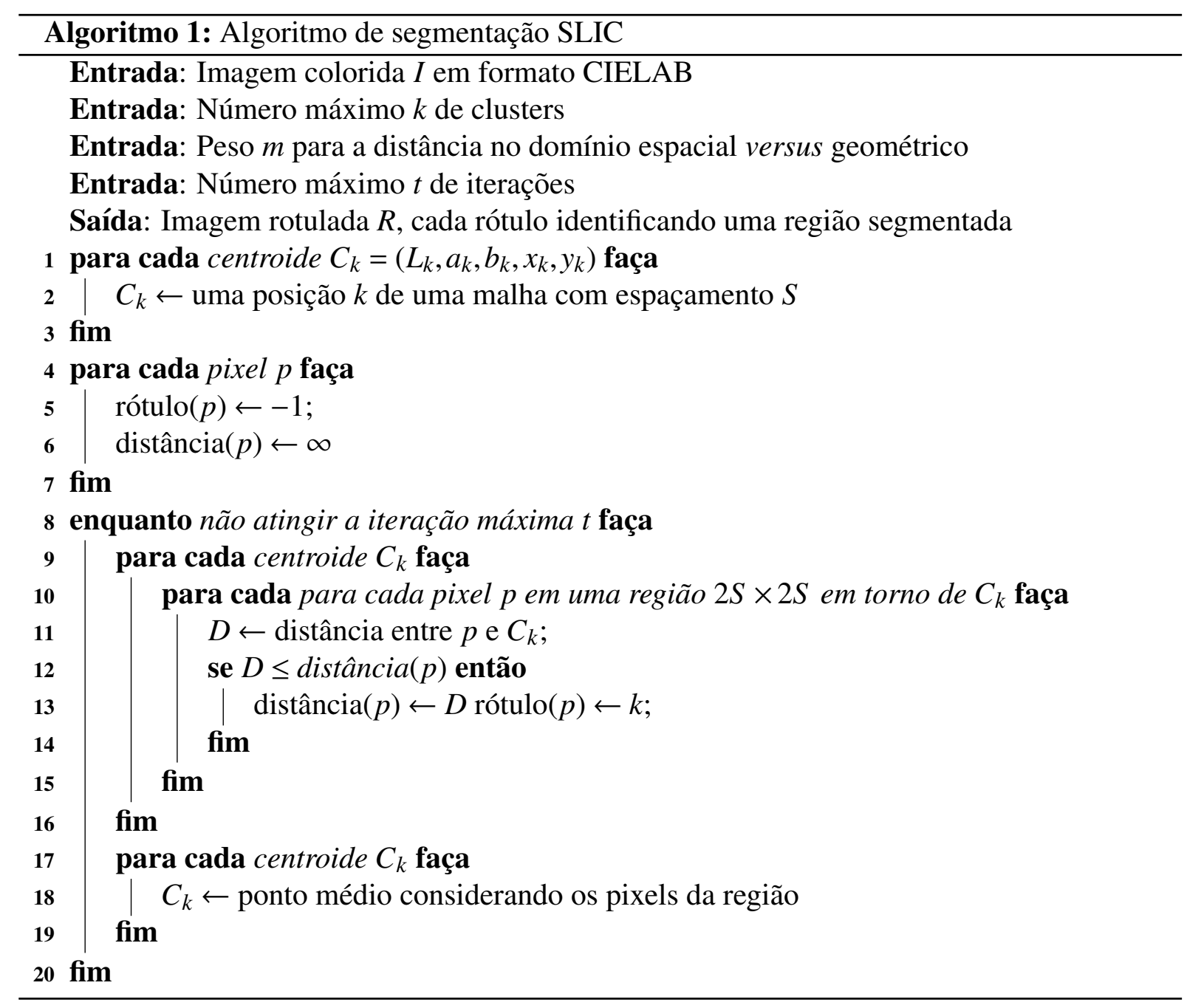


Após ter-se todas as regiões rotuladas por segmento pelo algoritmo SLIC, é necessário um passo de rotulação por conectividade, pois assim como a maioria dos algoritmos de segmentação, não há garantia do retorno de regiões conexas. Esse passo é feito na etapa de pós-processamento.

\subsubsection{Pós-processamento}

Algoritmos como os de segmentação têm como saída principal uma versão da imagem original com rótulos. Esses rótulos identificam cada região segmentada (ou segmento), como ilustrado na figura 3.7. Essa etapa é comumente chamada de rotulação.

Figura 2.18 - a) Rotulação das regiões após aplicação de algoritmo de segmentação segundo vizinhança-4: os rótulos identificam segmentos encontrados pela segmentação, porém não revelam necessariamente regiões conexas; b) Rotulação das regiões (ou componentes) conexas após aplicação de algoritmo para identificação de regiões conexas: esta é a rotulação desejada quando o que se pretende é identificar formas em uma imagem qualquer.

a)

\begin{tabular}{|l|l|l|l|l|l|l|l|}
\hline 1 & 1 & 0 & 0 & 0 & 0 & 0 & 0 \\
\hline 1 & 1 & 0 & 2 & 2 & 2 & 2 & 0 \\
\hline 0 & 0 & 0 & 0 & 0 & 0 & 0 & 0 \\
\hline 0 & 0 & 1 & 0 & 0 & 2 & 2 & 0 \\
\hline 0 & 0 & 1 & 1 & 0 & 2 & 2 & 0 \\
\hline 0 & 0 & 1 & 1 & 0 & 2 & 2 & 0 \\
\hline 0 & 0 & 0 & 0 & 0 & 2 & 2 & 0 \\
\hline 0 & 0 & 0 & 0 & 0 & 0 & 0 & 0 \\
\hline
\end{tabular}

b)

\begin{tabular}{|lll|l|l|l|l|l|}
\hline 2 & 2 & 0 & 0 & 0 & 0 & 0 & 0 \\
2 & 2 & 0 & 4 & 4 & 4 & 4 & 0 \\
\hline 0 & 0 & 0 & 0 & 0 & 0 & 0 & 0 \\
\hline 0 & 0 & 1 & 0 & 0 & 3 & 3 & 0 \\
\hline 0 & 0 & 1 & 1 & 0 & 3 & 3 & 0 \\
\hline 0 & 0 & 1 & 1 & 0 & 3 & 3 & 0 \\
\hline 0 & 0 & 0 & 0 & 0 & 3 & 3 & 0 \\
\hline 0 & 0 & 0 & 0 & 0 & 0 & 0 & 0 \\
\hline
\end{tabular}

Fonte: Elaborado pelo autor.

Porém, esses rótulos identificam as regiões segmentadas (detalhe $a$ da figura 3.7), quando o 
que se quer é geralmente as regiões conexas (detalhe $b$ da figura 3.7). Regiões conexas são aquelas cujos pixels estão todos conectados entre si dada uma vizinhança de pixels qualquer — no caso da figura 3.7, detalhe $b$, tem-se regiões conexas para vizinhança-4. Estas regiões são especialmente interessantes quando se quer identificar formas na imagem original. Um algoritmo simples de rotulação de componentes conexos pode ser definido através do procedimento descrito no algoritmo 2. Trata-se de um algoritmo que simula uma busca em largura em todos os pixels de mesmo rótulo $k$ a partir de um pixel $I_{(x, y)}$ qualquer da imagem segmentada $R$. Faz isso com o auxílio de uma estrutura de dados do tipo fila FIFO (primeiro a entrar, primeiro a sair).

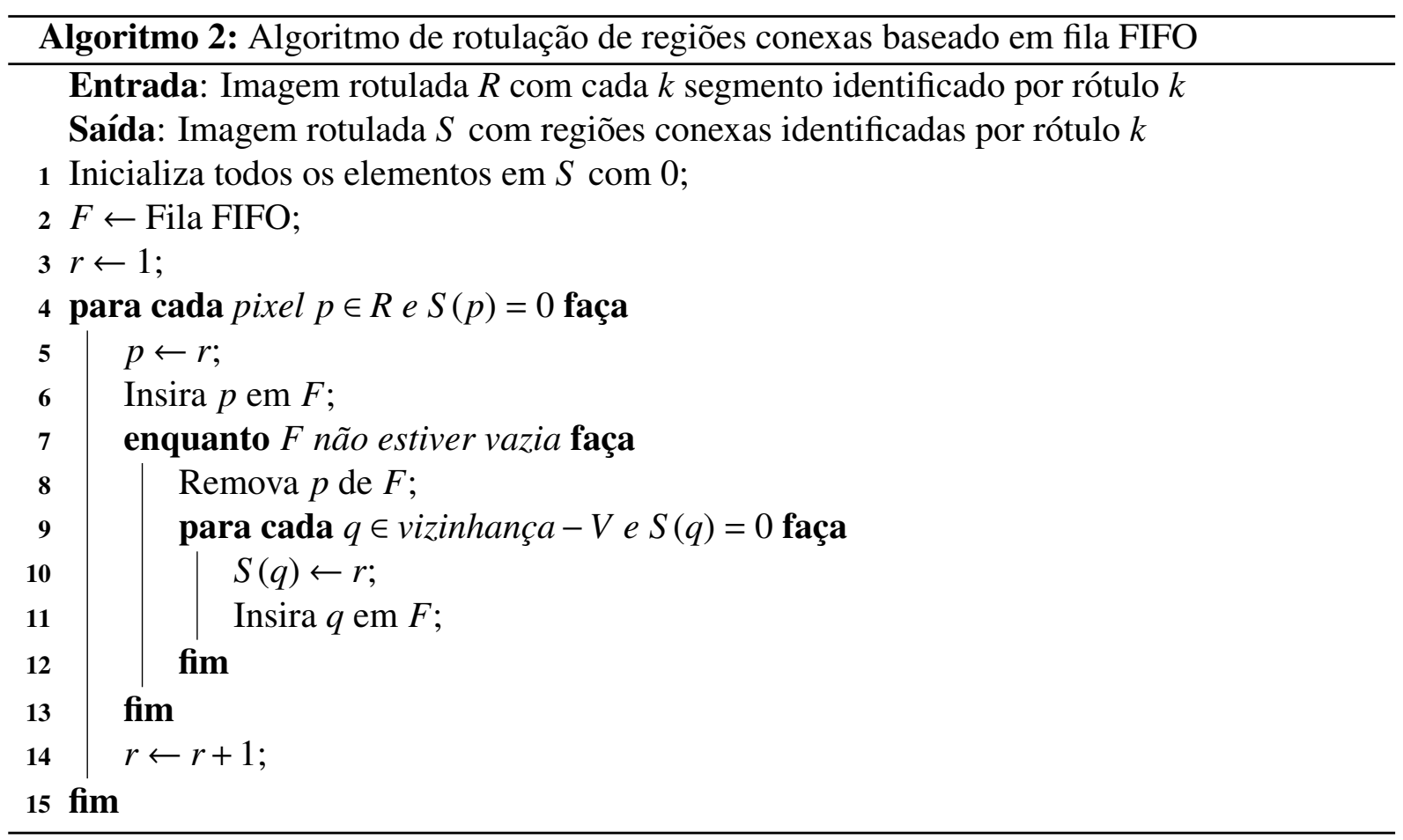

É comum tais imagens apresentarem deformações e ruído. Um exemplo de deformação é a presença de "buracos" ao longo de uma região segmentada. Esses espaços vazios provocam alterações em atributos que serão extraídos em um próximo passo, como a área da região. Ruídos são, por exemplo, regiões cujas áreas são ínfimas e em nada contribuem para um possível passo de extração de atributos, não sendo bons representantes das formas que compõem 
a imagem original. Esses erros devem ser eliminados e é esse o objetivo do passo de pósprocessamento.

Para remover "buracos" de uma região $R_{i}$ segmentada a partir de uma imagem original em escalas de cinza $I$ onde a matriz binária $R_{i}$ é construída a partir da segmentação de $I$ calculada em $S_{I}$ por

$$
R_{i}= \begin{cases}1 & \text { se } S_{I}(x, y)=i \\ 0 & \text { caso contrário }\end{cases}
$$

aplica-se um algoritmo que utiliza a operação morfológica binária de fechamento para remoção automática de todos os "buracos" em todas as regiões $R_{i}$ da imagem $I$. Para remover as regiões com áreas não representativas de uma região $R_{i}$ usa-se um limiar $\theta$. Assim, regiões com áreas $\leq \theta$ são preenchidas com 0 , eliminando-as de $S_{I}$. Essa operação é conhecida como filtro de área. (59)

\subsection{Extração de atributos}

Após as etapas de preparação, segmentação e pós-processamento das imagens, elas estarão prontas para a extração de atributos. Para caracterizar adequadamente uma imagem, certos aspectos devem ser considerados e são dependentes da natureza da imagem. No caso das pinturas, Romero(63) sugere o uso de complexidade de imagens para estimar características estéticas. Manovich(64-66) utiliza a análise de saturação de luz, contraste, brilho e demais atributos relacionados com a intensidade de cinza nas imagens.

Desta forma, um conjunto de descritores de imagens (ou atributos) foi selecionado e aplicado experimentalmente ao conjunto de imagens já processadas. Embora os algoritmos de extração sejam eficientes em suas funções, não há a garantia de que sejam suficientes para a correta 
caracterização de uma imagem. Assim, o procedimento canônico é considerar um amplo conjunto de atributos e em seguida selecionar, através de um método, aqueles que melhor atendem os objetivos da análise (discutido na seção 2.6). Esse conjunto deve portanto incluir atributos que irão, inicialmente, descrever uma larga gama de características como complexidade, textura e detalhes sobre a forma dos segmentos - e.g. área, perímetro, curvatura.

Para este estudo foram utilizados 100 atributos, descritos a seguir. Ao final desta seção, todos os atributos encontram-se sumarizados na tabela 2.22 .

\subsubsection{Atributo de complexidade}

Para descrever a complexidade, a medida de entropia da imagem foi considerada. A noção de entropia é emprestada da Teoria da Informação. Nela, a premissa fundamental é que a geração de informação pode ser modelada como um processo probabilístico, sendo medido de forma que concorde com a intuição humana. (59) Desta forma, um evento qualquer $E$ pode ocorrer com probabilidade $P(E)$ e

$$
I(E)=\log \frac{1}{P(E)}=-\log P(E)
$$

sendo a unidade de informação de $E$, denominada auto-informação de $E$. Isso equivale a dizer que a quantidade de informação atribuída ao evento $E$ é inversamente proporcional à probabilidade de $E$ ocorrer. Se $P(E)=1$, ou seja, se $E$ ocorre sempre, $I(E)=0$ e nenhuma informação é a ele atribuída. Caso $E$ não ocorrer, ou $P(E)=0$, tem-se $I(E)=\infty$. Quanto maior a probabilidade de $E$ ocorrer, menor informação estará incorporada, pois esse é um resultado que espera-se ocorrer com grande frequência. Por outro lado, quanto menor a probabilidade de $E$ ocorrer, mais informação estará incorporada, pois é um resultado menos provável de ocorrer. Se houverem $J$ símbolos $a_{j}$ associados a um evento $E$, a probabilidade da ocorrência de $a_{j}$ é 
$P\left(a_{j}\right) \mathrm{e}$

$$
\sum_{j=1}^{J} P\left(a_{j}\right)=1
$$

A auto-informação associada à ocorrência de um único símbolo $a_{j}$ é $I\left(a_{j}\right)=-\log P\left(a_{j}\right)$. Para a ocorrência de todos os símbolos, tem-se portanto:

$$
-k P\left(a_{1}\right) \log P\left(a_{1}\right)-k P\left(a_{2}\right) \log P\left(a_{2}\right)-\ldots-k P\left(a_{J}\right) \log P\left(a_{J}\right)
$$

ou ainda:

$$
-k \sum_{j=1}^{J} P\left(a_{j}\right) \log P\left(a_{j}\right) .
$$

Portanto, a informação média associada à ocorrência do evento $E$ dados todos os $a_{j}$ símbolos é:

$$
H(E)=-\sum_{j=1}^{J} P\left(a_{j}\right) \log P\left(a_{j}\right)
$$

onde $H(E)$ é denominada incerteza ou entropia de $E$.

Considerando a imagem em escala de cinza $I$ onde cada pixel é representado por $f(x, y)$, é possível calcular sua entropia aplicando a equação 2.33 a $I$ :

$$
\begin{aligned}
R & =\operatorname{hist}(I) \\
P & =\left\{p_{i}=\frac{R_{i}}{\sum_{i} R_{i}}\right\} \\
H & =-\sum_{i} p_{i} \log p_{i}, \quad p_{i} \neq 0 \\
\mathcal{A}_{0} & =H
\end{aligned}
$$


sendo hist o histograma dos valores dos níveis de cinza em $I, P$ as probabilidades $p_{i}$ de cada amostra $i$ e $H$ a entropia da imagem $I$. O valor de entropia da imagem também pode ser visualizado através de um escala de cores que corresponde aos valores de $H$ como visto na figura 2.19. Esse portanto é o primeiro atributo $\mathcal{A}_{0}$ do conjunto de atributos $\mathcal{A}$.

Figura 2.19 - a) Imagina da pintura original. b) Imagem em escala de cinza I. c) A entropia $H d a$ imagem I mapeada em uma escala de cores. É interessante notar como regiões de borda possuem entropia maior.

a) Imagem original RGB

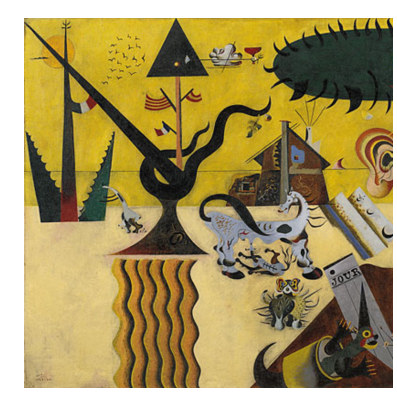

b) Imagem em escala de cinza

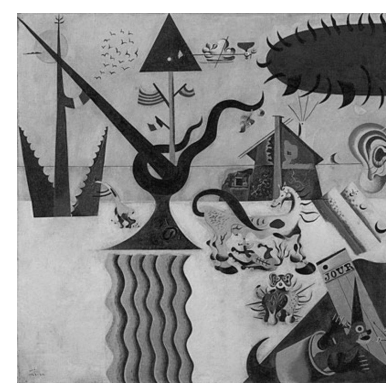

c) Níveis de entropia da imagem

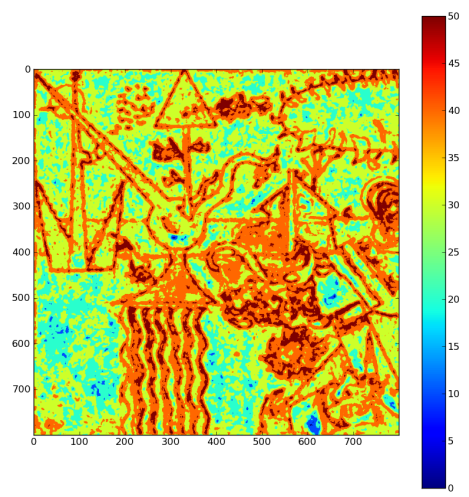

Fonte: Elaborado pelo autor.

\subsubsection{Atributos espectrais}

Atributos espectrais envolvem o cálculo da densidade espectral para a imagem total e para certos elementos da imagem, como colunas, linhas e centroides. A densidade espectral da imagem total é dada pelo cálculo da transformada de Fourier. Vale aqui introduzir tal conceito para se chegar à definição de densidade espectral. Seja $f(x)$ uma função contínua de uma variável real $x$, a transformada de Fourier $\mathcal{F}\{f(x)\}$ é definida pela equação 


$$
\mathcal{F}\{f(x)\}=F(u)=\int_{-\infty}^{+\infty} f(x) \exp [-2 i \pi u x] d x
$$

com $i=\sqrt{-1}$. A partir de $F(u)$ pode-se obter a função original $f(x)$ através da transformada inversa de Fourier:

$$
\mathcal{F}^{-1}\{F(u)\}=f(x)=\int_{-\infty}^{+\infty} F(u) \exp [2 i \pi u x] d u
$$

A transformada de Fourier de uma função real é geralmente complexa, e pode ser expressa por

$$
F(u)=\mathfrak{R}(u)+\mathfrak{J}(u) i
$$

onde $\mathfrak{R}(u)$ e $\mathfrak{J}(u)$ são os componentes real e imaginário de $F(u)$, respectivamente. É conveniente expressar a equação 2.40 em sua forma exponencial:

$$
F(u)=|F(u)| e^{\phi(u) i}
$$

onde $|F(u)|=\left[\mathfrak{R}^{2}(u)+\mathfrak{J}^{2}(u)\right]^{\frac{1}{2}}$ é o espectro de Fourier e $\phi(u)=\tan ^{-1}\left[\frac{\mathfrak{J}(u)}{\mathfrak{R}(u)}\right]$ o ângulo de fase. Tomando-se o quadrado do espectro tem-se a densidade espectral, também chamada de espectro de potência de $f(x)$ :

$$
P(u)=|F(u)|^{2}=\mathfrak{R}^{2}(u)+\mathfrak{J}^{2}(u) .
$$

A densidade espectral da imagem I pode ser calculada com base na equação 2.42:

$$
E=|\mathfrak{R}(X(I))|^{2}+|\mathfrak{J}(X(I))|^{2}
$$


onde $X$ é a transformada de Fourier de $I$ e a soma dos quadrados dos módulos da parte real e imaginária de $X$ corresponde à energia espectral procurada. Com base nessa medida, pode-se derivar as medidas de média e desvio padrão das energias nas linhas, colunas, centroides e da imagem total:

$$
\begin{aligned}
& \mathcal{A}_{1}=\frac{\sum_{j} E_{(x, y)}}{N_{y}} \text { média das energias nas linhas } x \\
& \mathcal{A}_{2}=\sqrt{\frac{\sum_{y}\left(E_{(x, y)}-\mu\right)^{2}}{N_{y}}} \text { desvio padrão das energias nas linhas } x \\
& \mathcal{A}_{3}=\frac{\sum_{x} E_{(x, y)}}{N_{x}} \text { média das energias nas colunas } y \\
& \mathcal{A}_{4}=\sqrt{\frac{\sum_{x}\left(E_{(x, y)}-\mu\right)^{2}}{N_{x}}} \text { desvio padrão das energias nas colunas } y \\
& \mathcal{A}_{5}=\frac{\sum_{y} y E_{(x, y)}}{N_{y}} \text { centroide das energias nas linhas } x \\
& \mathcal{A}_{6}=\frac{\sum_{x} i E_{(x, y)}}{N_{x}} \text { centroide das energias nas colunas } y \\
& \mathcal{A}_{7}=\frac{\sum E_{(x, y)}}{N_{x}+N_{y}} \text { média das energias nas linhas } x \text { e colunas } y \\
& \mathcal{A}_{8}=\sqrt{\frac{\sum\left(E_{(x, y)}-\mu\right)^{2}}{N_{x}+N_{y}}} \text { desvio padrão das energias nas linhas } x \text { e colunas } y
\end{aligned}
$$

Essas mesmas medidas, que foram aplicadas à representação da imagem original em níveis de cinza $\left(\mathcal{A}_{1-8}\right)$, podem ser aplicadas para cada uma das três imagens monocromáticas correspondentes a cada canal RGB da imagem $I$, obtendo assim o conjunto $\mathcal{A}_{9-16}$ de atributos para o canal vermelho, conjunto de atributos $\mathcal{A}_{17-24}$ para canal verde e $\mathcal{A}_{25-32}$ para o canal azul. 


\subsubsection{Atributos de textura}

Com o objetivo de analisar a textura das imagens, as 14 medidas propostas por Haralick (67) são de interesse. Elas são medidas ditas estatísticas de segunda ordem pois são calculadas a partir da matriz de coocorrência de níveis de cinza de uma dada imagem I. Uma das vantagens dessa abordagem é levar em conta a posição relativa de cada pixel da imagem. Cada uma das 14 medidas propostas procura caracterizar um aspecto de textura como contraste, homogeneidade e complexidade.

Dada uma imagem $I$ com $N_{G}$ níveis de cinza, sua matriz de coocorrência será uma matriz quadrada de dimensões $N_{G} \times N_{G}$ onde cada elemento $P_{\bar{d}}(i, j)$ representa a quantidade de pixels da imagem $I$ que possuem os níveis de cinza $i$ e $j$, separados por uma distância numa certa direção e sentido, determinado por $\vec{d}$. Para uma imagem, considera-se apenas o posicionamento relativo entre cada pixel e seus vizinhos (i.e. pixels adjacentes) e portanto, $\vec{d}$ poderá assumir apenas 8 direções possíveis considerando os possíveis ângulos $\beta \in\left\{0^{\circ}, 45^{\circ}, 90^{\circ}, 135^{\circ}, 180^{\circ}, 225^{\circ}, 270^{\circ}, 315^{\circ}\right\}$ que tal vetor pode assumir dado que encontra-se "aprisionado" em uma malha (i.e. possui vizinhança-8). Como trata-se de uma matriz de coocorrência, esta é simétrica, e portanto o conjunto de possíveis $\beta$ torna-se ainda menor. Por fim, dados os possíveis ângulos $\beta \in$ $\left\{0^{\circ}, 45^{\circ}, 90^{\circ}, 135^{\circ}\right\}$ e considerando os valores $\{-1,0,1\}$ como domínio das coordenadas $x, y$ de $\vec{d}$, tem-se o cálculo dos 14 atributos de Haralick para cada uma das seguintes direções:

$$
\begin{aligned}
\beta=0^{\circ} & \rightarrow \vec{d}=(1,0) \\
\beta=45^{\circ} & \rightarrow \vec{d}=(1,1) \\
\beta=90^{\circ} & \rightarrow \vec{d}=(0,1) \\
\beta=135^{\circ} & \rightarrow \vec{d}=(-1,1)
\end{aligned}
$$


a tabela 2.20 lista os 14 atributos de Haralick, lembrando que estes são calculados para cada uma das 4 direções possíveis de $\vec{d}$. Assim, essas medidas definem os $14 \cdot 4=56$ atributos seguintes considerados nesse estudo, o conjunto $\mathcal{A}_{33-88}$.

\subsubsection{Atributos de contorno e forma}

Após a identificação dos componentes conexos e seu pós-processamento, pode-se partir para a descrição da forma de tais componentes. A curvatura é um destes descritores. Trata-se de um atributo que mensura a mudança de direção "relativa" entre dois pontos conectados. (16) Esse descritor tem uma motivação biológica interessante relacionada com o sistema de visão humano - i.e. o reconhecimento de objetos é relacionado à identificação de cantos e pontos de alta curvatura. Esses pontos possuem mais informação sobre a forma do objeto do que linhas retas ou curvas suaves. Dessa forma, a curvatura é um atributo interessante para uso na caracterização das pinturas consideradas nesse estudo, pois pinturas como as de Miró parecem possuir maior quantidade de linhas retas (com poucas curvas) do que as pinturas barrocas, por exemplo. A curvatura de uma forma é calculada usando os seguintes descritores de Fourier e esquematizada na figura 2.21 .

A curvatura $k(t)$ de uma curva paramétrica $c(t)=(x(t), y(t))$ é definida como:

$$
k(t)=\frac{\dot{x}(t) \ddot{y}(t)-\dot{y}(t) \ddot{x}(t)}{\left(\dot{x}(t)^{2}+\dot{y}(t)^{2}\right)^{\frac{3}{2}}}
$$

onde $\dot{x}(t), \dot{y}(t), \ddot{x}(t)$ e $\ddot{y}(t)$ são respectivamente as derivadas de primeira e segunda ordem dos parâmetros $x(t)$ e $y(t)$ da curva $k(t)$. Essas derivadas podem ter seus valores estimados através da transformada de Fourier e do teorema da convolução: (68)

$$
\dot{x}=\mathfrak{J}^{-1}(2 \pi i \omega X(\omega))
$$


Tabela 2.20 - Os 14 atributos de textura de Haralick, considerando:

$$
\begin{aligned}
& p(i, j)=P_{\vec{d}}(i, j), \\
& p_{x}(i)=\sum_{j=1}^{N_{g}} p(i, j), \\
& p_{y}(j)=\sum_{i=1}^{N_{g}} p(i, j), \\
& p_{x+y}(k=i+j)=\sum_{i=1}^{N_{g}} \sum_{j=1}^{N_{g}} p(i, j), \\
& p_{x-y}(k=|i-j|)=\sum_{i=1}^{N_{g}} \sum_{j=1}^{N_{g}} p(i, j) .
\end{aligned}
$$

\begin{tabular}{|c|c|}
\hline Uniformidade & $f_{1}=\sum_{i=1}^{N_{g}} \sum_{j=1}^{N_{g}} p(i, j)^{2}$ \\
\hline Contraste & $f_{2}=\sum_{i=1}^{N_{g}} \sum_{j=1}^{N_{g}}(i-j)^{2} p(i, j)$ \\
\hline Correlação & $f_{3}=\frac{\sum_{i=1}^{N g} \sum_{j=1}^{N_{g}} i j p(i, j)-\mu_{x}-\mu_{y}}{\sigma_{x} \sigma_{y}}$ \\
\hline Variância & $f_{4}=\sum_{i=1}^{N_{g}} \sum_{j=1}^{N_{g}}(i-\mu)^{2} p(i, j)$ \\
\hline Momento inverso da diferença & $f_{5}=\sum_{i=1}^{N_{g}} \sum_{j=1}^{N_{g}} \frac{1}{1+(i-j)^{2}} p(i, j)$ \\
\hline Média da soma & $f_{6}=\sum_{k=2}^{2 N_{g}} k p_{x+y}(k)$ \\
\hline Variância da soma & $f_{7}=\sum_{k=2}^{2 N_{g}}\left(k-f_{6}\right)^{2} p_{x+y}(k)$ \\
\hline Entropia da soma & $f_{8}=-\sum_{k=2}^{2 N_{g}} p_{x+y}(k) \log \left(p_{x+y}(k)\right)$ \\
\hline Entropia & $f_{9}=-\sum_{i=1}^{N_{g}} \sum_{j=1}^{N_{g}} p(i, j) \log (p(i, j))$ \\
\hline Variância da diferença & $f_{10}=\operatorname{var}\left(p_{x-y}\right)$ \\
\hline Entropia da diferença & $f_{11}=-\sum_{k=0}^{N_{g}-1} p_{x-y}(k) \log \left(p_{x-y}(k)\right)$ \\
\hline Medida de correlação (1) & $f_{12}=\frac{f_{9}+\sum_{i=1}^{N g} \sum_{j=1}^{N g} p(i, j) \log \left[p_{x}(i) p_{y}(j)\right]}{\max \left\{H\left(p_{x}(i)\right), H\left(p_{y}(j)\right)\right\}}$ \\
\hline Medida de correlação (2) & $f_{13}=\sqrt{1-\exp \left[-2\left(\left(-\sum_{i=1}^{N_{g}} \sum_{j=1}^{N_{g}} p_{x}(i) p_{y}(j) \log \left(p_{x}(i) p_{y}(j)\right)\right)-f_{9}\right)\right]}$ \\
\hline Coeficiente de correlação máxima & $f_{14}=\sqrt{\operatorname{autoval}_{2}\left(-\sum_{k=1}^{N_{g}} \frac{p(i, k) p(j, k)}{p_{x}(i) p_{y}(j)}\right)}$ \\
\hline
\end{tabular}

Ainda, $H(X)$ é a entropia de $X$ e autoval $2(X)$ é o segundo maior autovalor de $X$. 
Figura 2.21 - a) Imagem da pintura original. b) Uma região segmentada da pintura. c) A curvatura extraída a partir da região segmentada. d) A curva paramétrica $k(t)$ dado um limiar em particular, com os picos em destaque.

a)

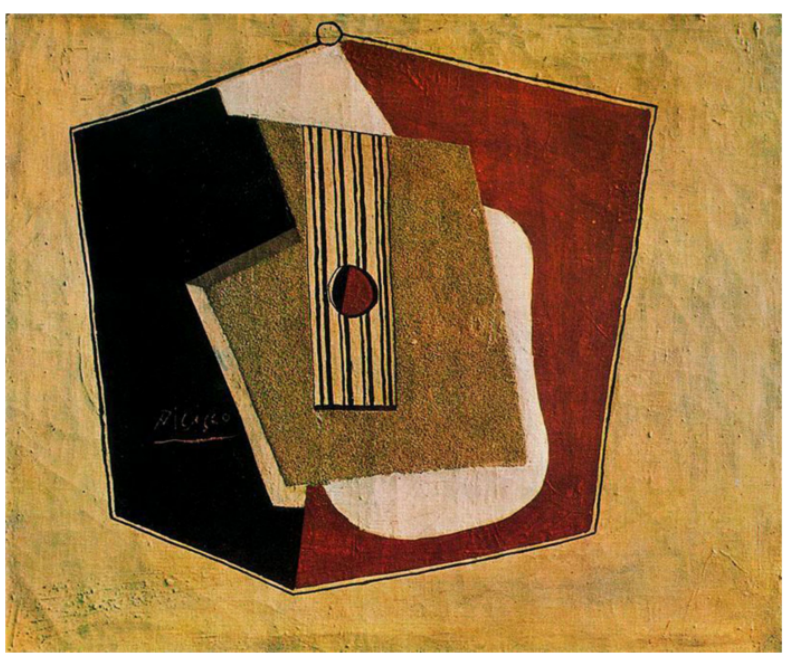

c)

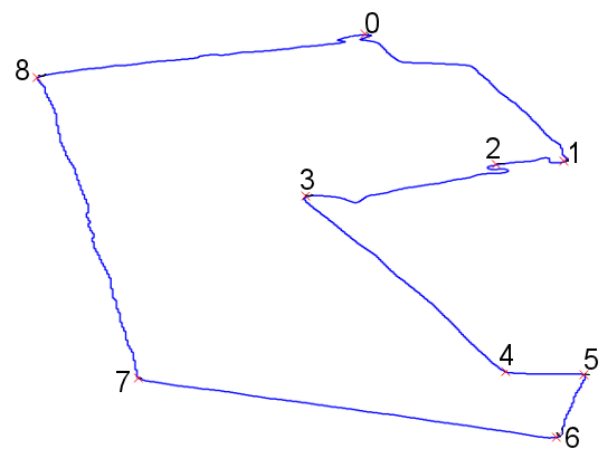

b)

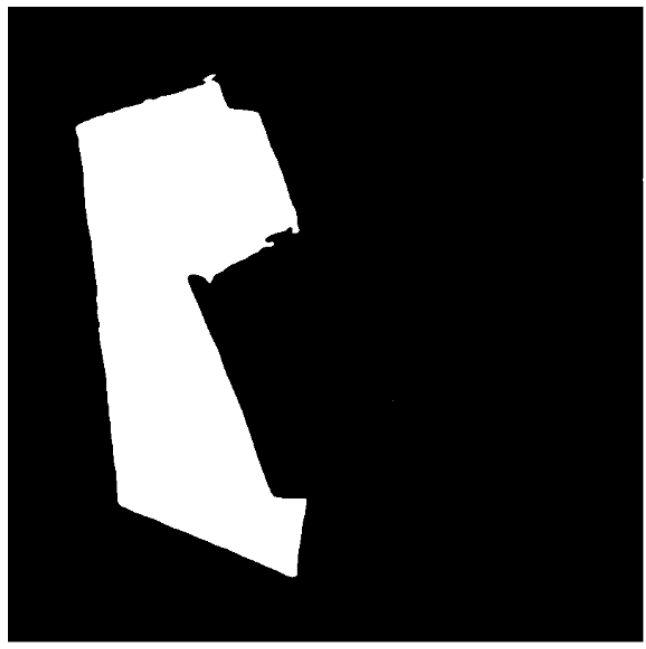

d)

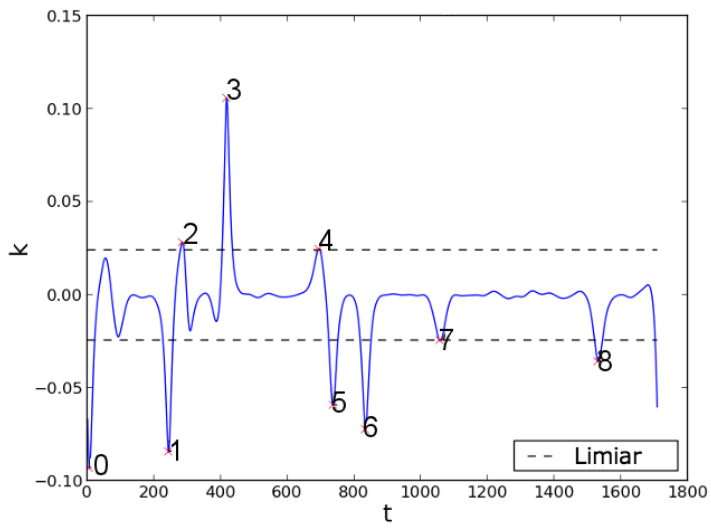

Fonte: Elaborado pelo autor.

$$
\begin{gathered}
\dot{y}=\mathfrak{J}^{-1}(2 \pi i \omega Y(\omega)) \\
\ddot{x}=\mathfrak{J}^{-1}\left(-(2 \pi \omega)^{2} X(\omega)\right) \\
\ddot{y}=\mathfrak{J}^{-1}\left(-(2 \pi \omega)^{2} Y(\omega)\right)
\end{gathered}
$$

onde $\mathfrak{J}^{-1}$ é a transformada inversa de Fourier, $X$ e $Y$ a transformada de Fourier de $x$ e $y$ respec- 
tivamente, $\omega$ é a frequência angular e $i$ a unidade imaginária.

O cálculo das derivadas $(\dot{x}(t), \dot{y}(t))$ e $(\ddot{x}(t), \ddot{y}(t))$ do sinal $t$ através do cálculo da transformada de Fourier - i.e. por um método numérico de diferenciação — acaba por realçar ruídos de alta frequência. Pode-se compensar este efeito através de uma filtragem, $(16,69)$ onde as funções diferenciadas durante o processo são suavizadas a partir da convolução de um filtro gaussiano aplicado ao sinal à ser diferenciado. Ou seja, a diferenciação por Fourier acaba por criar um filtro passa-altas, necessitando de um filtro passa-baixas para amenizar o ruído. Tal filtro gaussiano é definido por

$$
g(t)=\frac{1}{2 \pi \sigma^{2}} \exp \left(-\frac{t^{2}}{2 \sigma^{2}}\right)
$$

e sua transformada de Fourier é dada por

$$
G(\omega)=\exp \left(\frac{-(2 \pi)^{2} \omega^{2}}{(2 / \sigma)^{2}}\right)
$$

Utilizando-se o teorema da convolução é possível aplicar o filtro gaussiano $g(t)$ ao sinal a ser diferenciado:

$$
\begin{aligned}
& \hat{\dot{x}}(t)=\dot{x} * g(t)=\mathfrak{J}^{-1}(\dot{X}(\omega) G(\omega)) \\
& \hat{\dot{y}}(t)=\dot{y} * g(t)=\mathfrak{J}^{-1}(\dot{Y}(\omega) G(\omega)) \\
& \hat{\ddot{x}}(t)=\ddot{x} * g(t)=\mathfrak{J}^{-1}(\ddot{X}(\omega) G(\omega))
\end{aligned}
$$




$$
\hat{\ddot{y}}(t)=\ddot{y} * g(t)=\mathfrak{J}^{-1}(\ddot{Y}(\omega) G(\omega))
$$

obtendo assim a diferenciação multi-escala de primeira e segunda ordem $(\hat{\dot{x}}(t), \hat{\dot{y}}(t))$ e $(\hat{\bar{x}}(t), \hat{\dot{y}}(t))$ para $x(t)$ e $y(t)$, agora sim usadas para o cálculo de $k(t)$ (eq. 2.56) sem a presença de possíveis ruídos de alta-frequência.

É importante notar que um pico é definido como um ponto de alta curvatura. Um ponto a é considerado um pico se sua curvatura $k(a)$ satisfazer os seguintes critérios:

$$
\begin{aligned}
& k(a)>k(a-1) \\
& k(a)>k(a+1)
\end{aligned}
$$

Ou seja, um ponto $a$ é dito pico se sua curvatura $k(a)$ for maior que seus vizinhos anteriores e posteriores. Isto é suficiente para determinar todos os picos contidos no contorno de uma forma qualquer. Porém, é preciso controlar quais picos são interessantes e quais devem ser descartados. Desta forma, deve-se incluir um novo critério:

$$
k(a)>\tau
$$

ou seja, apenas pontos com curvaturas maiores que o limiar $\tau$ serão consideradas. Este limiar, por sua vez, pode ser definido como

$$
\operatorname{mediana}(k) \cdot \gamma
$$

onde $\gamma$ equivale a um fator obtido empiricamente com valores que revelam um determinado 
nível de detalhe de curvatura. Quanto maior o valor de $\gamma$, mais picos de curvatura e vice-versa. Tendo-se definido a curvatura $k(t)$ e um pico de curvatura $a$, pode-se partir para a definição de uma série de atributos. A média e o desvio padrão das distâncias geométricas entre um pico $a_{i}$ e seu próximo pico $a_{i+1}$ compõem os atributos $\mathcal{A}_{89}$ e $\mathcal{A}_{90}$, usados neste estudo:

$$
\begin{aligned}
& \mathcal{A}_{89}=\operatorname{média}\left(\sqrt{\left(a_{i}-a_{i+1}\right)^{2}}\right) \\
& \mathcal{A}_{90}=\operatorname{desvio~padrão}\left(\sqrt{\left(a_{i}-a_{i+1}\right)^{2}}\right)
\end{aligned}
$$

Também pode-se considerar tal distância dada em coordenadas do pixel da imagem associada ao pico $a$, o que leva aos atributos $\mathcal{A}_{91}$ e $\mathcal{A}_{92}$, que representam, respectivamente, a média e desvio padrão da distância em pixels entre um pico $a_{i}$ e seu próximo pico $a_{i+1}$.

A simples quantidade de picos $a$ de uma dada curvatura $k(t)$ revela um novo atributo:

$$
\mathcal{A}_{93}=\operatorname{tam}\left(\left\{a_{i}, a_{i+1}, \ldots, a_{N}\right\}\right)
$$

sendo tam o tamanho do conjunto de todos os picos $a$ de uma curvatura calculada. Da mesma forma, a quantidade de elementos $k(t)$ da curvatura permite saber o perímetro em pixels da região conexa:

$$
\mathcal{A}_{94}=\operatorname{tam}\left(\left\{k\left(t_{i}\right), k\left(t_{i+1}\right), \ldots, k\left(t_{N}\right)\right\}\right)
$$

Ainda, somando-se todos os elementos da região conexa $C_{i}=i$, onde $i$ representa o rótulo da região, tem-se a área desta região, em pixels, e portanto define-se um novo atributo $\mathcal{A}_{95}$. A razão entre o perímetro e a área, ambos em pixels, oferece mais um atributo: 


$$
\mathcal{A}_{96}=\frac{\left(\mathcal{A}_{94}\right)^{2}}{\mathcal{A}_{95}}
$$

essa razão indica quanto uma forma se aproxima de um círculo.

A quantidade $C_{N}$ de regiões conexas $C_{i}$ também caracteriza um atributo de interesse $\mathcal{A}_{97}$. Tratase de um atributo importante pois indica o quanto uma imagem é complexa em relação ao número de elementos que a compõe. Por exemplo, as pinturas de Pollock possuem um número muito maior de componentes do que a maioria dos demais pintores.

A área da região convexa de uma forma fornece outro atributo. É calculado através do algoritmo convex-hull (16) e define o atributo $\mathcal{A}_{98}$. A razão entre a área da região convexa e da região original do componente $\left(\mathcal{A}_{95}\right)$ indicam outra medida de circularidade, ou o quanto o componente possui uma forma rica em curvas acentuadas:

$$
\mathcal{A}_{99}=\frac{\mathcal{A}_{98}}{\mathcal{A}_{95}}
$$

O conjunto de todos os 100 atributos $\mathcal{A}_{i}$ discutidos estão sumarizados na tabela 2.22. É importante ressaltar que cada imagem de pintura acaba apresentando um número arbitrário de regiões conexas após os processos de segmentação e pós-processamento. Desta forma, para cada pintura tem-se um ou mais valores para os atributos $\mathcal{A}_{89-99}$, e portanto a média destes valores foi tomada para representar cada um destes atributos para uma dada imagem. 
Tabela 2.22 - Sumário de todos os 100 atributos utilizados neste estudo, considerando detalhes de contraste, textura (descritas pelas medidas de entropias e energias, assim como as medidas de Haralick) e forma (descritas pelas medidas de curvatura e medidas geométricas como perímetro, área e sua razão).

\begin{tabular}{l|l}
\hline \hline $\mathcal{A}_{i}$ & Descrição \\
\hline $\mathcal{A}_{0}$ & Entropia da imagem em tons de cinza \\
$\mathcal{A}_{1}$ & Média das energias nas linhas $x$ da imagem em tons de cinza \\
$\mathcal{A}_{2}$ & Desvio padrão das energias nas linhas $x$ da imagem em tons de cinza \\
$\mathcal{A}_{3}$ & Média das energias nas colunas $y$ da imagem em tons de cinza \\
$\mathcal{A}_{4}$ & Desvio padrão das energias nas colunas $y$ da imagem em tons de cinza \\
$\mathcal{A}_{5}$ & Centroide das energias nas linhas $x$ da imagem em tons de cinza \\
$\mathcal{A}_{6}$ & Centroide das energias nas colunas $y$ da imagem em tons de cinza \\
$\mathcal{A}_{7}$ & Média das energias nas linhas $x$ e colunas $y$ da imagem em tons de cinza \\
$\mathcal{A}_{8}$ & Desvio padrão das energias nas linhas $x$ e colunas $y$ da imagem em tons de cinza \\
$\mathcal{A}_{9-16}$ & As mesmas medidas $\mathcal{A} 1-8$ mas aplicadas à banda vermelha da imagem \\
$\mathcal{A}_{17-24}$ & As mesmas medidas $\mathcal{A}_{1-8}$ mas aplicadas à banda verde da imagem \\
$\mathcal{A}_{25-32}$ & As mesmas medidas $\mathcal{A}_{1-8}$ mas aplicadas à banda azul da imagem \\
$\mathcal{A}_{33-46}$ & As 14 medidas de textura de Haralick para a direção $\beta=0^{\circ}$ ou $\vec{d}=(1,0)$ \\
$\mathcal{A}_{47-60}$ & As 14 medidas de textura de Haralick para a direção $\beta=45^{\circ}$ ou $\vec{d}=(1,1)$ \\
$\mathcal{A}_{61-74}$ & As 14 medidas de textura de Haralick para a direção $\beta=90^{\circ}$ ou $\vec{d}=(0,1)$ \\
$\mathcal{A}_{75-88}$ & As 14 medidas de textura de Haralick para a direção $\beta=135^{\circ}$ ou $\vec{d}=(-1,1)$ \\
$\mathcal{A}_{89}$ & Média das distâncias (euclidiana) entre os picos de curvatura \\
$\mathcal{A}_{90}$ & Desvio padrão das distâncias (euclidiana) entre os picos de curvatura \\
$\mathcal{A}_{91}$ & Média das distâncias (em pixels do contorno) entre os picos de curvatura \\
$\mathcal{A}_{92}$ & Desvio padrão das distâncias (em pixels do contorno) entre os picos de curvatura \\
$\mathcal{A}_{93}$ & Quantidade de picos de curvatura \\
$\mathcal{A}_{94}$ & Perímetro da curvatura \\
$\mathcal{A}_{95}$ & Área da região conexa \\
$\mathcal{A}_{96}$ & Razão entre o perímetro e a área da região \\
$\mathcal{A}_{97}$ & Quantidade de segmentos de uma pintura \\
$\mathcal{A}_{98}$ & Área da região convexa \\
$\mathcal{A}_{99}$ & Razão entre a área da região convexa e a área da região conexa original \\
\hline \hline &
\end{tabular}

Fonte: Elaborado pelo autor. 


\subsection{Análise de atributos e redução de dimensionalidade}

Na maioria das rotinas de análises de dados, a quantidade de atributos leva à necessidade de selecionar quais atributos são mais relevantes ao objetivo previsto (e.g. garantir máximo agrupamento das amostras em certas classes) e reduzir a dimensionalidade das amostras a um ponto que se consiga visualizá-las. Essas necessidades estão presentes também neste estudo e alguns métodos foram selecionados para supri-las.

Existe um grande número de métodos para a identificação dos melhores atributos, aqui dois deles são descritos: matriz de espalhamento e LDA (Linear Discriminant Analysis). (16, 17, 70) Esse último também pode ser utilizado para a redução da dimensão da matriz de entrada, e é portanto descrito juntamente com outro método para redução de dimensionalidade, o PCA (Principal Components Analysis). (16, 71)

O método conhecido como matrizes de espalhamento procura encontrar a melhor razão de Fisher, que é um indicador quantitativo de quanto duas ou mais classes estão apresentando menor covariância interna (agrupamento) e maior covariância entre as classes (dispersão). Ou seja, busca-se a projeção que mais separa as classes umas das outras. $(16,17)$

Para todas as $N$ amostras (no caso, pinturas), considerando todas as possíveis combinações de pares de atributos $F_{N, a}$ e $F_{N, b}$, as matrizes de espalhamento $S_{\text {inter }}$ e $S_{\text {intra }}$ são calculadas com $K$ classes (no caso, $K=12$ para 12 pintores), uma classe $C_{i}$ para cada pintor:

$$
\begin{gathered}
S_{\text {intra }}=\sum_{i=1}^{K} S_{i} \\
S_{\text {inter }}=\sum_{i=1}^{K} N_{i}\left(\overrightarrow{\mu_{i}}-\vec{M}\right)\left(\overrightarrow{\mu_{i}}-\vec{M}\right)^{T}
\end{gathered}
$$


sendo $N_{i}$ o número de amostras para a classe $C_{i}$ e a matriz de espalhamento para a classe $C_{i}$ definida como

$$
S_{i}=\sum_{i \in C_{i}}\left(\vec{f}_{i}-\overrightarrow{\mu_{i}}\right)\left(\vec{f}_{i}-\vec{\mu}_{i}\right)^{T}
$$

onde $\vec{f}_{i}$ é uma amostra da matriz de atributos $F$ cujas linhas e colunas correspondem às amostras e seus atributos $F=\left[\leftarrow f_{i}^{T} \rightarrow\right]$ e $\overrightarrow{\mu_{i}}$ e $\vec{M}$ são os vetores de média dos atributos para as amostras da classe $C_{i}$ e para todas as amostras, respectivamente:

$$
\begin{gathered}
\overrightarrow{\mu_{i}}=\frac{1}{N_{i}} \sum_{i \in C_{i}} \vec{f}_{i} \\
\vec{M}=\frac{1}{N} \sum_{i=1}^{N} \vec{f}_{i}
\end{gathered}
$$

O traço da razão entre as matrizes intra- e interclasse resulta na razão de Fisher, a constante:

$$
\alpha=\operatorname{tr}\left(S_{\text {inter }} S_{\text {intra }}^{-1}\right)
$$

Se ao invés de calcular o traço for calculado os autovalores e autovetores da razão das matrizes, tem-se a projeção que melhor separa as classes, ou seja, o LDA:

$$
\operatorname{eig}\left(S_{\text {inter }} S_{\text {intra }}^{-1}\right)
$$

onde eig corresponde ao cálculo dos autovetores e autovalores do produto entre as matrizes de espalhamento. Ao tomar os autovetores dos maiores autovalores, em módulo, tem-se tal projeção. É por isso que o LDA pode ser concebido como um método de redução de dimensão, reduzindo os $N$ atributos a um número de atributos $r<N$ (geralmente $r \leq 3$ para possibilitar a 
projeção em 2 ou 3 dimensões visíveis) que melhor separam as classes.

Convém aqui abordar um outro método de redução de dimensionalidade, o PCA, que lembra o LDA. No PCA, se está interessado em calcular os autovalores e autovetores que mais correlacionam os dados em questão. Para isso, toma-se a matriz de atributos $F$ e calcula-se sua matriz de covariância, que nada mais é que a operação de covariância aplicada a cada dimensão $i$ de uma matriz $X$ qualquer. Considerando os momentos estatísticos básicos, a matriz de covariância $C^{n \times n}(X)$ dadas $n$ dimensões de $X$ é dada por

$$
C^{n \times n}(X)=\left(\begin{array}{cccc}
\operatorname{cov}\left(x_{1}, x_{1}\right) & \operatorname{cov}\left(x_{1}, x_{2}\right) & \ldots & \operatorname{cov}\left(x_{1}, x_{n}\right) \\
\operatorname{cov}\left(x_{2}, x_{1}\right) & \operatorname{cov}\left(x_{2}, x_{2}\right) & \ldots & \operatorname{cov}\left(x_{2}, x_{n}\right) \\
\vdots & \vdots & \vdots & \vdots \\
\operatorname{cov}\left(x_{n}, x_{1}\right) & \operatorname{cov}\left(x_{n}, x_{2}\right) & \ldots & \operatorname{cov}\left(x_{n}, x_{n}\right)
\end{array}\right)
$$

onde $x_{i}$ é a $i$-ésima dimensão da matriz $X$.

Novamente, calculando os autovalores (e seus respectivos autovetores) da matriz de covariância $C^{n \times n}(F)$ e tomando os autovetores dos maiores autovalores, em módulo, tem-se os componentes principais

$$
V=\left(\text { autovetor }_{0} \text { autovetor } r_{1} \ldots \text { autovetor } r_{n}\right)
$$

que formarão uma base para a projeção dos dados com maior correlação possível através da multiplicação da matriz original $F$ com os componentes principais $V$, ambos transpostos:

$$
D=V^{T} \times F^{T}
$$

ou seja, $D$ é a base que mais "reúne características" dos demais atributos. Tomando-se apenas 
estes $r<N$ atributos, tem-se portanto uma redução na dimensão. Os autovalores indicam o quanto cada atributo contribui para a correlação. (16)

\subsubsection{Validação cruzada}

A projeção obtida pelo método LDA através da equação 2.83 não garante a classificação dos dados, visto que as classes são conhecidas previamente (fazendo com que o método LDA seja utilizado como parte de um método supervisionado de classificação). Assim, é preciso validar tal projeção obtida frente a outras possíveis escolhas dos conjuntos de treinamento e teste.

Um procedimento comum neste caso é a validação cruzada ou cross validation. Nesta pesquisa utilizou-se o método de validação cruzada conhecido como repeated random sub-sampling validation. Trata-se de um método bastante simples, onde os dados de amostra são divididos em dois grupos: um conjunto de treinamento e um conjunto de teste. Os elementos de ambos os grupos são selecionados aleatoriamente. O método LDA é então aplicado ao conjunto de treinamento, obtendo-se a projeção (eq. 2.83). O LDA é aplicado em seguida ao conjunto de teste, mas utilizando a projeção obtida para o conjunto de treinamento (i.e. os mesmos autovetores). Conta-se agora quais amostras do conjunto de teste foram projetadas próximas ao conjunto de treinamento, e quais estão distantes. Essa contagem revela se o conjunto de treinamento condiz com o esperado e desta forma, valida o método LDA aplicado. (16)

Uma forma interessante de visualizar a validação cruzada é através da matriz de confusão, representada na figura 2.23. Cada linha da matriz de confusão representa uma classe $C_{i}$ do grupo de treinamento (no caso deste estudo, as classes correspondem a cada um dos pintores analisados) e cada coluna representa uma classe $\hat{C}_{i}$ do grupo de teste. Cada elemento da matriz representa a contagem de amostras pertencentes a uma determinada classe, ou seja, as amostras de $C_{i}$ que deveriam ser classificadas como $\hat{C}_{i}$. Desta forma, espera-se que a diagonal principal desta matriz esteja o mais próximo possível do número máximo de elementos para cada classe. 
Ou seja, elementos de uma classe $C_{1}$ devem ser classificados como pertencentes a esta classe, e não a qualquer outra classe. Um exemplo de matriz de confusão para o método LDA pode ser visto na figura 3.29 da seção 3.7 de resultados deste estudo.

Figura 2.23 - Esquema representando uma matriz de confusão. Deseja-se que a diagonal principal possua valores próximos ao número máximo de elementos em cada classe $C_{i}$, caracterizando assim uma boa classificação. $C_{i}$ é uma classe do conjunto de treino e $\hat{C}_{i}$ uma classe do conjunto de teste.

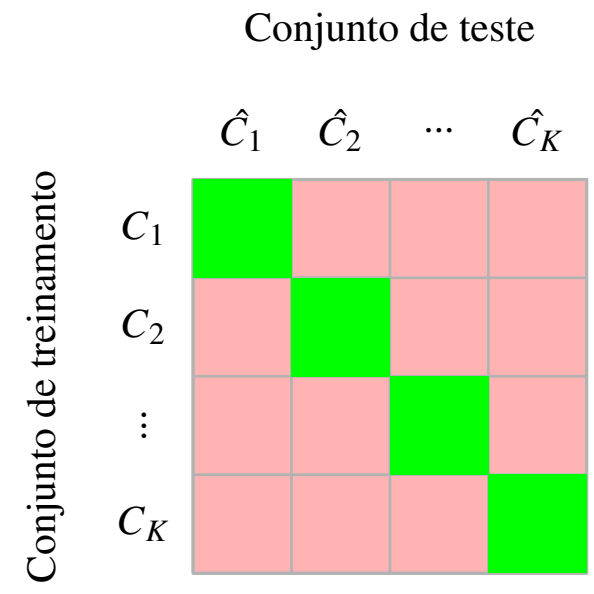

Fonte: Elaborado pelo autor.

Conhecendo-se a quantidade de amostras que foram classificadas corretamente e aquelas que não o foram, é possível calcular a acurácia da classificação, definida como

$$
\operatorname{acc}\left(C_{i}, \hat{C}_{i}\right)=\frac{1}{N_{s}} \sum_{j=0}^{N_{s}-1} \mathbf{1}\left(\hat{c}_{j}=c_{j}\right)
$$

onde $N_{s}$ é o número de amostras para uma classe $C_{i}, c_{j}$ é uma amostra pertencente à $C_{i}$ e $\hat{c_{j}}$ é uma amostra pertencente à $\hat{C}_{i}$. Ainda, a função 1 é a função característica ou indicadora, que indica se um elemento pertence ao conjunto $Q$ (assumindo o valor 1) ou não (assumindo o valor $0)$, ou seja: 


$$
\mathbf{1}(x)= \begin{cases}1 & : x \in Q \\ 0 & : x \notin Q\end{cases}
$$

Assim, a acurácia pode ser interpretada como a fração das amostras que foram classificadas como corretas para um determinado grupo de treino e teste. 


\section{Capítulo 3}

\section{Desenvolvimentos e resultados}

\subsection{Pintores escolhidos}

Para a análise foram selecionados 12 pintores de relevância histórica. Esse grupo abrange os estilos artísticos que vão do período Barroco aos movimentos da Arte Moderna. Seis dos pintores representam o período Barroco enquanto os 6 restantes representam movimentos modernos. O grupo é apresentado na tabela 3.1 juntamente com seu estilo e período ou movimento artístico mais representativo. É de conhecimento que pintores como Picasso demonstraram mais de um estilo durante a vida. Porém, para tal análise, foi escolhido apenas o estilo pelo qual melhor se conhece e define o artista. No caso de Picasso, apenas pinturas de sua fase Cubista (de 1909 a 1912) foram escolhidas, com o objetivo de representar este movimento. Destaca-se que a escolha de dois períodos distantes - cerca de 218 anos separam o período Barroco dos movimentos da Arte Moderna - é proposital. A história da Arte assim como a análise estética das pinturas de ambos períodos revela características contrastantes, porém tais afirmações são qualitativas. Neste estudo, fez-se tal escolha justamente com o objetivo de refutar ou afirmar estas observações, mas agora com base em medidas quantitativas. 
Tabela 3.1 - Pintores escolhidos para a análise, exibidos em ordem cronológica, juntamente com o estilo artístico que melhor representa. Divididos em dois grupos: 6 pintores barrocos e 6 pintores modernos.

\begin{tabular}{l|l|l}
\hline \hline Artistas & Estilos/movimentos/períodos mais marcantes & Período cronológico \\
\hline Caravaggio & Barroco & $1593-1610$ \\
Frans Hals & Barroco, Idade de ouro Holandesa & $1620-1660$ \\
Nicolas Poussin & Barroco, Classicismo & $1620-1660$ \\
Diego Velázquez & Barroco & $1618-1660$ \\
Rembrandt & Barroco, Idade de ouro Holandesa, Realismo & $1632-1650$ \\
Johannes Vermeer & Barroco, Idade de ouro Holandesa & $1632-1670$ \\
\hline Vincent van Gogh & Pós-Impressionismo & $1888-1890$ \\
Wassily Kandinsky & Expressionismo, Arte abstrata & $1922-1944$ \\
Henri Matisse & Modernismo, Fauvismo & $1904-1910$ \\
Pablo Picasso & Cubismo & $1909-1912$ \\
Joan Miró & Surrealismo, Dada & $1922-1958$ \\
Jackson Pollock & Expressionismo abstrato & $1947-1950$ \\
\hline \hline
\end{tabular}

Fonte: Elaborado pelo autor.

\subsection{Corpus de pinturas}

Para cada pintor, foram consideradas 20 imagens de suas pinturas, obtidas de arquivos em domínio público, organizados pela Wikipedia. Uma amostra dessas pinturas e seu respectivo ano de criação está listada na tabela 3.2. Todas as 240 pinturas são apresentadas em forma de galeria no apêndice B. Os arquivos de imagem das pinturas assim como o código-fonte que implementa esta análise encontram-se disponíveis online em http://github.com/automata/ ana-pintores e no apêndice A há instruções de sua instalação e uso.

\subsection{Análise de imagens para extração de atributos}

Todas as 240 imagens foram cortadas em janelas de $800 \times 800$ pixels. Esta janela quadrada foi posicionada com seu ponto superior mais à esquerda equivalendo ao ponto superior mais à 
Tabela 3.2 - Algumas das 240 pinturas juntamente com a data de sua criação. Todas as pinturas usadas no estudo estão apresentadas em forma de galeria no apêndice $B$.

\begin{tabular}{|c|c|c|}
\hline Pintores & Título da obra & Ano de criação \\
\hline \multirow[t]{3}{*}{ Caravaggio } & Músicos & 1595 \\
\hline & Judite decapitando Holofernes & 1598 \\
\hline & Davi com a cabeça de Golias & 1610 \\
\hline \multirow[t]{3}{*}{ Frans Hals } & Retrato de uma mulher desconhecida & $1618 / 20$ \\
\hline & Retrato de Paulus van Beresteyn & $1620 \mathrm{~s}$ \\
\hline & Retrato de Stephanus Geeraerdts & $1648 / 50$ \\
\hline \multirow[t]{3}{*}{ Nicolas Poussin } & Vênus e Adônis & 1624 \\
\hline & Céfalo e Aurora & 1627 \\
\hline & Ácis e Galateia & 1629 \\
\hline \multirow[t]{3}{*}{ Diego Velázquez } & Três músicos & $1617 / 18$ \\
\hline & O almoço & 1618 \\
\hline & La mulatto & 1620 \\
\hline \multirow[t]{3}{*}{ Rembrandt } & O vendedor de óculos (visão) & $1624 / 25$ \\
\hline & Os três cantores (audição) & $1624 / 25$ \\
\hline & Balaão e o burro & 1626 \\
\hline \multirow[t]{3}{*}{ Johannes Vermeer } & A leiteira & 1658 \\
\hline & O astrônomo & 1668 \\
\hline & Garota com brincos de pérola & 1665 \\
\hline \multirow[t]{3}{*}{ Vincent van Gogh } & Noite estrelada sobre o Ródano & 1888 \\
\hline & A noite estrelada & 1889 \\
\hline & Auto-retrato com chapéu de palha & $1887 / 88$ \\
\hline \multirow[t]{3}{*}{ Wassily Kandinsky } & Em branco II & 1923 \\
\hline & Composição X & 1939 \\
\hline & Pontos & 1920 \\
\hline \multirow[t]{3}{*}{ Henri Matisse } & Auto-retrato em uma camiseta listrada & 1906 \\
\hline & Retrato de Madame Matisse & 1905 \\
\hline & A dança (primeira versão) & 1909 \\
\hline \multirow[t]{3}{*}{ Pablo Picasso } & Les Demoiselles d'Avignon & 1907 \\
\hline & Guernica & 1937 \\
\hline & Dora Maar au Chat & 1941 \\
\hline \multirow[t]{3}{*}{ Joan Miró } & O fazendeiro & $1921 / 22$ \\
\hline & O campo lavrado & $1923 / 24$ \\
\hline & Bleu II & 1961 \\
\hline \multirow[t]{3}{*}{ Jackson Pollock } & No. 5 & 1948 \\
\hline & Ritmo de outono & 1950 \\
\hline & Pólos azuis & 1952 \\
\hline
\end{tabular}

Fonte: Elaborado pelo autor. 
esquerda da pintura (figura 3.3). As imagens que possuíam dimensões menores que $800 \times 800$ foram escaladas para tal dimensão, mantendo o mesmo aspecto da imagem original em todas as pinturas.

Figura 3.3 - Pré-processamento para recorte das imagens originais em janelas de dimensão $800 \times 800$. a) a imagem original, b) a janela em destaque, c) a imagem de dimensões $800 \times 800$ utilizada neste estudo. Embora se percam detalhes da imagem original, o janelamento é necessário para facilitar o processamento ao se utilizar uma dimensão única para as imagens.
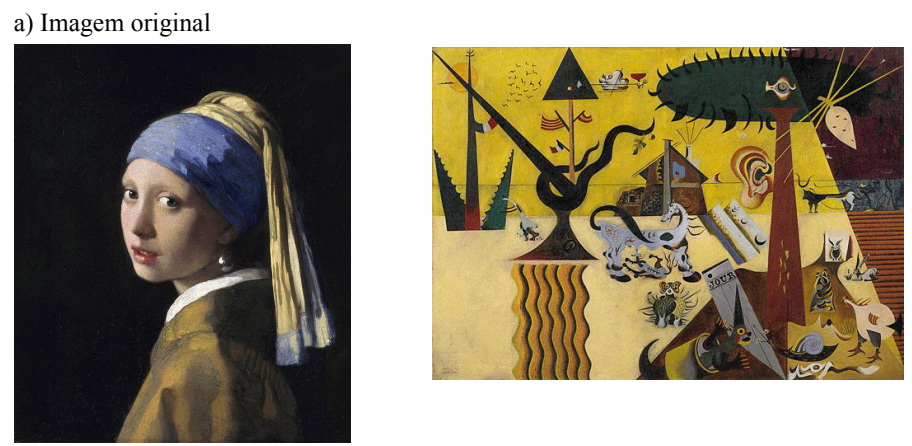

b) Janela em destaque
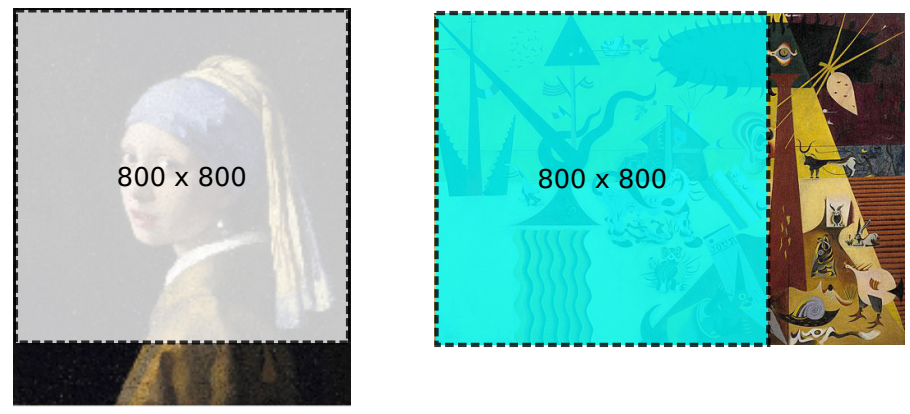

c) Imagem recortada utilizada
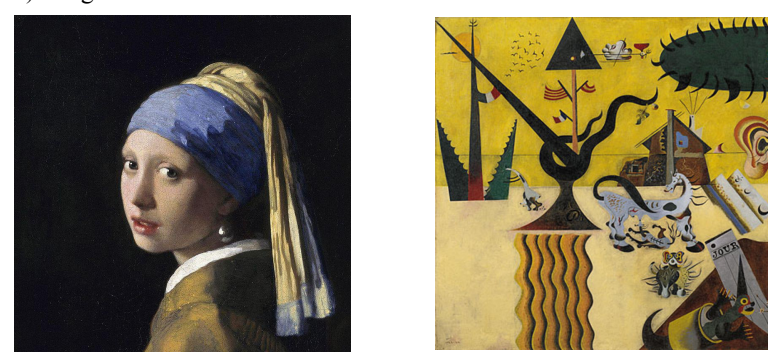

Fonte: Elaborado pelo autor. 
Em seguida, as imagens foram pré-processadas aplicando-se equalização de histograma e filtro por mediana com janela de vizinhança-8 (figura 3.4), ambas descritas na subseção 2.4.2.

Figura 3.4 - Pré-processamento utilizando equalização de histograma e filtro por mediana com janela de vizinhança-8. a) a imagem original em escala de cinza, b) a imagem equalizada, c) a imagem filtrada através do filtro de mediana. Pode-se perceber que a luminosidade da imagem está homogênea. Seus detalhes de borda foram suavizados, porém ainda estão presentes, dada a natureza do filtro por mediana.

a) Imagem original

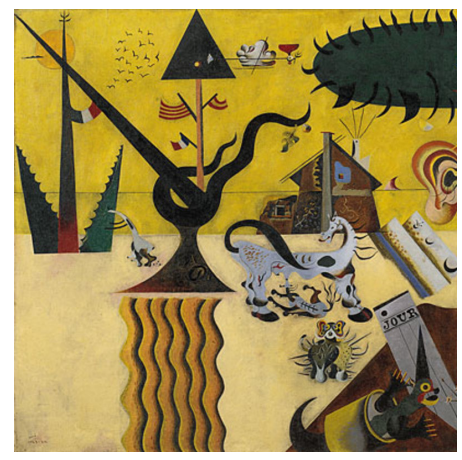

b) Equalização de histograma

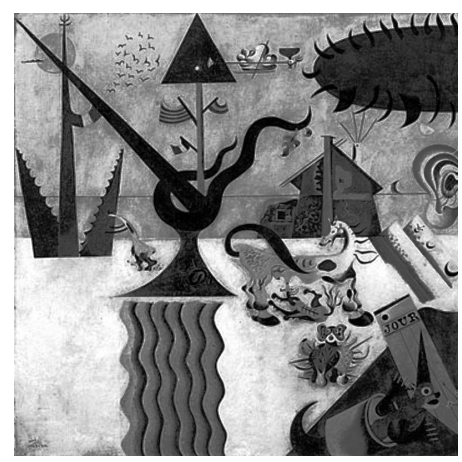

c) Filtro por mediana

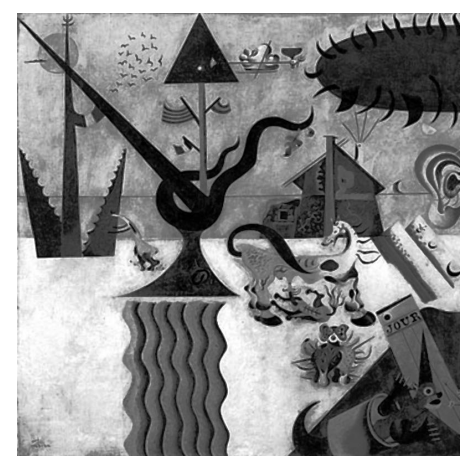

Fonte: Elaborado pelo autor.

Algoritmos de extração de características foram aplicados a versões coloridas, em escala de cinza e preto-e-branco das imagens (figura 3.5), conforme necessário. Por exemplo, para o algoritmo convex-hull, uma imagem binária foi utilizada, enquanto que para o algoritmo de textura de Haralick, uma imagem em escala de cinza foi utilizada, já a segmentação SLIC utilizou a versão RGB de cada imagem.

Com o objetivo de mensurar características de regiões das pinturas, métodos de segmentação foram utilizados, a saber: Watershed, SLIC e Felzenswald. $(16,59)$ Após experimentos (figura 3.6), preferiu-se o método de segmentação SLIC (descrito na subseção 2.4.3), por apresentar melhor separação das regiões de cada pintura. O parâmetro $k$ (número de clusters) da segmentação SLIC foi ajustado de forma a melhor segmentar as regiões. Como é possível notar 
Figura 3.5 - Tipos de imagens utilizadas no estudo. a) imagem colorida em formato RGB, b) imagem em escala de cinza, e c) imagem binária.

a) Imagem original RGB

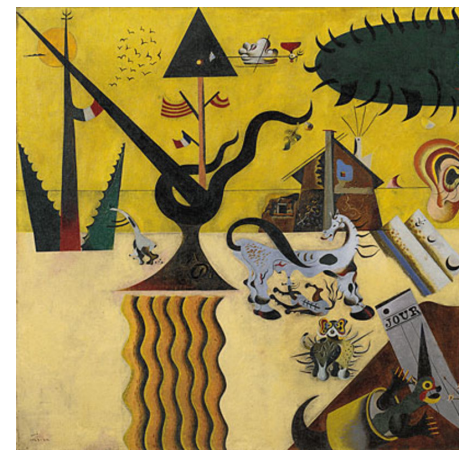

b) Imagem em escala de cinza

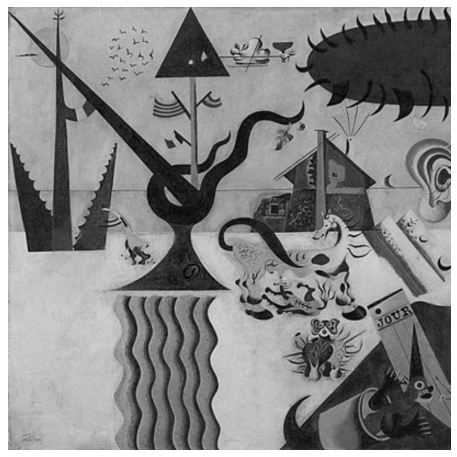

c) Imagem binária

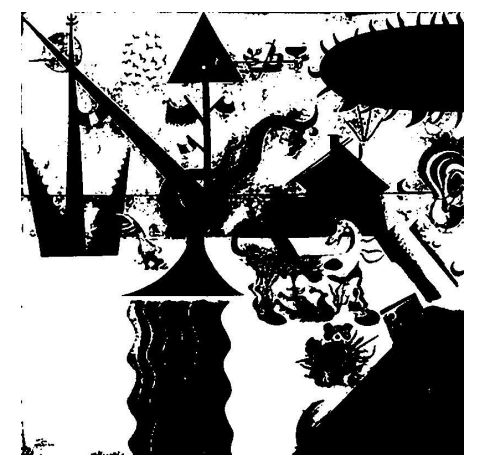

Fonte: Elaborado pelo autor.

no detalhe $e$ ) da figura 3.6, valores de $k>10$ revelaram resultados que não contribuiriam para a segmentação desejada.

Tendo-se as regiões segmentadas, estas foram rotuladas em objetos conexos, ou seja, em regiões conectadas e independentes umas das outras. Os objetos conexos com área menor que um dado limiar (definido experimentalmente) foram removidos da imagem, como mostra a figura 3.7. Após esta etapa de pós-processamento, partiu-se para o cálculo de curvatura de cada região e demais atributos descritos na seção 2.5. A figura 3.8 mostra algumas das regiões segmentadas e suas respectivas curvaturas. É possível notar que o cálculo da curvatura consegue identificar os picos de curvatura (marcados em vermelho) da maneira esperada.

Todo o processo está representado esquematicamente na figura 3.9 e abrange todos os passos, do processamento das pinturas até o cálculo das medidas de dialética, oposição e inovação, discutidas em detalhes nas próximos seções, e portanto, destacadas na figura. 
Figura 3.6 - Experimentos realizados para segmentação de pinturas, considerando ambas pinturas barrocas e modernas. a) a imagem original, b) segmentação por Watershed, c) Felzenswald, d) SLIC com $k=10$ e e) SLIC com $k=20$. O método SLIC com $k=10$ foi escolhido por apresentar, visualmente, melhor separação dos segmentos, e os parâmetros escolhidos contribuíram para a segmentação apresentada.
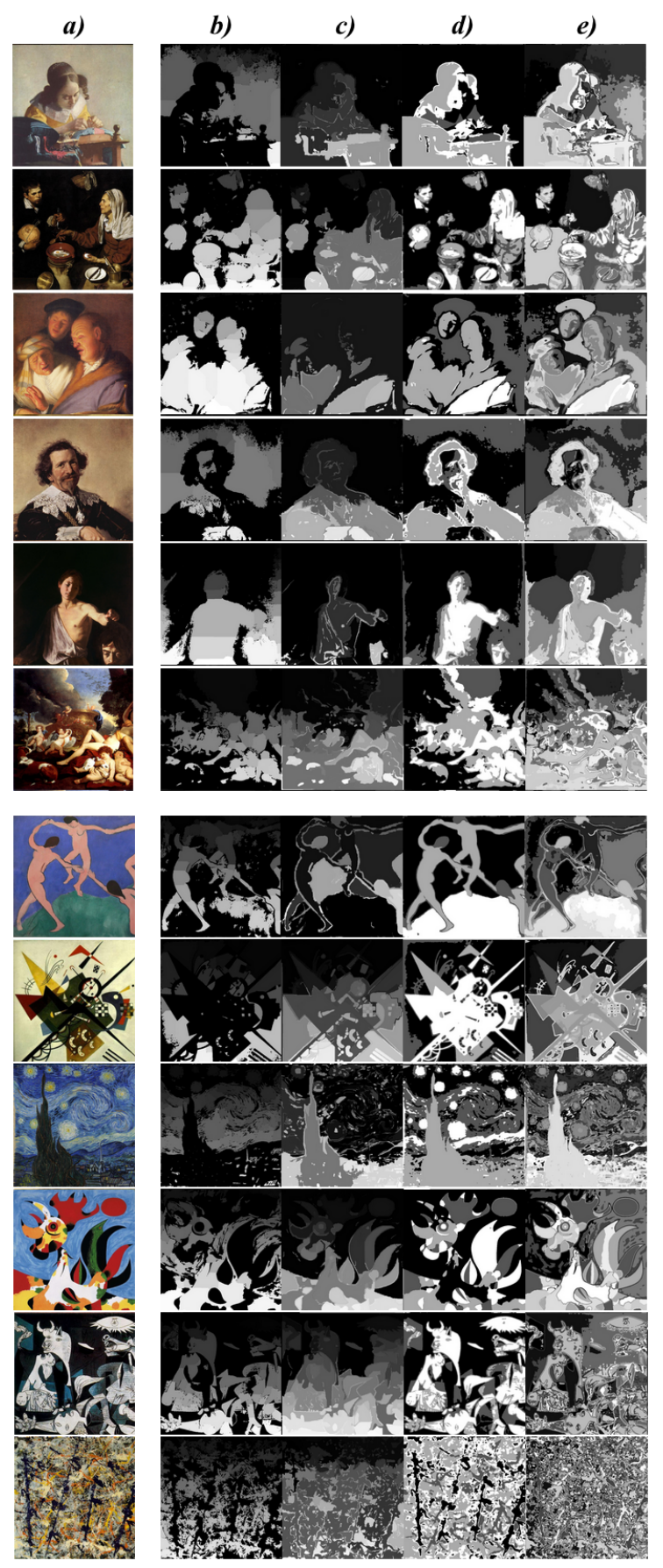

Fonte: Elaborado pelo autor. 
Figura 3.7 - Pós-processamento através da rotulação dos componentes conexos e sua filtragem, removendo as regiões com áreas menores que um dado limiar. a) Detalhe de regiões segmentadas através do algoritmo SLIC, b) objetos rotulados, c) objetos com área menor que limiar removidos. É a partir desta última imagem que se realizou a extração de características.

a) Regiões segmentadas

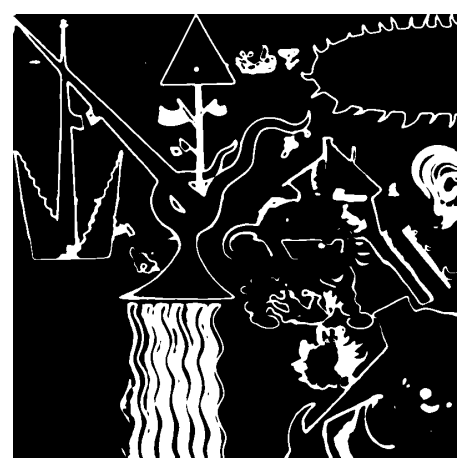

b) Objetos conexos rotulados

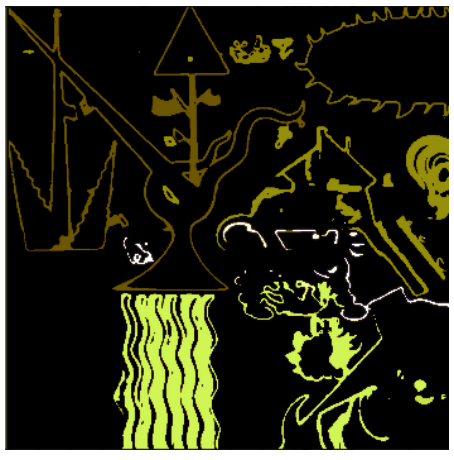

c) Objetos menores removidos

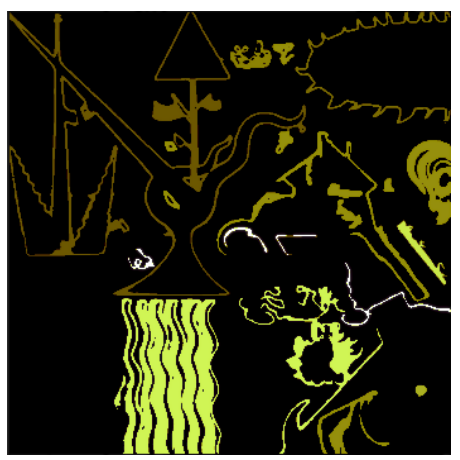

Fonte: Elaborado pelo autor. 
Figura 3.8 - Regiões segmentadas e suas respectivas curvaturas. Os marcadores em vermelho identificam os picos de curvatura no perfil e sua localização na região segmentada. O cálculo de curvatura demonstra desempenho esperado na identificação dos picos de curvatura.

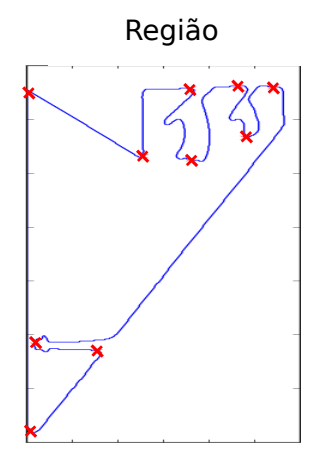

Perfil da curvatura

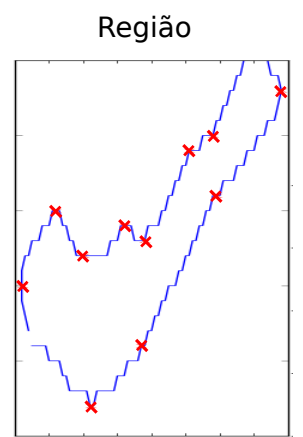

Perfil da curvatura
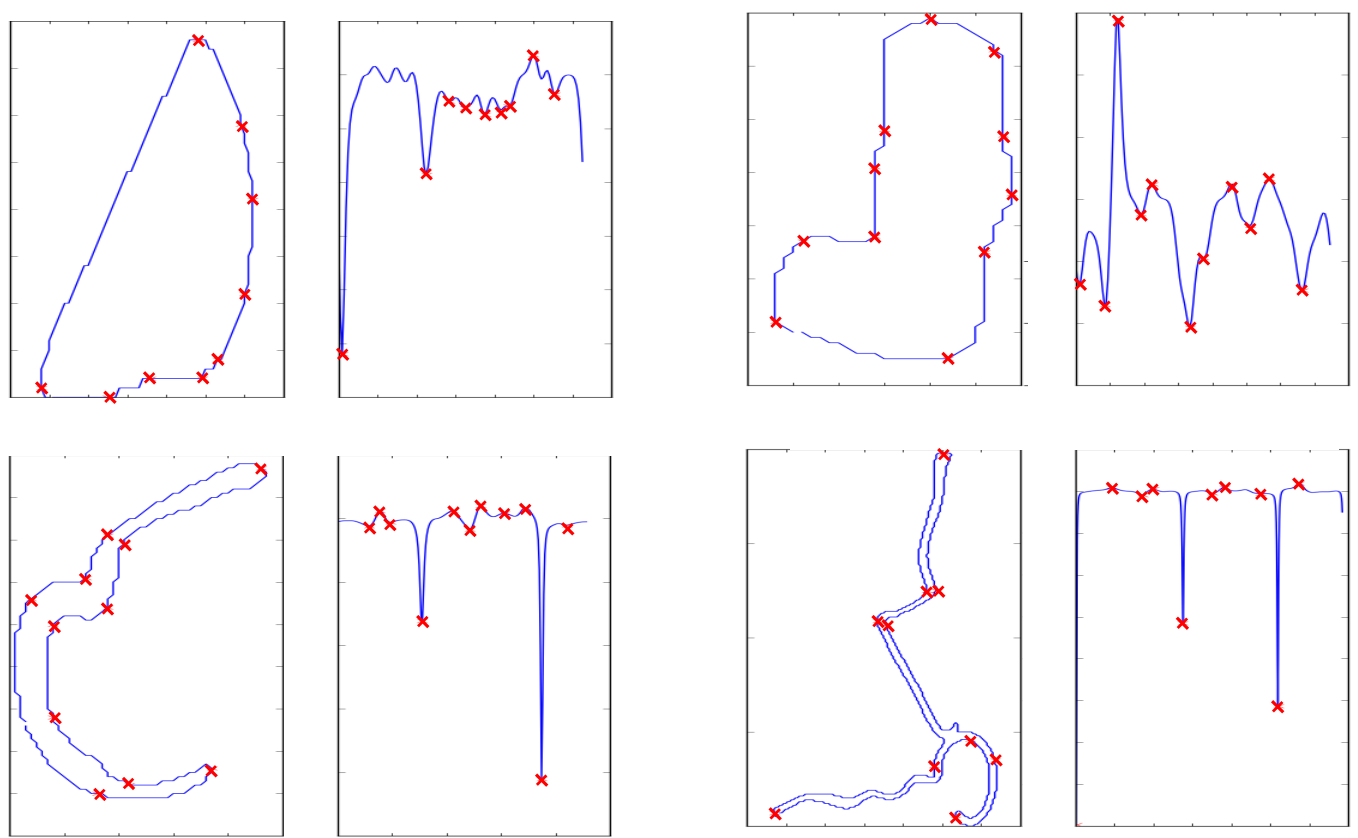

Fonte: Elaborado pelo autor. 
Figura 3.9 - Diagrama com todos os passos tomados, desde o processamento das imagens das pinturas até a extração de características, assim como a obtenção da série temporal onde foram calculadas as medidas de oposição, inovação e dialética.

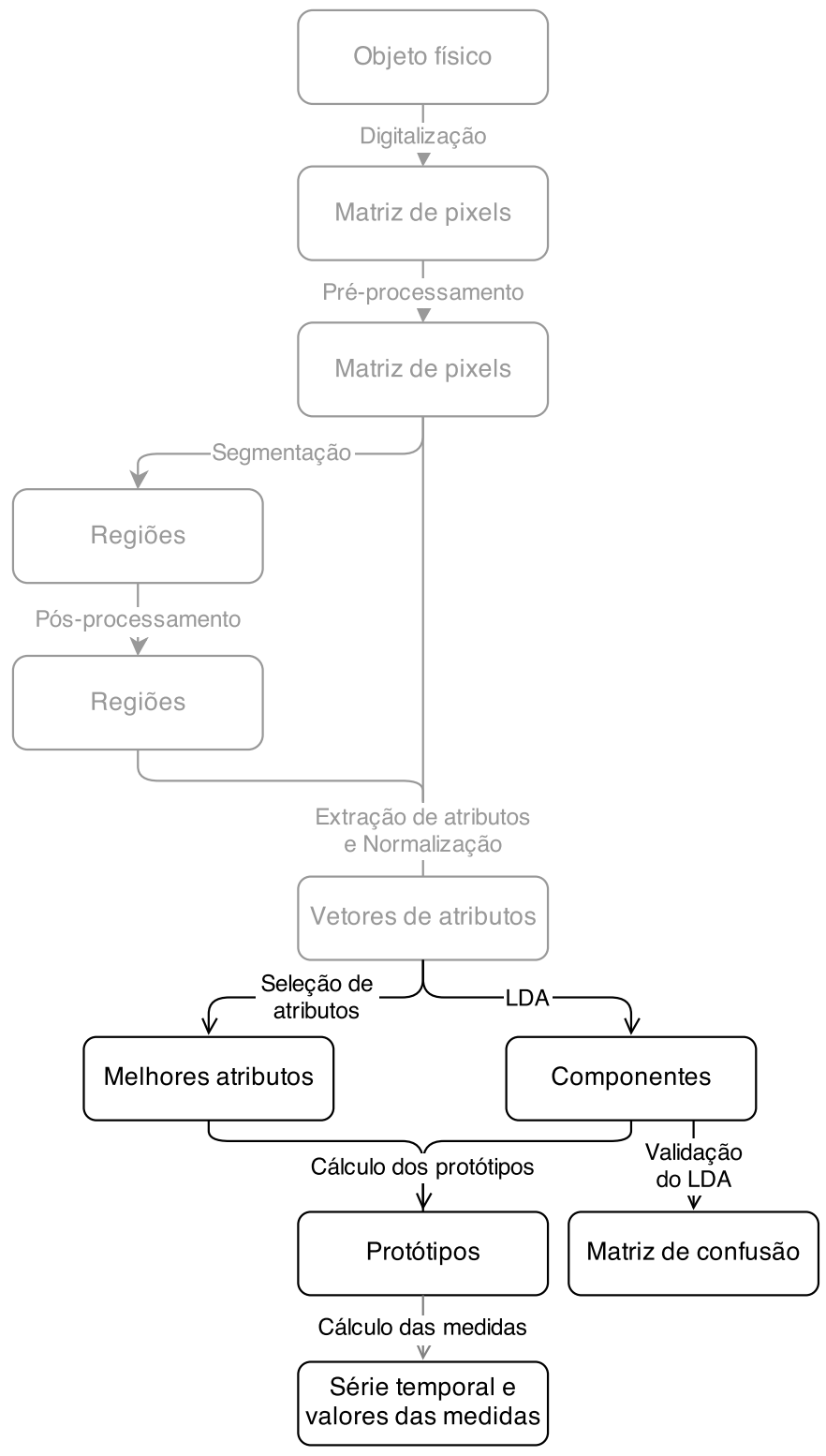

Fonte: Elaborado pelo autor. 


\subsection{Seleção de atributos}

Para selecionar os atributos mais relevantes, neste caso, os atributos que separassem melhor os grupos de pinturas - em outras palavras, que garantissem menor covariância interna em cada classe e maior covariância entre as classes - uma medida de dispersão foi aplicada usando as matrizes de espalhamento discutidas na seção 2.6.

Calculando $\alpha$ através da eq. 2.82 para todos os possíveis pares de atributos $F_{N, a}$ e $F_{N, b}$ dos $N=100$ atributos e ordenando os resultados por $\alpha$, é possível selecionar os atributos mais relevantes para a classificação. Pares com maiores valores de $\alpha$ apresentam melhor dispersão interclasse e agrupamento intraclasse do que pares com menores valores. Como visto na tabela 3.10 (e mais a frente, nas figuras 3.14 e 3.15), os atributos média dos picos de curvatura e média do número de segmentos possuem maior valor de $\alpha$ e foram selecionados para a análise das medidas de oposição, inovação e dialética — ambos atributos se mostraram predominan-

tes mesmo na projeção por LDA, discutida na seção 3.7. É interessante notar a natureza dos atributos selecionados: o número de segmentos em cada pintura e os picos de curvatura são características proeminentes para a classificação das pinturas, melhores até mesmo que os atributos de textura de Haralick e de complexidade de imagens (i.e. entropia). Outros atributos que apresentaram valores altos de $\alpha$ são também relacionados com características de forma, como: média da área de convex-hull, média do perímetro dos segmentos, média da área dos segmentos, e circularidade. Estes atributos apresentaram projeções e propriedades de agrupamento similares às da figura 3.14 como mostrado na figura 3.11 . 
Tabela 3.10 - Pares de atributos $F_{N, a}$ e $F_{N, b}$ ordenados por $\alpha$. Pares com valores maiores de $\alpha$ mostram maior dispersão interclasse enquanto menor dispersão intraclasse (maior agrupamento). $O$ melhor par de atributos: média dos picos de curvatura $e$ média do número de segmentos foram selecionados para a análise e cálculo das medidas de oposição, inovação e dialética.

\begin{tabular}{llll}
\hline \hline Par & Atributo $\boldsymbol{a}$ & Atributo $\boldsymbol{b}$ & $\boldsymbol{\alpha}$ \\
\hline 1 & média do número de picos & média do número de segmentos & 42.445 \\
2 & média do número de segmentos & média da área de convex-hull & 37.406 \\
3 & média do perímetro do segmento & média do número de segmentos & 36.703 \\
4 & média da área do segmento & média do número de segmentos & 36.214 \\
5 & média do número de segmentos & média área convexa / área total & 34.885 \\
6 & média de circularidade (Per. ${ }^{2}$ /Area) & média do número de segmentos & 33.540 \\
7 & média da energia das linhas (canal verde) & média do número de segmentos & 32.954 \\
8 & média da energia das linhas e colunas (canal verde) & média do número de segmentos & 32.954 \\
9 & d.p. da energia das linhas (canal verde) & média do número de segmentos & 32.932 \\
10 & d.p. da energia das linhas e colunas (canal verde) & média do número de segmentos & 32.906 \\
11 & média de entropia local (janela de dimensão 5) & média do número de segmentos & 32.898 \\
12 & entropia (Haralick adj. 4) & média do número de segmentos & 32.898 \\
13 & entropia (Haralick adj. 3) & média do número de segmentos & 32.883 \\
14 & entropia (Haralick adj. 1) & média do número de segmentos & 32.874 \\
15 & entropia (Haralick adj. 2) & média do número de segmentos & 32.869 \\
16 & média da energia das linhas (canal vermelho) & média do número de segmentos & 32.865 \\
\hline \hline
\end{tabular}

Fonte: Elaborado pelo autor. 
Figura 3.11 - Matrizes de espalhamento para cada i-ézimo par de atributos, listadas na tabela $3.10 \mathrm{em}$ ordem decrescente de $\alpha$. A primeira projeção (par 1) foi utilizada nesse estudo.
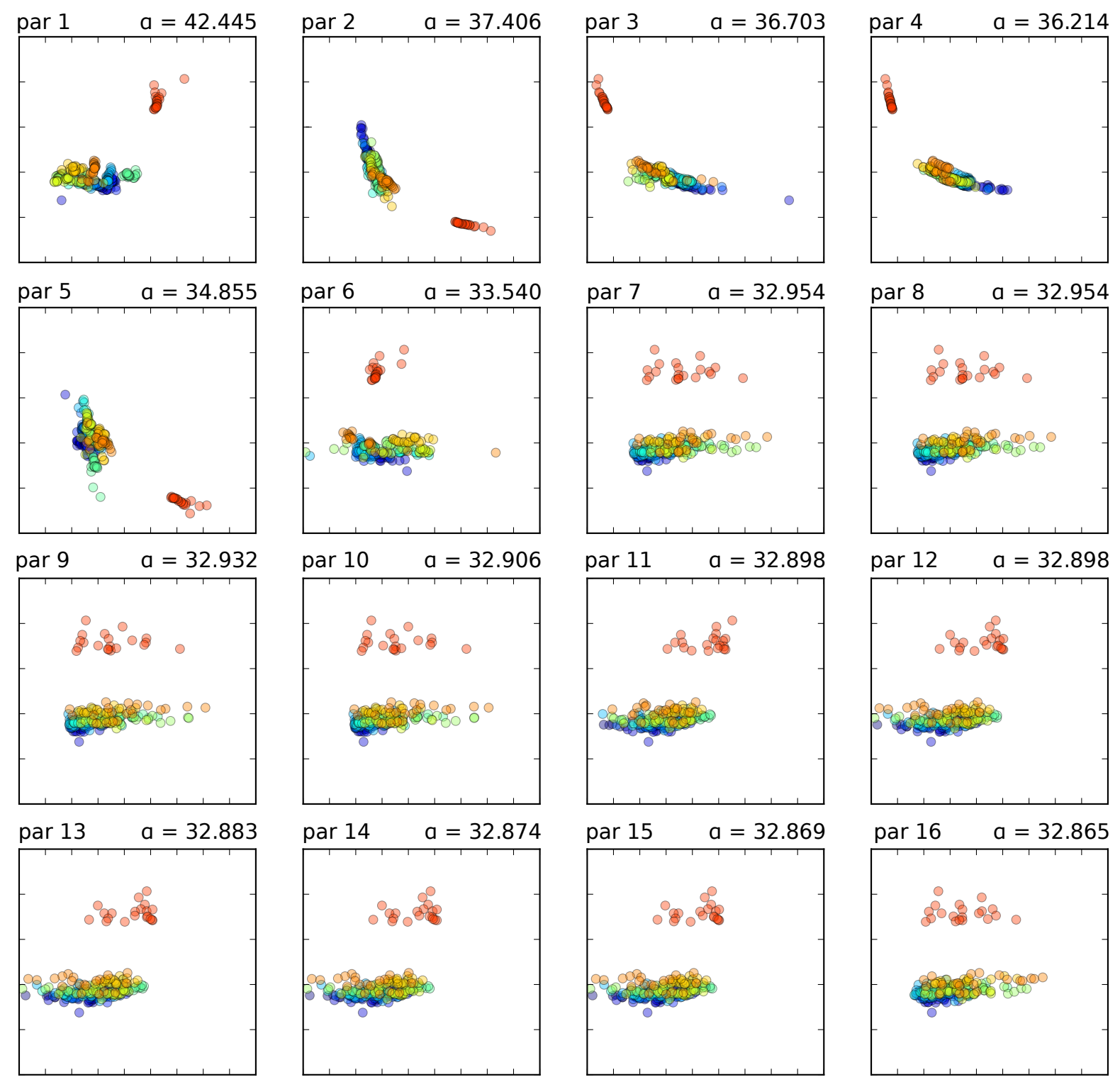

Fonte: Elaborado pelo autor. 


\subsection{Medidas de dialética, oposição e inovação}

Havendo $N_{f}$ atributos $\vec{f}_{i}$, define-se um espaço $N_{f}$-dimensional chamado de espaço criativo, pois a exemplo do espaço criativo sugerido por Deleuze, (13) tem como objetivo a representação de uma superfície onde artefatos (e.g. pinturas, peças musicais ou poemas) criados por agentes (e.g. pintores, compositores ou escritores) caracterizam uma região que foi explorada criativamente. É neste espaço criativo que as medidas de dialética, oposição e inovação são calculadas. (1)

Para simplificar o cálculo, um protótipo $\overrightarrow{p_{i}}$ é definido para cada classe $C_{p}$. Cada protótipo su-

mariza uma classe de pinturas (ou um pintor), correspondendo ao seu centroide: $\vec{p}_{i}=\frac{1}{N_{p}} \sum_{i=1}^{N_{p}} \vec{f}_{i}$ calculado no espaço projetado. É importante notar que essa medida é independente de dimensão, porém métodos de redução de dimensionalidade são aplicados à matriz de atributos para possibilitar a visualização do espaço criativo em duas dimensões.

Uma sequência $S$ de $\overrightarrow{p_{i}}$ estados define uma série temporal que modela uma aproximação do que seria a linha cronológica para as pinturas e seus movimentos artísticos. Um estado médio em um dado tempo $i$ abrangendo os estados $\overrightarrow{p_{1}}$ até $\overrightarrow{p_{i}}$ é definido como

$$
\vec{a}_{i}=\frac{1}{i} \sum_{j=1}^{i} \vec{p}_{j}
$$

O estado de oposição $\overrightarrow{r_{i}}$ define uma medida de oposição à $\overrightarrow{p_{i}}$ como

$$
\vec{r}_{i}=\vec{p}_{i}+2\left(\vec{a}_{i}-\vec{p}_{i}\right)
$$

e dessa forma, um vetor de oposição $\vec{D}_{i}$ pode ser definido como

$$
\vec{D}_{i}=\vec{r}_{i}-\vec{p}_{i}
$$


que representa o deslocamento do estado $\vec{r}_{i}$ em função de $\vec{p}_{i}$.

Sabendo que qualquer deslocamento a partir de um estado $\overrightarrow{p_{i}}$ até um outro estado $\overrightarrow{p_{j}}$ é definido como

$$
\vec{M}_{i, j}=\vec{p}_{j}-\vec{p}_{i}
$$

é possível definir um índice de oposição $W_{i, j}$ para quantificar quanto um protótipo $\overrightarrow{p_{j}}$ se opõe a outro protótipo $\overrightarrow{p_{i}}$ (ou seja, um deslocamento na direção de $\overrightarrow{r_{i}}$ ) ou concorda com outro protótipo $p_{i}$ (um deslocamento na direção de $\left.-\overrightarrow{r_{i}}\right)$ :

$$
W_{i, j}=\frac{\left\langle\vec{M}_{i, j}, \vec{D}_{j}\right\rangle}{\left\|\vec{D}_{j}\right\|^{2}}
$$

sendo portanto a projeção de $\vec{M}_{i, j}$ em $\vec{D}_{i}$, ou seja, não importa onde o deslocamento tenha se dado, ele é considerado em relação ao vetor de oposição (ou deslocamento) $\vec{D}_{i}$. A figura 3.12 ilustra $\vec{D}_{i}$, dados dois estados consecutivos $\overrightarrow{p_{i}}$ e $\overrightarrow{p_{j}}$, o estado de oposição $\overrightarrow{r_{i}}$ e o estado médio $\overrightarrow{a_{i}}$. Porém, movimentos nesse espaço criativo não estão restritos à confirmação ou contradição de “ideias". Ideias alternativas podem existir fora desse deslocamento dualístico. Isso é modelado como um índice de inovação que quantifica quanto um protótipo $\overrightarrow{p_{j}}$ é inovador quando comparado com um outro protótipo $\overrightarrow{p_{i}}$ :

$$
s_{i, j}=\sqrt{\frac{\left|\vec{p}_{i}-\vec{p}_{j}\right|^{2}\left|\vec{a}_{i}-\vec{p}_{i}\right|^{2}-\left[\left(\vec{p}_{i}-\vec{p}_{j}\right) \cdot\left(\vec{a}_{i}-\vec{p}_{i}\right)\right]^{2}}{\left|\vec{a}_{i}-\vec{p}_{i}\right|^{2}}}
$$

ou seja, quanto $\overrightarrow{p_{j}}$ se afasta da linha $L_{i}$ formada por $\overrightarrow{p_{i}}$ e $\overrightarrow{r_{i}}$ : a linha de "oposição". A figura 3.12 também ilustra os cálculos dos índices de oposição e inovação para dois estados consecutivos $\overrightarrow{p_{i}}$ e $\overrightarrow{p_{j}}$ da série temporal e uma linha $L_{i}$. 
Figura 3.12 - Cálculo dos índices de oposição $W_{i, j}$ - com base no deslocamento $\vec{D}_{j}$ e inovação $s_{i, j}$ dados dois estados consecutivos $\overrightarrow{p_{i}}$ e $\overrightarrow{p_{j}}$.

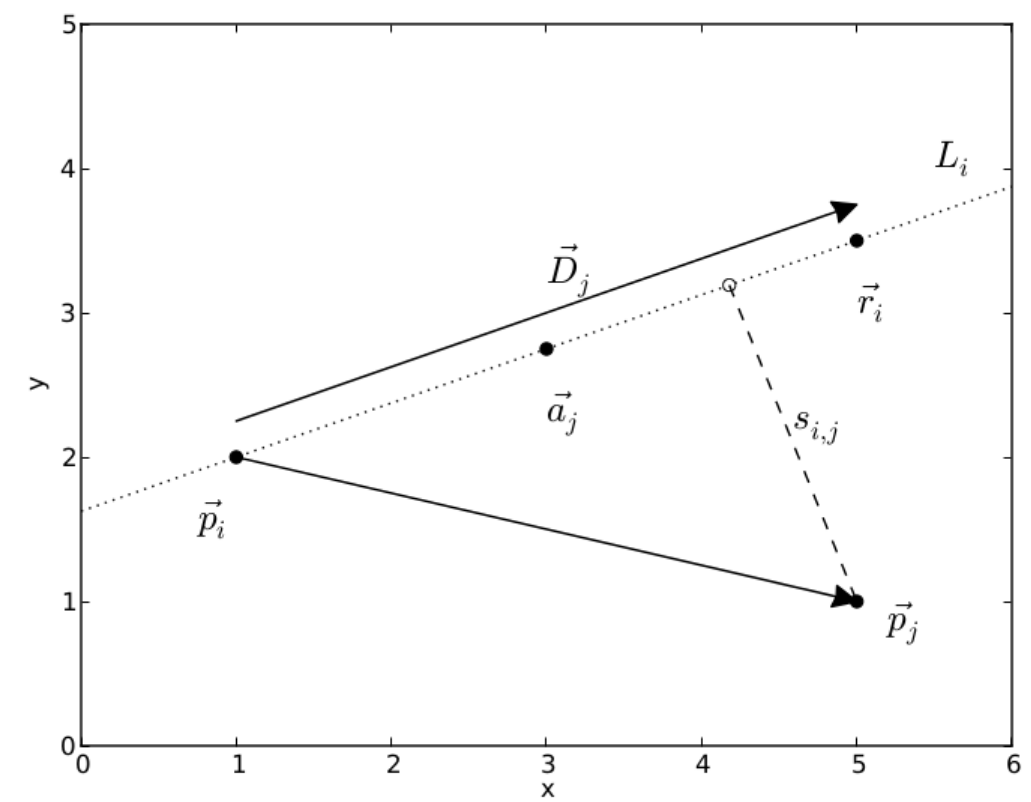

Fonte: Elaborado pelo autor.

Uma outra medida surge quando consideram-se três estados consecutivos nos tempos $i, j$ e $k$. Sendo $\overrightarrow{p_{i}}$ a tese, $\overrightarrow{p_{j}}$ a antítese e $\overrightarrow{p_{k}}$ a síntese, um índice de contra-dialética (1) pode ser definido como

$$
d_{i \rightarrow k}=\frac{\left|\left\langle\vec{p}_{j}-\vec{p}_{i}, \vec{p}_{k}\right\rangle+\frac{1}{2}\left\langle\vec{p}_{i}-\vec{p}_{j}, \vec{p}_{i}+\vec{p}_{j}\right\rangle\right|}{\left|\vec{p}_{j}-\vec{p}_{i}\right|}
$$

ou, a distância entre $\overrightarrow{p_{k}}$ e a mediatriz $B_{i, j}$ (ou um "hiperplano mediatriz" quando considerando espaços $N_{f}$-dimensionais com $N_{f}>3$ ) entre $\overrightarrow{p_{i}}$ e $\overrightarrow{p_{j}}$. Em outras palavras, um estado $\overrightarrow{p_{k}}$ com grande distância $d_{i \rightarrow k}$ está afastado da síntese (possui baixa dialética) e vice-versa. A medida de contra-dialética $d_{i \rightarrow k}$ é ilustrada na figura 3.13 para três estados consecutivos $\overrightarrow{p_{i}}, \overrightarrow{p_{j}}$ e $\overrightarrow{p_{k}}$ da série temporal, dada uma mediatriz $B_{i, j}$ formada pelos dois primeiros estados da série. 
Figura 3.13 - Cálculo da contra-dialética $d_{i \rightarrow k}$ dados os estados consecutivos de tese $\vec{p}_{i}$, antítese $\vec{p}_{j} e$ síntese $\overrightarrow{p_{k}}$. Quanto maior o valor da distância $\vec{d}_{i \rightarrow k}$ de $\overrightarrow{p_{k}}$ à síntese ideal formada pela mediatriz $B_{i, j}$ entre $\overrightarrow{p_{i}}$ e $\overrightarrow{p_{j}}$, menor a dialética.

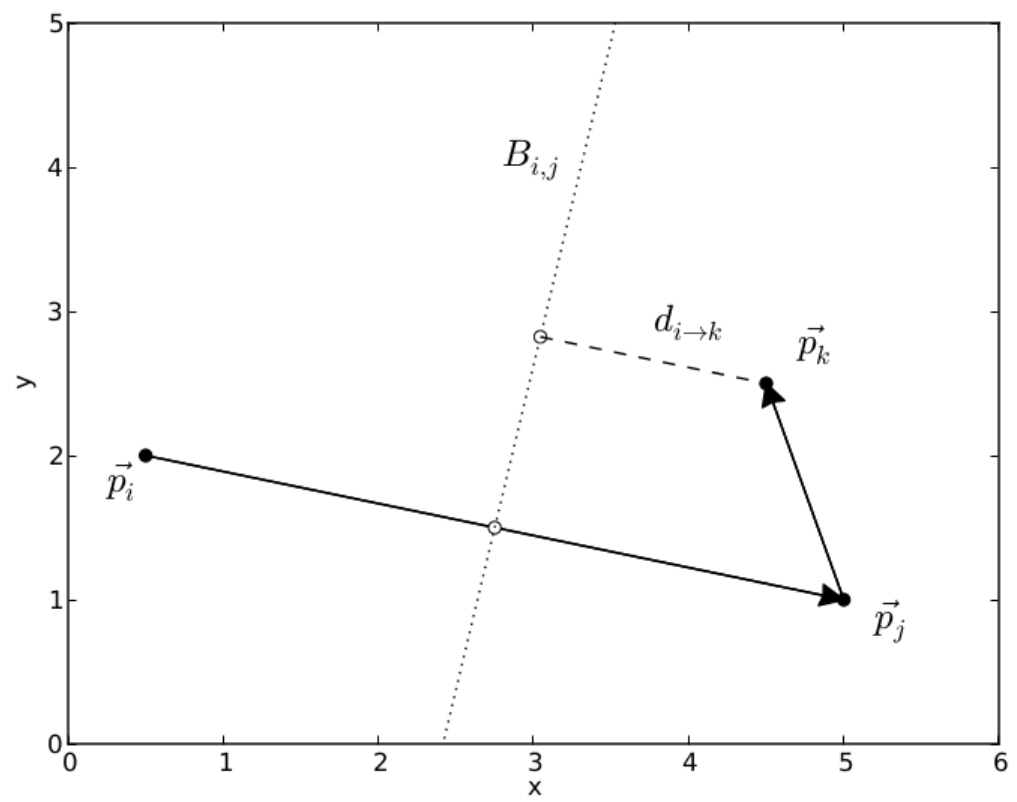

Fonte: Elaborado pelo autor. 


\subsection{Análise das pinturas para atributos com maior dispersão}

O espaço criativo considerando todas as pinturas "representadas" por $\overrightarrow{p_{i}}$ e tendo como bases os atributos média de picos da curvatura e média do número de segmentos é apresentado na figura 3.14. A série temporal formada pelos protótipos $\vec{p}_{i}$ para cada pintor no espaço projetado é visto na figura 3.15, facilitando a visualização da evolução da série.

Detalhes interessantes surgem dessa projeção e confirmam algumas das hipóteses levantadas na seção 2.1.3, aqui relembradas e confrontadas com interpretações a partir dos dados quantitativos obtidos na projeção:

- Os pintores da Arte Moderna são caracterizados por sua independência em estilo. Já os pintores do período Barroco apresentam semelhanças, por compartilharem estilos tradicionais. Essa é uma das observações mais relevantes deste estudo. É possível notar na figura 3.14 que há maior sobreposição entre pintores barrocos do que pintores dos movimentos modernos. Esse fato é confirmado pela história da Arte, onde os pintores modernos experimentam novos materiais e desenvolvem estilos próprios, enquanto os barrocos tendem a utilizar estilos tradicionais, como o chiaroscuro de Caravaggio. Os deslocamentos de um artista ao outro também são claramente contrastantes: o módulo dos vetores de deslocamento $\vec{M}_{i, j}$ para os pintores modernos é, em média, maior que os deslocamentos para os pintores barrocos. Este é mais um indicador de que os artistas barrocos compartilhavam semelhanças em estilo, enquanto que os modernos distanciavam-se claramente uns dos outros. Ao contemplar a figura 3.15 percebe-se que há uma certa exploração do que seria o espaço criativo por parte dos artistas barrocos, mas a largura dessa exploração não se compara à realizada pelos pintores modernos que percorrem uma região muito mais ampla, chegando a explorar regiões de extremos opostos como no caso de Pollock.

- Há uma diferença cronológica considerável entre o Barroco e os movimentos da Arte 
Figura 3.14 - Projeção do espaço criativo considerando o melhor par de atributos média de picos da curvatura $e$ média do número de segmentos.

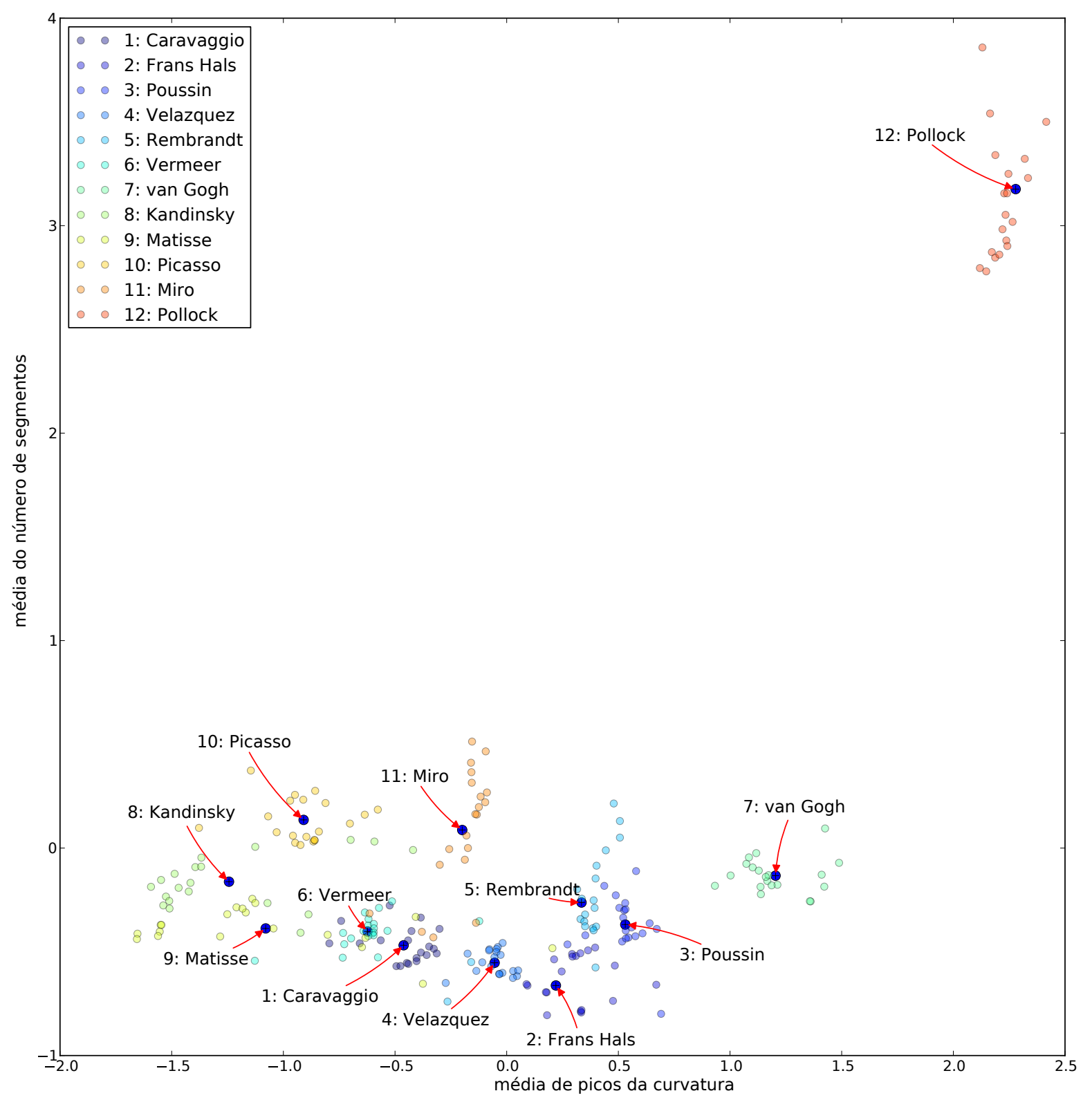

Fonte: Elaborado pelo autor.

Moderna. Quando se observa a série temporal da figura 3.15, a diferença entre os períodos fica evidente: enquanto os barrocos retornam uns aos outros, há um deslocamento abrupto em Van Gogh - o primeiro pintor moderno considerado nesse estudo - que o separa 
Figura 3.15 - Série temporal considerando o melhor par de atributos média de picos da curvatura $e$ média do número de segmentos.

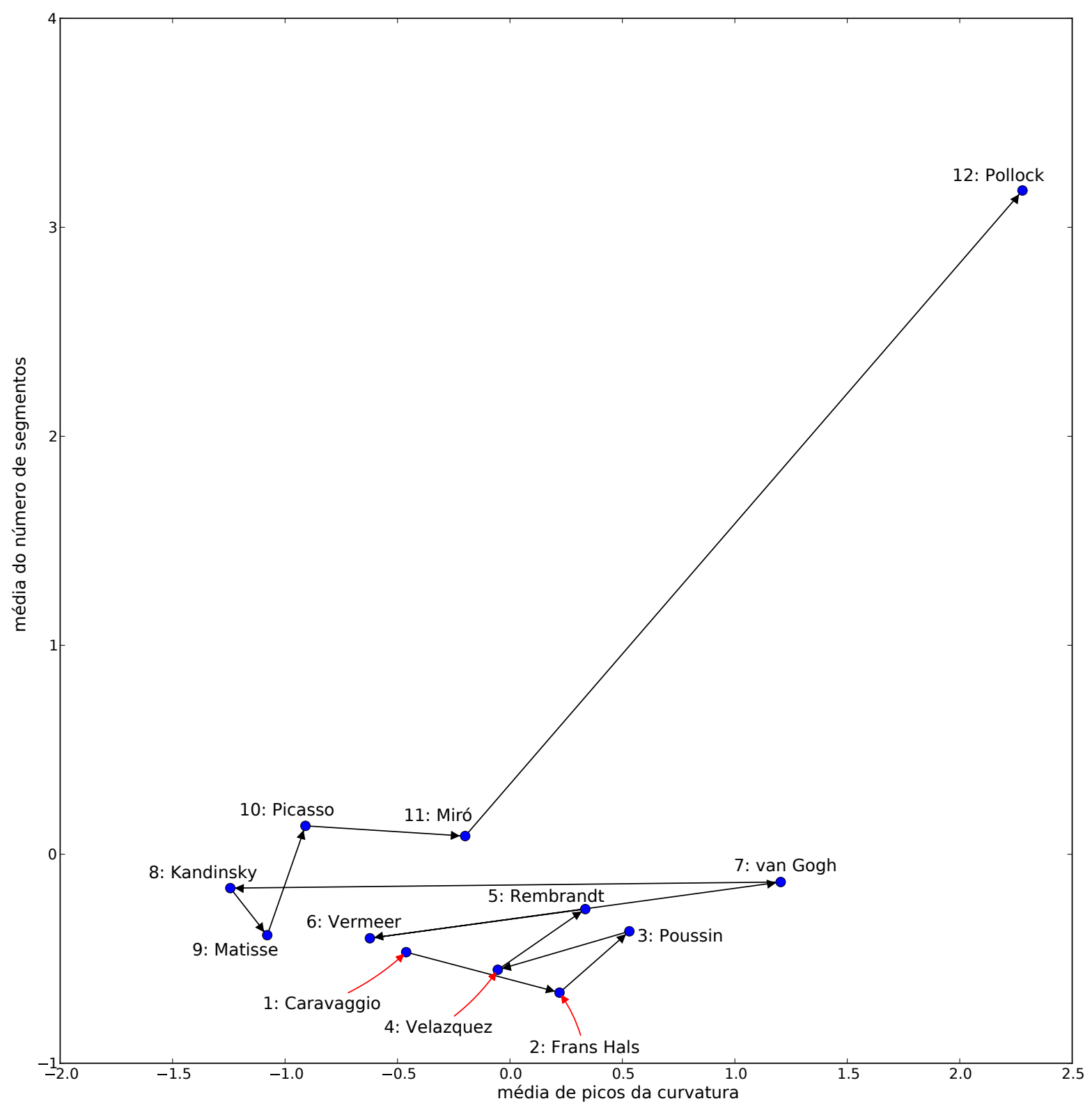

Fonte: Elaborado pelo autor.

dos primeiros pintores. Van Gogh, embora localizado próximo aos pintores barrocos e no extremo oposto da maioria dos pintores modernos, estabelece o início do período Moderno e depois dele os deslocamentos de um vetor ao outro continuam a evoluir até 
alcançar seu ápice, em Pollock. Essa mesma separação entre os períodos Barroco e da Arte Moderna é notada nas medidas de dialética, oposição e inovação, discutidas mais à frente.

- Pollock apresenta pinturas que diferem de todos os outros pintores escolhidos. De todos os clusters da projeção na figura 3.14, Pollock é quem mais se distancia dos demais pintores. Isso se deve ao grande número de segmentos presentes nas pinturas de Pollock quando comparado aos demais artistas: o eixo-y corresponde à projeção do atributo média do número de segmentos. De qualquer forma, ambos eixos $x$ (média do número de picos da curvatura) e $y$ são relevantes para separar os períodos Barroco e Moderno.

- Velázquez e Vermeer se assemelham com Caravaggio pois ambos utilizavam chiaroscuro. A trajetória desenhada (na figura 3.15) de Caravaggio e Frans Hals até Poussin estabelece um caminho que termina com um movimento de oposição de Velázquez, que retorna a Caravaggio. Esse retorno a Caravaggio é também notado em Vermeer. Alguns críticos (72) sugerem que pintores como Vermeer nem teriam existido se não fosse a influência de Caravaggio: os agrupamentos de pinturas de Vermeer e Caravaggio apresentam a maior sobreposição dentre todos os agrupamentos presentes no espaço criativo. Isso pode ser atribuído à influência do mestre do chiaroscuro em ambos pintores, principalmente em Velázquez que foi reconhecidamente um estudioso das pinturas de Caravaggio. (6) Ambos fatos são confirmados pelos histogramas do nível médio de cinza das pinturas, mostrados na figura 3.16. Os histogramas de Velázquez e Vermeer são os que mais se aproximam do histograma de Caravaggio quando comparados aos outros pintores barrocos. Nota-se que os histogramas de Rembrandt e Frans Hals também assemelham-se ao de Caravaggio, e estes pintores também utilizavam o chiaroscuro. O histograma de Poussin é mais bem distribuído, refletindo suas pinturas mais claras, opondo-se à Caravaggio.

- Caravaggio é expoente no uso da técnica do chiaroscuro. Além da influência de Ca- 
ravaggio em pintores como Velázquez e Vermeer, isso é também confirmado quando se comparam os histogramas dos pintores modernos na figura 3.17 com os histogramas para os pintores barrocos da figura 3.16: há baixa similaridade entre os pintores modernos considerados, contrastando diretamente com os pintores barrocos, onde as curvas do histograma tendem à Caravaggio. Assim, afirma-se que há grande diferença de contraste entre as pinturas barrocas (principalmente as de Caravaggio) e aquelas da Arte Moderna.

- Poussin se opõe à Caravaggio: ele não deseja retratar a verdade, mas sim o belo. Poussin é o pintor que mais se distancia do grupo barroco e também compreende o grupo de pinturas com menor sobreposição, visível na figura 3.14. É também o pintor barroco que mais se distancia de Caravaggio segundo o valor de $\left|\vec{M}_{i, j}\right|$ na projeção apresentada na figura 3.15 .

Quando são consideradas as medidas de oposição e inovação, outros resultados interessantes apresentam-se, como mostrado na tabela 3.18 e figura 3.19. O maior valor de oposição é atribuído a Rembrandt. Esse fato é curioso por si, considerando que este pintor holandês é reconhecido como um "contraponto" ao movimento Barroco, mesmo tendo sido parte desse movimento. (6) Vermeer também apresenta forte oposição e a natureza de suas pinturas (e.g. interiores domésticos, uso de cores claras) pode explicar esse fenômeno. Um padrão torna-se visível no começo de ambos períodos Barroco e Moderno: decréscimo contínuo nos valores de oposição, seguido de acréscimo. Da mesma forma, um platô com alta oposição é observado nos pintores barrocos. Esse platô ocorre exatamente na transição de um período artístico ao outro, diminuindo gradualmente enquanto os artistas modernos começam a se estabelecer na história. Esse decréscimo dos valores de oposição reflete um aspecto de baixa oposição entre os primeiros artistas barrocos enquanto há o acréscimo da oposição presente nos deslocamentos que precedem o período Moderno, embora os valores de inovação se mantém oscilando mas aumentando durante toda a série temporal. Em resumo, no que se pode falar dos índices de oposição 
Figura 3.16 - Histogramas dos níveis médios de cinza para todos os pintores barrocos. Vermeer e Velázquez mostram maior similaridade com Caravaggio do que os outros pintores barrocos: a proximidade em contraste encontra fundamento na história (seção 2.1.3), tendo sido ambos pintores influenciados por Caravaggio.
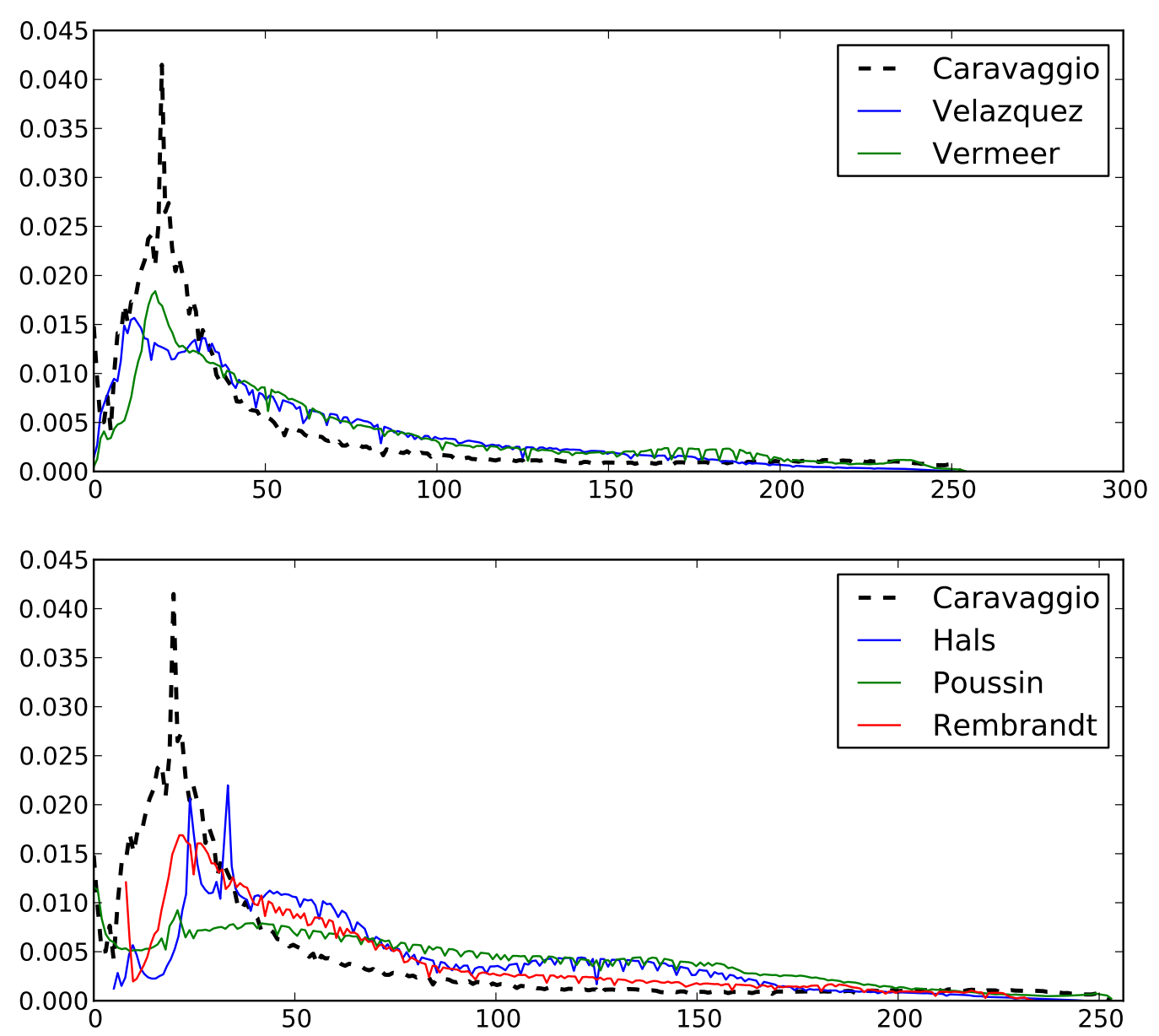

Fonte: Elaborado pelo autor.

e inovação, de maneira geral, a série temporal é marcada por aumento constante de inovação — desconsiderando pequenas oscilações — grande oposição em momentos específicos de sua evolução (a transição entre o Barroco e a Arte Moderna) e menor oposição entre artistas de um mesmo movimento, principalmente no Barroco. 
Figura 3.17 - Histogramas nos níveis médios de cinza para os pintores modernos. Há baixa similaridade entre os pintores modernos, diferente do que ocorre para os pintores barrocos.

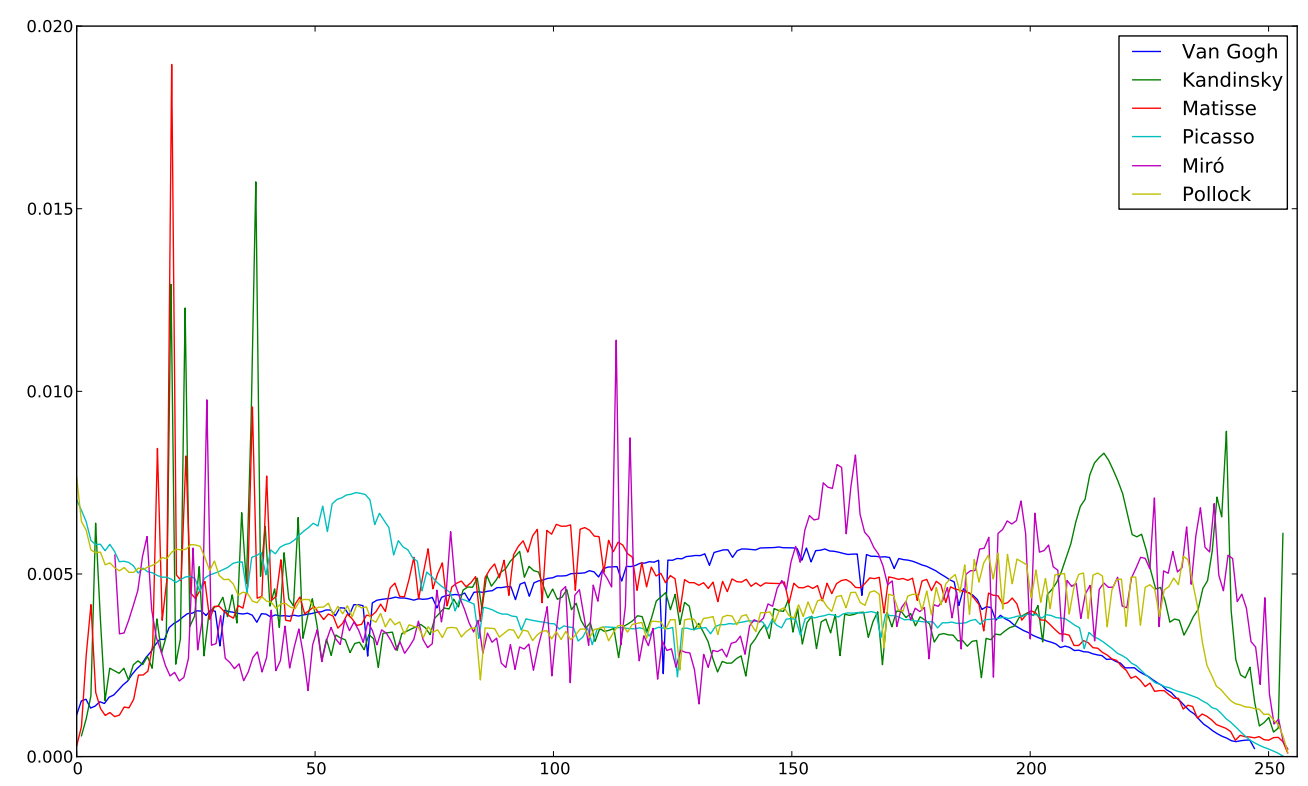

Fonte: Elaborado pelo autor.

Tabela 3.18 - Índice de oposição $W_{i, j}$ e inovação $s_{i, j}$ para cada um dos 11 deslocamentos de um pintor a outro.

\begin{tabular}{lll}
\hline \hline Deslocamento & $\boldsymbol{W}_{\boldsymbol{i}, \boldsymbol{j}}$ & $\boldsymbol{s}_{\boldsymbol{i}, \boldsymbol{j}}$ \\
\hline Caravaggio $\rightarrow$ Frans Hals & 1. & 0. \\
Frans Hals $\rightarrow$ Poussin & 0.111 & 0.425 \\
Poussin $\rightarrow$ Velázquez & 0.621 & 0.004 \\
Velázquez $\rightarrow$ Rembrandt & 1.258 & 0.072 \\
Rembrandt $\rightarrow$ Vermeer & 1.152 & 0.341 \\
Vermeer $\rightarrow$ Van Gogh & 1.158 & 0.280 \\
Van Gogh $\rightarrow$ Kandinsky & 0.970 & 0.452 \\
Kandinsky $\rightarrow$ Matisse & 0.089 & 0.189 \\
Matisse $\rightarrow$ Picasso & 0.117 & 0.509 \\
Picasso $\rightarrow$ Miró & 0.385 & 0.325 \\
Miró $\rightarrow$ Pollock & 2.376 & 3.823 \\
\hline \hline
\end{tabular}

Fonte: Elaborado pelo autor. 
Figura 3.19 - Valores de oposição $W_{i, j}$ e inovação $s_{i, j}$ considerando os dois melhores atributos.

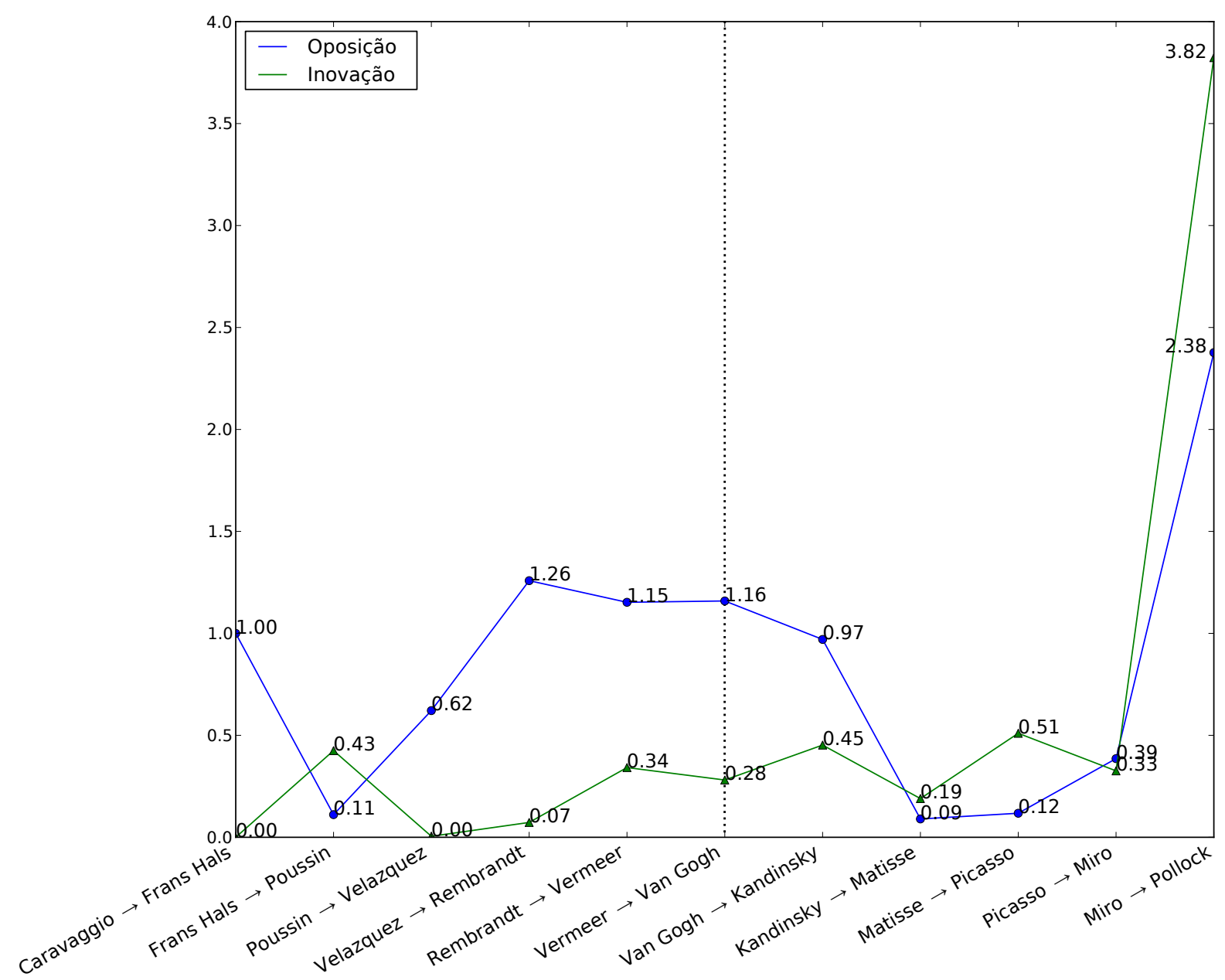

Fonte: Elaborado pelo autor. 
Além destas observações gerais sobre as medidas de oposição e inovação, pode-se interpretar tais medidas para cada par de pintores consecutivos. Estas observações estão apresentadas na tabela 3.20 .

Tabela 3.20 - Possivel interpretação, com base na história da Arte e características estéticas, para cada valor de oposição e inovação calculado. Consideram-se os dois melhores atributos: média do número de segmentos e média da quantidade de picos de curvatura.

\begin{tabular}{|c|c|c|c|}
\hline Deslocamento & $W_{i, j}$ & $s_{i, j}$ & Possível interpretação \\
\hline Caravaggio $\rightarrow$ Frans Hals & 1. & 0 . & $\begin{array}{l}\text { Não é possível considerar, pois para } i= \\
0, j=1 \text { os valores de oposição e inovação } \\
\text { serão sempre } W_{i, j}=1 \text { e } s_{i, j}=0 .\end{array}$ \\
\hline Frans Hals $\rightarrow$ Poussin & 0.111 & 0.425 & $\begin{array}{l}\text { É a menor oposição do período Barroco } \\
\text { e não encontra paralelo com a história, } \\
\text { visto que Frans Hals, por ter sido influ- } \\
\text { enciado por Caravaggio, deveria opor-se } \\
\text { a Poussin. Porém, a inovação é satis- } \\
\text { fatória, pois Poussin enfatiza a pintura de } \\
\text { paisagens ao invés de retratos, comuns em } \\
\text { Hals, para citar um exemplo. }\end{array}$ \\
\hline Poussin $\rightarrow$ Velázquez & 0.621 & 0.004 & $\begin{array}{l}\text { A oposição é esperada, pois Poussin se } \\
\text { opõe a Velázquez, que é influenciado por } \\
\text { Caravaggio. A baixa inovação, por outro } \\
\text { lado, não revela o esperado. }\end{array}$ \\
\hline
\end{tabular}




\begin{tabular}{|c|c|c|c|}
\hline Velázquez $\rightarrow$ Rembrandt & 1.258 & 0.072 & $\begin{array}{l}\text { É o valor mais alto de oposição e encon- } \\
\text { tra paralelo com a história: as pinturas de } \\
\text { Rembrandt nada têm de parecido com as } \\
\text { de Velázquez, embora se esperasse um va- } \\
\text { lor maior para a inovação, dada a inventi- } \\
\text { vidade de Rembrandt. }\end{array}$ \\
\hline Rembrandt $\rightarrow$ Vermeer & 1.152 & 0.341 & $\begin{array}{l}\text { Ambos valores de oposição e inovação re- } \\
\text { fletem a história. Vermeer volta-se ao es- } \\
\text { tilo de Caravaggio, que não possui tanta } \\
\text { influência em Rembrandt. A inovação é a } \\
\text { segunda mais alta do período Barroco, e } \\
\text { corresponde ao estilo alternativo de Ver- } \\
\text { meer para a época, mesmo quando com- } \\
\text { parado a outro contraponto ao Barroco } \\
\text { como Rembrandt. }\end{array}$ \\
\hline Vermeer $\rightarrow$ Van Gogh & 1.158 & 0.280 & $\begin{array}{l}\text { Por se tratar de pintores de épocas muito } \\
\text { diferentes, esperam-se valores altos para } \\
\text { ambas oposição e inovação, talvez ainda } \\
\text { maiores do que o apresentado. }\end{array}$ \\
\hline Van Gogh $\rightarrow$ Kandinsky & 0.970 & 0.452 & $\begin{array}{l}\text { Espera-se alto valor de oposição dados os } \\
\text { estilos contrastantes de ambos pintores. A } \\
\text { inovação é alta e justifica-se, pois Kan- } \\
\text { dinsky inova ao utilizar formas abstratas, } \\
\text { não presentes nas pinturas de Van Gogh. }\end{array}$ \\
\hline
\end{tabular}




\begin{tabular}{|c|c|c|c|}
\hline Kandinsky $\rightarrow$ Matisse & 0.089 & 0.189 & $\begin{array}{l}\text { Correspondem aos valores mais baixos de } \\
\text { oposição e inovação do período Moderno. } \\
\text { Embora tenham características próximas } \\
\text { em forma, esperava-se maior oposição, } \\
\text { dada a natureza mais abstrata de Kan- } \\
\text { dinsky quando comparado a Matisse. }\end{array}$ \\
\hline Matisse $\rightarrow$ Picasso & 0.117 & 0.509 & $\begin{array}{l}\text { A baixa oposição é esperada pois Matisse } \\
\text { costuma retratar formas humanas assim } \\
\text { como Picasso, com certa preferência para } \\
\text { linhas retas ao desenhá-las. A inovação } \\
\text { também encontra paralelo com a história, } \\
\text { já que Picasso inaugura o Cubismo. É a } \\
\text { maior inovação do período Moderno. }\end{array}$ \\
\hline Picasso $\rightarrow$ Miró & 0.385 & 0.325 & $\begin{array}{l}\text { Miró se opõe e inova à Picasso com } \\
\text { mesma intensidade. Há também funda- } \\
\text { mento na história, pois Miró é mais abs- } \\
\text { trato que Picasso, e inova no uso de pin- } \\
\text { tura automática e simbólica, quase não } \\
\text { havendo formas da realidade em suas pin- } \\
\text { turas. }\end{array}$ \\
\hline Miró $\rightarrow$ Pollock & 2.376 & 3.823 & $\begin{array}{l}\text { Esse alto contraste é esperado. Pollock é } \\
\text { o pintor que mais se diferencia de todos } \\
\text { os demais pintores, inclusive Miró. }\end{array}$ \\
\hline
\end{tabular}

Fonte: Elaborado pelo autor. 
No que tange a contra-dialética, mostrada na tabela 3.21 e figura 3.22, há um paralelo com a curva de oposição. A contra-dialética reforça fatos já observados: pintores do mesmo período apresentam inicialmente decréscimo em seus valores, seguido por acréscimo contínuo. O pico de contra-dialética acontece em Van Gogh e Kandinsky: exatamente o ponto onde o Barroco termina e a Arte Moderna começa. A tabela 3.23 oferece uma possível interpretação para cada valor de dialética calculado, ao compará-los com a história da Arte.

Tabela 3.21 - Índices de contra-dialética para cada um dos 10 deslocamentos entre tese, antítese e síntese, considerando os dois melhores atributos: média do número de segmentos e média da quantidade de picos de curvatura.

\begin{tabular}{ll}
\hline \hline Tese, antítese e síntese & $\boldsymbol{d}_{\boldsymbol{i} \rightarrow \boldsymbol{k}}$ \\
\hline Caravaggio $\rightarrow$ Frans Hals $\rightarrow$ Poussin & 0.572 \\
Frans Hals $\rightarrow$ Poussin $\rightarrow$ Velázquez & 0.337 \\
Poussin $\rightarrow$ Velázquez $\rightarrow$ Rembrandt & 0.151 \\
Velázquez $\rightarrow$ Rembrandt $\rightarrow$ Vermeer & 0.608 \\
Rembrandt $\rightarrow$ Vermeer $\rightarrow$ Van Gogh & 1.362 \\
Vermeer $\rightarrow$ Van Gogh $\rightarrow$ Kandinsky & 1.502 \\
Van Gogh $\rightarrow$ Kandinsky $\rightarrow$ Matisse & 1.062 \\
Kandinsky $\rightarrow$ Matisse $\rightarrow$ Picasso & 0.183 \\
Matisse $\rightarrow$ Picasso $\rightarrow$ Miró & 0.447 \\
Picasso $\rightarrow$ Miró $\rightarrow$ Pollock & 2.616 \\
\hline
\end{tabular}

Fonte: Elaborado pelo autor.

Tabela 3.23 - Possível interpretação, com base na história da Arte e características estéticas, para cada valor de contra-dialética calculado.

\begin{tabular}{lll}
\hline \hline Tese, antítese e síntese & $d_{i \rightarrow k}$ & Possível interpretação \\
\hline Caravaggio $\rightarrow$ Frans Hals $\rightarrow$ Poussin & 0.572 & Poussin, segundo a história da Arte, não repre- \\
& senta a síntese entre Caravaggio e Frans Hals. \\
& Pelo contrário, Poussin distancia-se de ambos \\
& pintores. Portanto, o valor de contra-dialética \\
& corresponde ao esperado. \\
\hline
\end{tabular}




\begin{tabular}{|c|c|c|}
\hline Frans Hals $\rightarrow$ Poussin $\rightarrow$ Velázquez & 0.337 & $\begin{array}{l}\text { Espera-se também que Velázquez afaste-se da } \\
\text { síntese entre Frans Hals e Poussin, já que } \\
\text { Velázquez assemelha-se mais a Frans Hals. }\end{array}$ \\
\hline Poussin $\rightarrow$ Velázquez $\rightarrow$ Rembrandt & 0.151 & $\begin{array}{l}\text { É a maior dialética de toda a série, e encontra } \\
\text { fundamento na história. Rembrandt, dada sua } \\
\text { inventividade, parece ter explorado tanto paisa- } \\
\text { gens (como Poussin) quanto retratos utilizando } \\
\text { chiaroscuro (como Velázquez). }\end{array}$ \\
\hline Velázquez $\rightarrow$ Rembrandt $\rightarrow$ Vermeer & 0.608 & $\begin{array}{l}\text { Vermeer realmente difere de ambos Velázquez } \\
\text { e Rembrandt, pintando em um estilo alternativo } \\
\text { para a época, portanto o valor alto de contra- } \\
\text { dialética é justificado. }\end{array}$ \\
\hline Rembrandt $\rightarrow$ Vermeer $\rightarrow$ Van Gogh & 1.362 & $\begin{array}{l}\text { Sendo um pintor moderno, Van Gogh se opõe } \\
\text { aos pintores Barrocos e este aumento abrupto } \\
\text { de contra-dialética é esperado, pois é neste ins- } \\
\text { tante que se dá a transição de um período para } \\
\text { o outro. }\end{array}$ \\
\hline Vermeer $\rightarrow$ Van Gogh $\rightarrow$ Kandinsky & 1.502 & $\begin{array}{l}\text { Kandinsky, um pintor abstrato, apre- } \\
\text { senta a maior contra-dialética da série } \\
\text { (desconsiderando-se Pollock). Realmente } \\
\text { não possui semelhanças com ambos Vermeer e } \\
\text { Van Gogh. }\end{array}$ \\
\hline
\end{tabular}




\begin{tabular}{|c|c|c|}
\hline Van Gogh $\rightarrow$ Kandinsky $\rightarrow$ Matisse & 1.062 & $\begin{array}{l}\text { Matisse distancia-se da síntese entre Van Gogh } \\
\text { e Kandinsky. Embora suas pinturas tenham for- } \\
\text { mas humanas e com variações de cores, como } \\
\text { as de Van Gogh, não são abstratas como as de } \\
\text { Kandinsky. }\end{array}$ \\
\hline Kandinsky $\rightarrow$ Matisse $\rightarrow$ Picasso & 0.183 & $\begin{array}{l}\text { Picasso realmente parece combinar elementos } \\
\text { abstratos (e.g. figuras geométricas presentes em } \\
\text { Kandinsky) com formas encontradas na natu- } \\
\text { reza e figuras humanas, pintadas também por } \\
\text { Matisse. Espera-se portanto alta dialética. }\end{array}$ \\
\hline Matisse $\rightarrow$ Picasso $\rightarrow$ Miró & 0.447 & $\begin{array}{l}\text { Por ser um pintor abstrato, espera-se que Miró } \\
\text { se distancie da síntese entre Matisse e Picasso, } \\
\text { principalmente por Matisse não empregar for- } \\
\text { mas abstratas. Porém, isto não é revelado pelo } \\
\text { valor de contra-dialética. }\end{array}$ \\
\hline Picasso $\rightarrow$ Miró $\rightarrow$ Pollock & 2.616 & $\begin{array}{l}\text { Assim como para as medidas de oposição e } \\
\text { inovação, Pollock apresenta o maior valor de } \\
\text { contra-dialética da série, dada a natureza de } \\
\text { suas obras, que diferem de todos os demais pin- } \\
\text { tores considerados. }\end{array}$ \\
\hline
\end{tabular}

Fonte: Elaborado pelo autor. 
Figura 3.22 - Valores de contra-dialética considerando os dois melhores atributos.

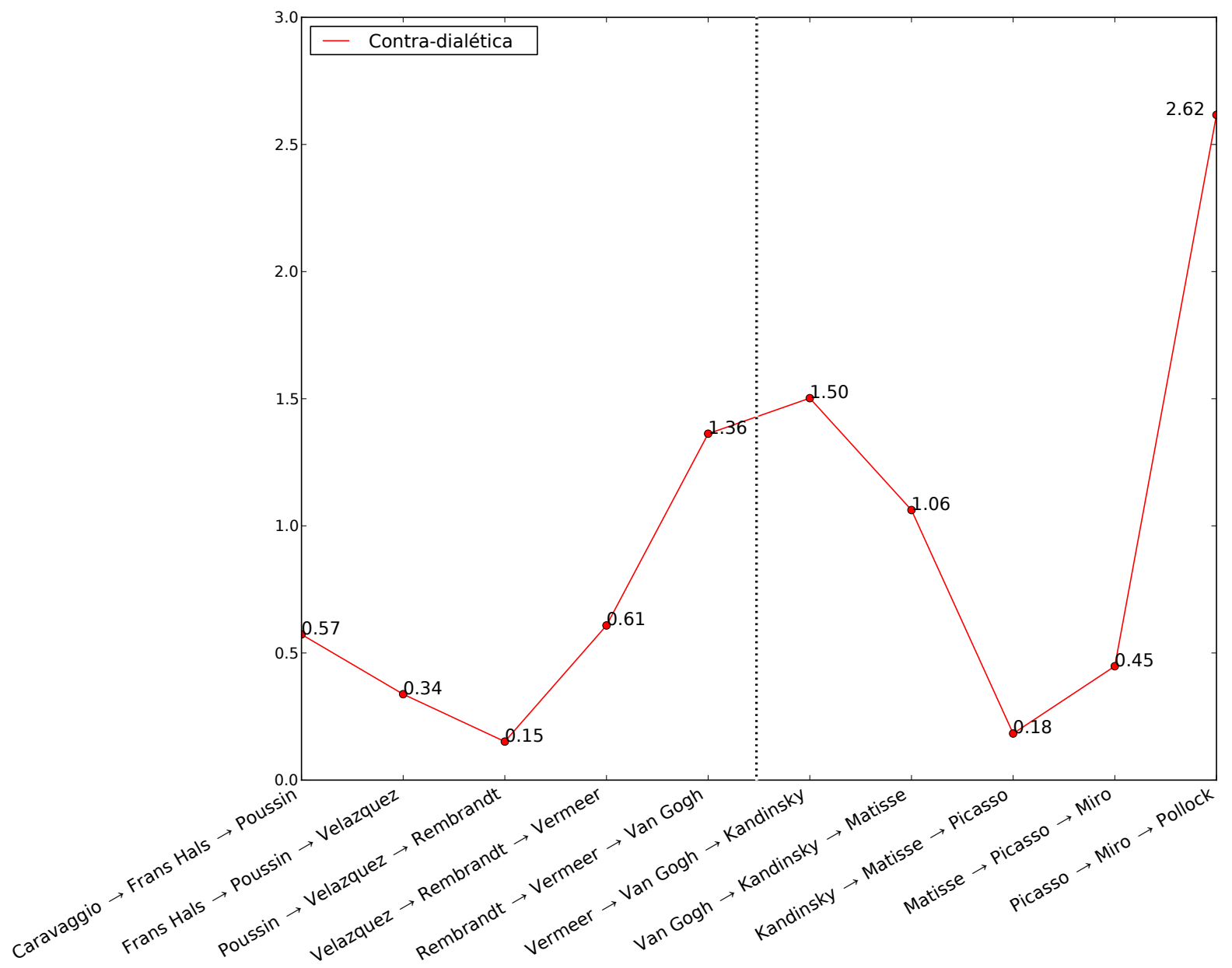

Fonte: Elaborado pelo autor. 


\subsection{Análise por LDA de todos os atributos}

Embora os atributos média de picos de curvatura e média do número de segmentos apresentaramse como opções interessantes para a classificação, o método LDA foi aplicado considerando todos os $N=100$ atributos com o objetivo de testar a relevância dos atributos originalmente selecionados e a estabilidade dos resultados. O método LDA projeta os atributos em um espaço de $r<N$ dimensões que melhor separa as pinturas e que acaba por resultar em uma nova série temporal como feito para o caso dos melhores atributos. Nesse caso, para permitir a visualização das medidas, considerou-se a projeção com $r=2$ componentes que resultou em um espaço de 2 dimensões, mostrado na figura 3.24. É possível notar que os resultados para a análise por LDA são ainda mais aparentes do que aqueles obtidos na seção 3.6: os índices de inovação (tabela 3.25 e figura 3.26) apresentam uma curva ascendente ainda mais bem definida durante toda a evolução da série. Os padrões notados na evolução de ambos índices de oposição e contradialética continuam visíveis nessa nova projeção por LDA, como é possível notar na figura 3.26, tabela 3.27 e figura 3.28 .

Tabela 3.25 - Índices de oposição e inovação para cada um dos 11 deslocamentos de um pintor ao outro.

\begin{tabular}{lll}
\hline \hline Deslocamento & $\boldsymbol{W}_{\boldsymbol{i}, \boldsymbol{j}}$ & $\boldsymbol{s}_{\boldsymbol{i}, \boldsymbol{j}}$ \\
\hline Caravaggio $\rightarrow$ Frans Hals & 1. & 0. \\
Frans Hals $\rightarrow$ Poussin & -0.101 & 0.132 \\
Poussin $\rightarrow$ Velázquez & 0.588 & 0.037 \\
Velázquez $\rightarrow$ Rembrandt & 1.526 & 0.050 \\
Rembrandt $\rightarrow$ Vermeer & 1.101 & 0.143 \\
Vermeer $\rightarrow$ Van Gogh & 1.153 & 0.157 \\
Van Gogh $\rightarrow$ Kandinsky & 1.279 & 0.512 \\
Kandinsky $\rightarrow$ Matisse & 0.179 & 0.149 \\
Matisse $\rightarrow$ Picasso & -0.201 & 0.516 \\
Picasso $\rightarrow$ Miró & 0.432 & 0.163 \\
Miró $\rightarrow$ Pollock & 4.031 & 2.662 \\
\hline \hline
\end{tabular}

Fonte: Elaborado pelo autor. 
Figura 3.24 - Série temporal resultante da projeção em 2 dimensões do espaço criativo considerando os dois primeiros componentes com maiores autovalores obtidos a partir da transformação LDA na matriz de $N=100$ atributos.

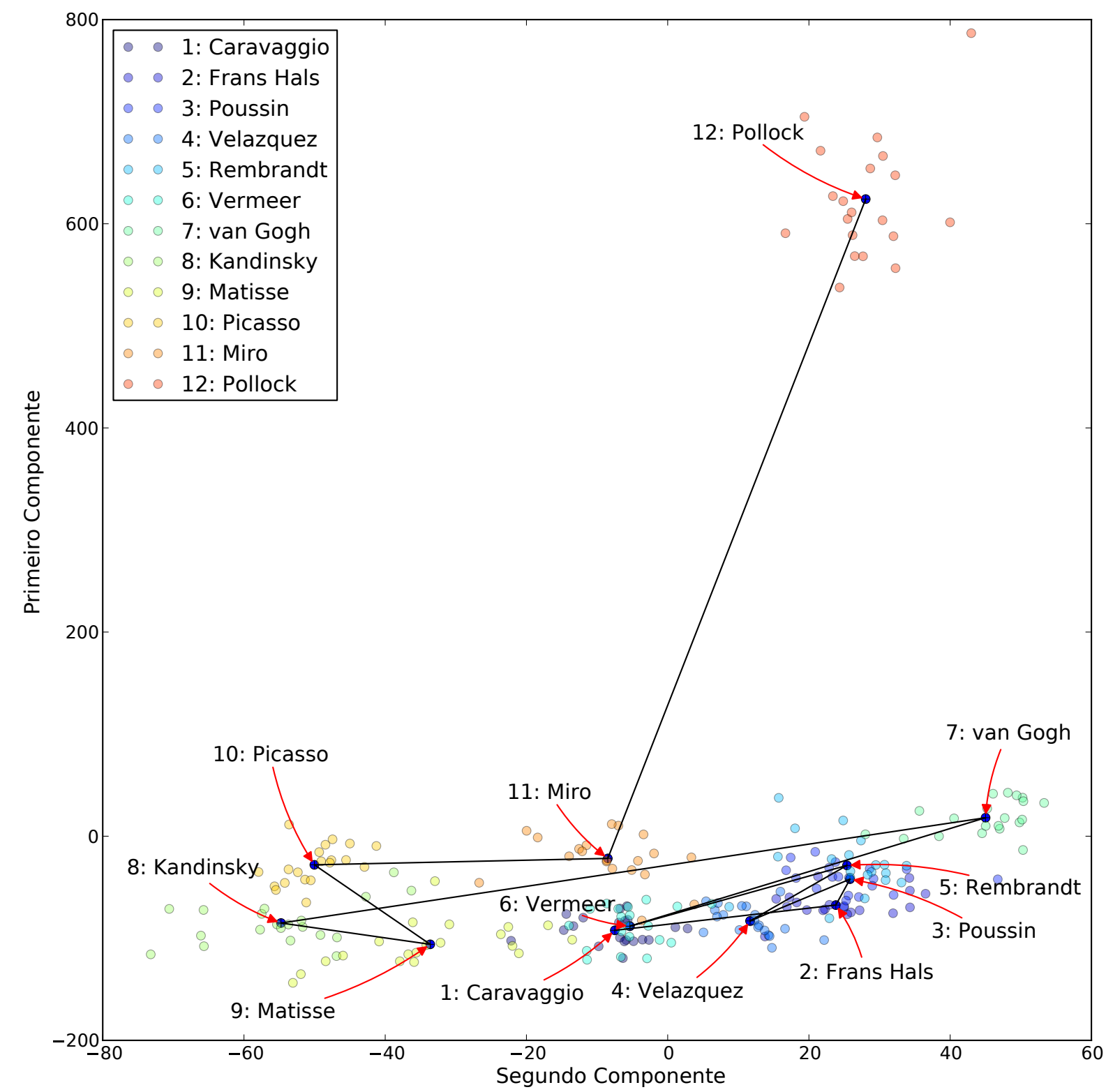

Fonte: Elaborado pelo autor.

Para validação do LDA aplicou-se cross validation por repeated random sub-sampling. O grupo de 240 pinturas foi dividido em dois: um conjunto de treinamento contendo 10 pinturas selecionadas aleatoriamente para cada artista, e um conjunto de teste contendo as 10 pinturas restantes 
Figura 3.26 - Valores de oposição e inovação considerando a série temporal para todos os $N=100$ atributos refletidos nos dois primeiros componentes obtidos pelo método LDA. Os mesmos padrões observados quando considerando os dois melhores atributos ainda permanecem nessa observação, como esperado.

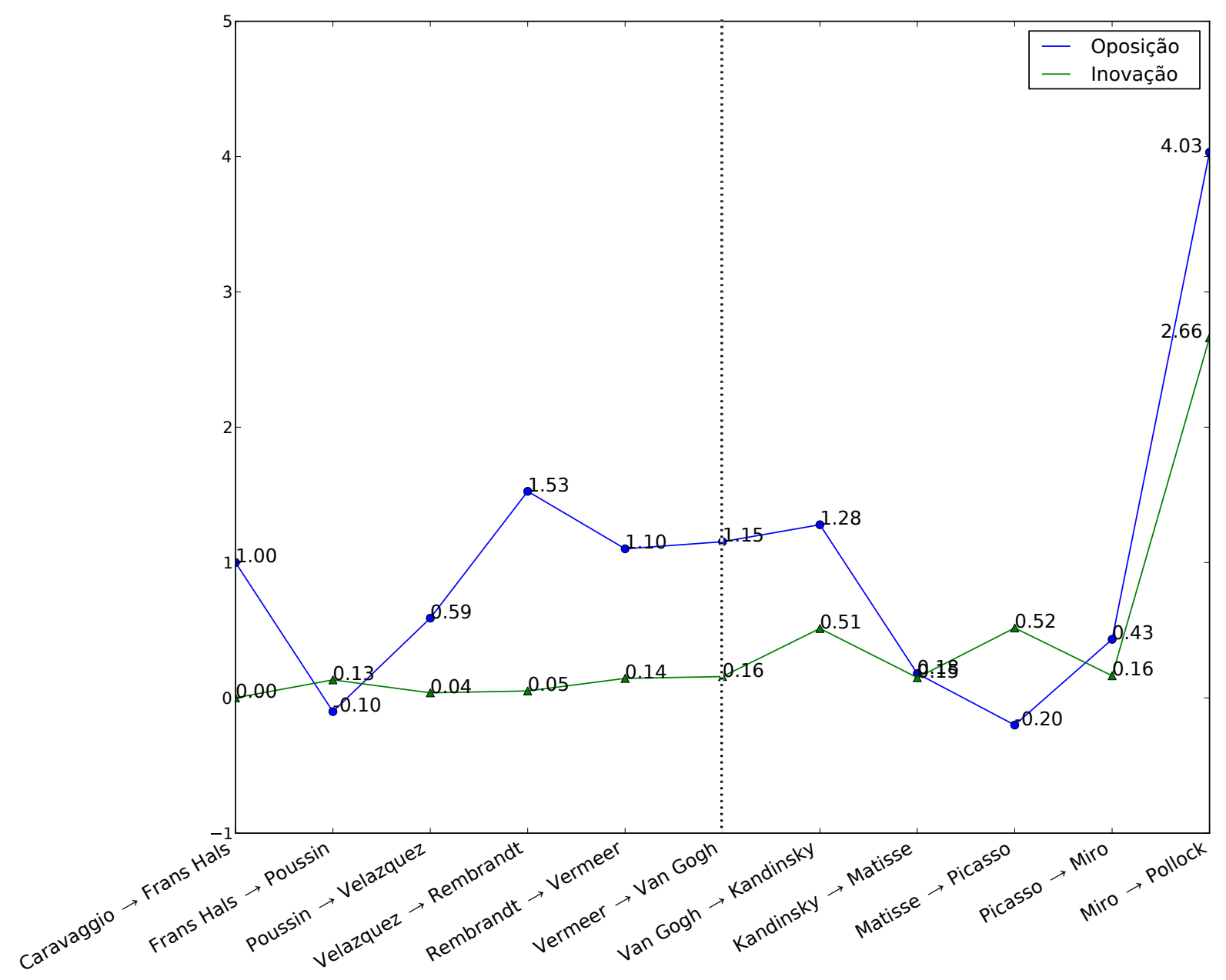

Fonte: Elaborado pelo autor.

para cada artista, ambos sem repetição. A matriz de confusão indica o quão satisfatória é a classificação. O cálculo da matriz de confusão foi repetido 100 vezes e a figura 3.29 mostra a matriz de confusão média. Ainda, a função de acurácia foi calculada em cada uma das repetições e teve seu valor em média ultrapassando 58\% de acurácia. Os elementos da diagonal principal representam o número de amostras (pinturas) para as quais a classe obtida no conjunto de teste coincide com a classe esperada (obtida na fase de treinamento). Elementos localizados 
Tabela 3.27 - Índices de contra-dialética para cada um dos deslocamentos para os dois melhores componentes do LDA.

\begin{tabular}{ll}
\hline$\overline{\text { Deslocamento }}$ & Contra-dialética $\left(\boldsymbol{d}_{\boldsymbol{i} \rightarrow \boldsymbol{k}}\right)$ \\
\hline Caravaggio $\rightarrow$ Frans Hals $\rightarrow$ Poussin & 0.587 \\
Frans Hals $\rightarrow$ Poussin $\rightarrow$ Velázquez & 0.317 \\
Poussin $\rightarrow$ Velázquez $\rightarrow$ Rembrandt & 0.268 \\
Velázquez $\rightarrow$ Rembrandt $\rightarrow$ Vermeer & 0.736 \\
Rembrandt $\rightarrow$ Vermeer $\rightarrow$ Van Gogh & 1.192 \\
Vermeer $\rightarrow$ Van Gogh $\rightarrow$ Kandinsky & 2.352 \\
Van Gogh $\rightarrow$ Kandinsky $\rightarrow$ Matisse & 0.974 \\
Kandinsky $\rightarrow$ Matisse $\rightarrow$ Picasso & 0.241 \\
Matisse $\rightarrow$ Picasso $\rightarrow$ Miró & 0.704 \\
Picasso $\rightarrow$ Miró $\rightarrow$ Pollock & 1.924 \\
\hline
\end{tabular}

Fonte: Elaborado pelo autor.

fora da diagonal principal indicam aquelas amostras que não foram classificadas corretamente. Quanto maiores os valores da diagonal principal, melhor a predição de classes. Como é possível observar, o método LDA demonstra predição esperada para o grupo de pinturas considerado. As amostras com melhor classificação são as pinturas de Pollock, o que é esperado, pois é o pintor que mais se distancia dos outros no espaço criativo. Em geral, a matriz de confusão reflete os resultados previamente discutidos: há similaridade entre pintores barrocos, principalmente Velázquez, Caravaggio e Rembrandt e é possível notar claramente a separação entre pintores anteriores e posteriores a Van Gogh, que define a fronteira entre os períodos Barroco e Moderno. Porém, o desempenho do método LDA para Miró e Rembrandt não corresponde ao esperado, sendo estes os piores resultados da matriz de confusão. 
Figura 3.28 - Contra-dialética (valores altos indicam baixa incidência de dialética) calculada para os componentes principais obtidos por LDA. O padrão observado anteriormente para o melhor par de atributos apresenta-se ainda mais visivel aqui: é possivel observar claramente que o maior valor está no ponto de transição dos movimentos artísticos (Van Gogh e Kandinsky).

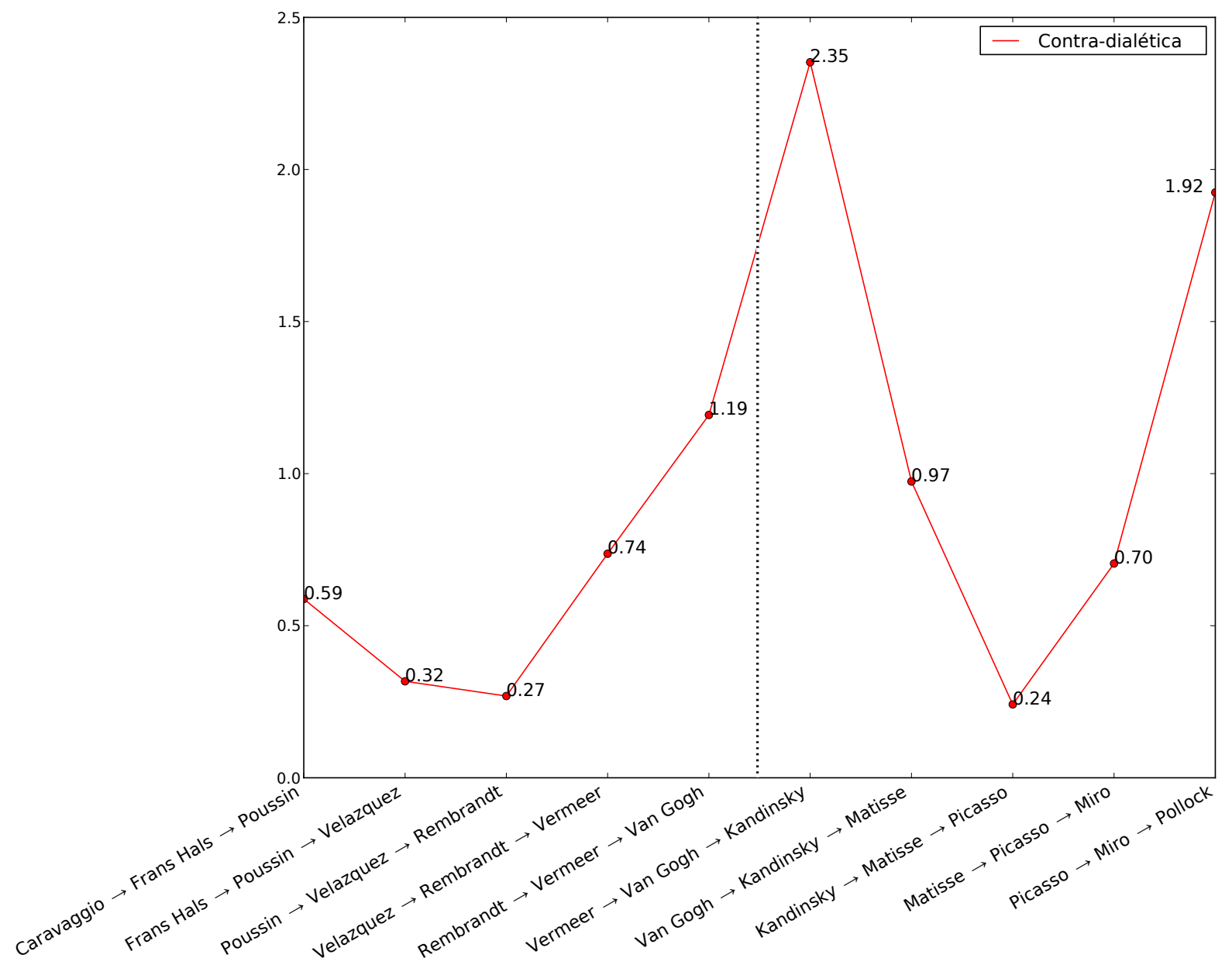

Fonte: Elaborado pelo autor. 
Figura 3.29 - Matriz de confusão média para o método LDA calculada durante 100 iterações. Metade das pinturas de cada artista é usada como conjunto de treino e a metade restante como conjunto de teste. Os elementos da diagonal principal mostram o número de amostras da classe esperada que correspondem com a classe obtida pelo método. Dada a grande quantidade de valores na diagonal principal, a validação sugere que o método LDA foi suficiente para a classificação das pinturas. Além disso, detalhes já observados nos resultados desse estudo são novamente observados na matriz: separação entre os pintores antecessores e sucessores à Van Gogh e similaridade entre pintores do mesmo período, principalmente Barroco. A função de acurácia também foi calculada, equivalendo em média a $58 \%$ para as repetições consideradas.

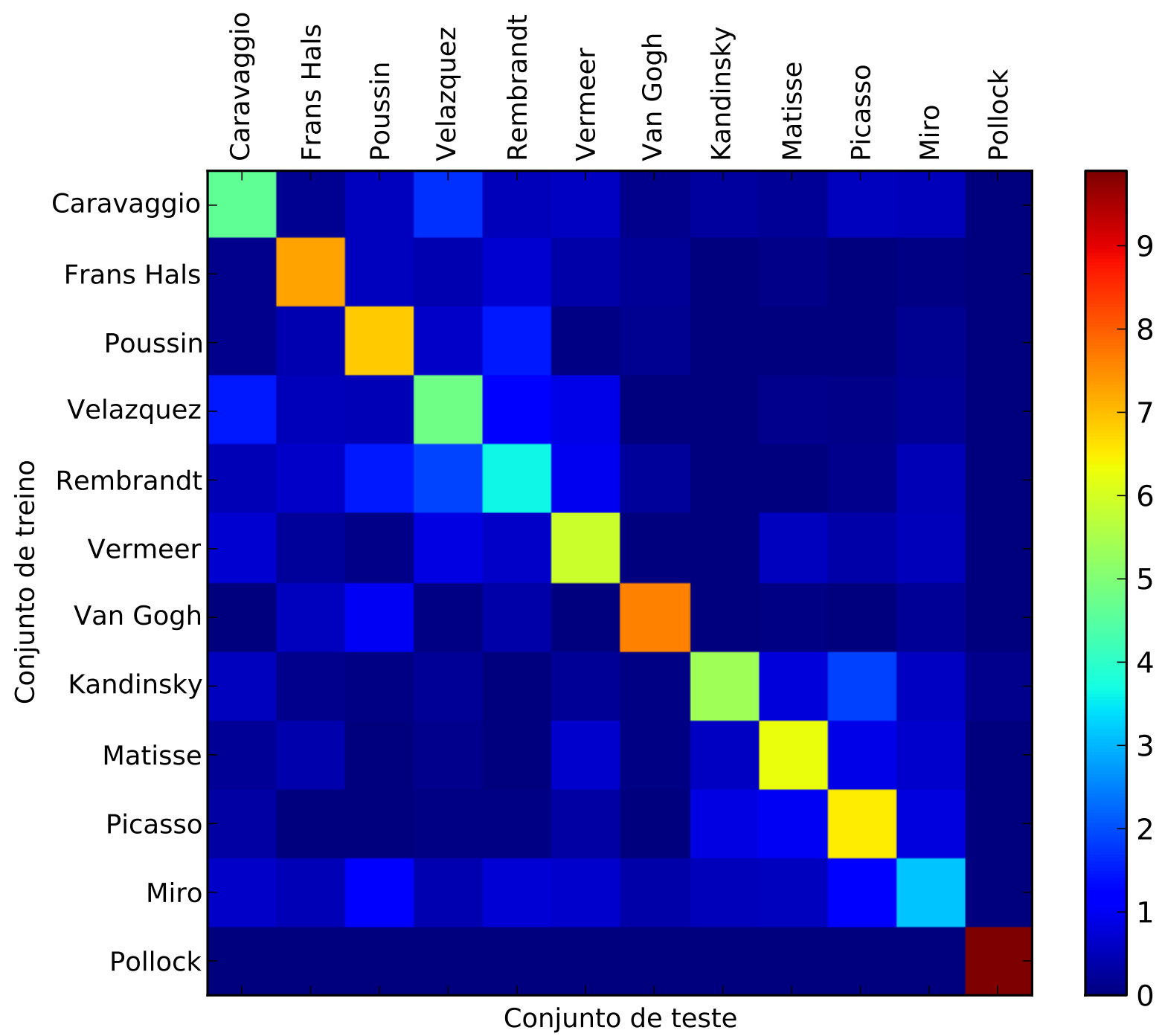

Fonte: Elaborado pelo autor. 


\section{Capítulo 4}

\section{Conclusões}

Este trabalho propõe um método para o estudo da evolução de estilos artísticos através da quantificação de conceitos, antes exclusivamente humanos. Como caso de estudo, aplicouse tal método para o entendimento dos períodos Barroco e movimentos da Arte Moderna, na Pintura. Iniciando com a escolha de representantes de cada um destes movimentos, 12 nomes foram selecionados e 240 pinturas destes artistas foram escolhidas. Rotinas de processamento de imagens permitiram a extração de características deste corpus de pinturas. Foi extraído, de cada pintura, um vetor de 100 atributos que caracterizam aspectos de complexidade da imagem, textura, forma e contorno.

A relevância de tais atributos foi atestada pela análise do índice de dispersão $\alpha$ calculado através de matrizes de espalhamento para cada par possível de atributos. Uma análise baseada na medida $\alpha$ revelou que os atributos que melhor classificaram as pinturas foram: a) número médio de picos de curvatura e b) número médio de segmentos por imagem, ambos relacionados com a forma dos segmentos extraídos das imagens automaticamente. Uma interpretação possível para este resultado é que as pinturas barrocas apresentam formas maiores (e.g. paisagens da natureza e formas humanas) com poucos detalhes de curvatura. Já as pinturas modernas apre- 
sentam formas menores e em maior número (e.g. os quadros de Kandinsky e Miró são repletos de pequenas formas, assim como as pinturas abstratas de Pollock). As formas encontradas na pinturas modernas também são diferentes das do barroco: apresentam maior detalhe de curvatura devido ao uso de retas e cantos agudos, como é possível perceber no Cubismo e no uso de formas geométricas por Kandinsky ou Miró. Outros atributos que apresentaram altos valores para $\alpha$ também estavam, em geral, relacionados com a forma. Esses atributos podem ser usados satisfatoriamente para a classificação de pintores, apresentando resultados ainda melhores que descritores canônicos em processamento de imagens como as medidas de textura de Haralick ou medidas baseadas na complexidade de figuras (i.e. entropia).

Essa seleção de atributos foi reforçada através da aplicação do método LDA, pela projeção dos componentes que mais dispersam os grupos de pinturas. Os resultados obtidos para essa projeção apresentaram grande similaridade com aqueles encontrados para os melhores pares de atributos, segundo os valores de $\alpha$. O método LDA, por sua vez, foi validado através de validação cruzada, que acabou por reforçar as observações e padrões obtidos para as medidas de inovação, oposição e dialética. A matriz de confusão resultante, além de revelar a classificação esperada (i.e. quando se observa sua diagonal principal, a classe esperada para determinado pintor coincide com a classe obtida) ainda confirmou a separação entre os grupos de pintores barrocos e modernos e o isolamento de Pollock do restante do grupo, apresentando-o com 100\% de acerto na matriz de confusão.

A caracterização das pinturas pelo uso destes atributos tornou possível a análise de medidas quantitativas (i.e. geométricas). Embora de importância central para o entendimento da evolução da humanidade, conceitos filosóficos como a dialética não são abordados comumente pelas ciências exatas. Enquanto tratadas como medidas geométricas, as medidas de oposição, inovação e dialética revelaram conceitos importantes que puderam ser comparados com resultados já obtidos para a Música e Filosofia. (1) Compositores mostram altos valores de dialética, o 
que sugere a tradição mestre-aprendiz — reconhecida nas escolas musicais. Filósofos, por sua vez, mostram grandes valores de oposição, o que também encontra base em como a evolução da Filosofia se dá: geralmente, através do conflito de ideias. Pintores, como mostrado nesse estudo, exibem decréscimo nos valores de oposição e dialética no início de cada período artístico considerado. Esse decréscimo é seguido por um aumento constante até encontrar seu ápice, exatamente no momento onde há a mudança de um período (Barroco) para o outro (Moderno). Ainda, diferente dos filósofos e músicos, na Pintura a inovação apresenta valores com acréscimo constante, durante toda a série temporal. Isso pode refletir a influência de cada movimento ou período artístico em seus representantes, juntamente com um constante desejo de inovar, presente principalmente nos pintores modernos. Dessa forma, fatos já fundamentados na história das artes são confirmados por tais medidas quantitativas. Nesse sentido, uma das observações mais sumárias é a sobreposição de pinturas barrocas enquanto nos pintores modernos isso não acontece. Pelo contrário, os grupos de pintores modernos apresentam pouca sobreposição e, ao mesmo tempo, cobrem uma região maior do espaço vetorial quando comparados aos barrocos. Essas observações encontram paralelo na história, com os barrocos compartilhando as características estéticas de suas obras uns com os outros, enquanto os modernos procuram definir cada um seu próprio estilo.

Embora insuficiente para esgotar todas as características encontradas em um artista e sua obra, esse método sugere um framework para o estudo das ciências humanas através de medidas geométricas em um espaço de atributos. Mais uma vez reforça-se que, ao invés de suplantar as discussões humanas, que tanto trazem de valor para o entendimento da sociedade, esse framework pretende somar, fornecendo mais um ponto de vista.

Como trabalhos futuros, os métodos de processamento de imagens digitais podem ser espandidos, como através do uso do algoritmo de segmentação SLIC com $k$ variante ao invés da versão estática utilizada. Novos descritores de imagens também podem ser explorados (e.g. descri- 
tores invariantes como SIFT, SURF ou ORB), assim como a análise dos atributos obtidos por estes descritores. Por exemplo, os atributos podem ser agrupados dada sua natureza (e.g. forma, complexidade, textura) ou valor de espalhamento (e.g. os melhores 20 atributos), e um método de redução de dimensionalidade como PCA poderia ser aplicado a esses grupos, refinando-os para um subsequente cálculo das medidas propostas neste trabalho. No que diz respeito a área de aplicação, o número de pintores pode ser expandido e um conjunto de pintores pode ser escolhido especificamente para investigar suas influências. Por exemplo, pinturas dos filhos de Frans Hals podem ser incluídas para verificar a influência de seu pai e mestre. Pinturas de Rafael, Poussin, Guido Reni e Carracci podem ser comparadas entre si com o objetivo de verificar a já reconhecida similaridade entre estes pintores. (6) Ainda, a influência de Cézanne em Matisse e Picasso - que declarou: "meu primeiro e único mestre, (...) Cézanne é o pai de todos nós" (49) - também pode ser verificada. A evolução de um mesmo artista pode ser analisada, assim como a evolução ocorrida dentro de uma escola específica. Pode-se assim comparar tal análise com as evoluções obtidas para outras escolas e confirmar (ou não) o mesmo aspecto observado na análise deste estudo — onde as medidas de dialética e oposição apresentaram picos de valores nos momentos de transição do período Barroco para a Arte Moderna. Ainda, um número maior de pinturas para cada artista pode ser considerado para análise. O mesmo framework pode ser aplicado (como já demonstrado para a Música, Filosofia e Pintura) a outros campos de interesse humano como Cinema e Literatura. A mesma automatização aplicada aqui pode ser replicada para a Música (e possivelmente à Filosofia), dando continuidade ao trabalho realizado pelos autores. (1) 


\section{REFERÊNCIAS}

1 VIEIRA, V. et al. A quantitative approach to evolution of music and philosophy. Journal of Statistical Mechanics: theory and experiment, v. 2012, n. 08, p. P08010, 2012. Disponível em: <http://stacks . iop.org/1742-5468/2012/i=08/a=P08010>. Acesso em: 05 jun. 2014.

2 DEMPSEY, A. Styles, schools and movements: the essential encyclopaedic guide to modern art. New York: Thames and Hudson, 2005. (Word of art : modern and contemporary art).

3 ANDERSEN, K. The geometry of an art: the history of the mathematical theory of perspective. New York: Springer, 2007.

4 KEMP, M. et al. The science of art: optical themes in western art from brunelleschi to seurat. New Haven: Yale University Press, 1990.

5 EDGERTON, S. Y. The mirror, the window, and the telescope: how renaissance linear perspective changed our vision of the universe. New York: Cornell University Press, 2009.

6 GOMBRICH, E. The story of art. London: Phaidon Press, 1995.

7 SEDLMAYR, H. Art in crisis: the lost center. New Jersey: Transaction Books, 2006.

8 PERSPECTIVE (graphical). 2014. Disponível em: <http://en.wikipedia.org/wiki/ Perspective_(graphical)>. Acesso em: 18 jun. 2014.

9 PEGUS, L. Leonardo da Vinci: anatomical drawings. Journal of Visual Communication in Medicine, v. 1, n. 2, p. 63-69, 1978.

10 HALL, M. B.; GILL, M. J. Color and meaning: practice and theory in renaissance painting. Renaissance and Reformation/Renaissance et Réforme, v. 16, n. 4, p. 83-85, 1992. Disponível em: <https://jps.library.utoronto.ca/index.php/renref/article/ view/11686/8587>. Acesso em: 05 jun. 2014.

11 KLEINER, F. S. Gardner's art through the ages: the western perspective. 14th ed. Boston: Cengage Learning, 2012. 
12 GORDON, D. E. Expressionism: art and idea. New York: Yale University Press, 1987.

13 WILliAMS, J. Gilles Deleuze's difference and repetition: a critical introduction and guide. Cambridge: Cambridge University Press, 2003.

14 PINTO, R. C. Argument, inference and dialectic: collected papers on informal logic. New York: Springer, 2001.

15 VAN EEMEREN, F. H.; BLAIR, J. A.; WILLARD, C. A. Anyone who has a view: theoretical contributions to the study of argumentation. New York: Springer, 2003.

16 FONTOURA COSTA, L. da; CESAR JUNIOR, R. M. Shape analysis and classification: theory and practice. Boca Raton, USA: CRC Press, Inc, 2000.

17 FISHER, R. A. The use of multiple measurements in taxonomic problems. Annals of Eugenics, v. 7, n. 2, p. 179-188, 1936.

18 HILLS, H. Rethinking the Baroque. Burlington: Ashgate Publishing, Ltd., 2011.

19 BAYER, A.; GREGORI, M. Painters of reality: the legacy of Leonardo and Caravaggio in Lombardy. New York: Metropolitan Museum of Art, 2004.

20 TATARKIEWICZ, W. History of aesthetics. Warszawa: Continuum International Publishing Group, 2006.

21 PUGLISI, C. Caravaggio. London: Phaidon, 1998.

22 CARAVAGGIO, M. M.; WARWICK, G. Caravaggio: realism, rebellion, reception. Newark, DE: University of Delaware Press, 2006.

23 CHRONOLOGY of works by Caravaggio. 2014. Disponível em: <http://en. wikipedia.org/wiki/Chronology_of_works_by_Caravaggio>. Acesso em: 18 jun. 2014.

24 GRIMM, C. Frans Hals: the complete work. New York: HN Abrams, 1990.

25 LIST of paintings by Frans Hals. 2014. Disponível em: <http: //en.wikipedia.org/ wiki/List_of_paintings_by_Frans_Hals>. Acesso em: 18 jun. 2014.

26 SCHJELDAHL, P. Haarlem Shuffle: the fast world of Frans Hals. The New Yorker, p. 74-75, 2011. Disponível em: <http://www. newyorker.com/arts/critics/artworld/ 2011/08/08/110808craw_artworld_schjeldahl>. Acesso em: 18 jun. 2014.

27 UNGLAUB, J.; POUSSIN, N. Poussin and the poetics of painting: pictorial narrative and the legacy of Tasso. Cambridge: Cambridge University Press, 2006.

28 LIST of Nicolas Poussin paintings. 2014. Disponível em: <http://en.wikipedia. org/wiki/List_of_Nicolas_Poussin_paintings>. Acesso em: 18 jun. 2014. 
29 LIST of works by Diego Velázquez. 2014. Disponível em: <http://en.wikipedia. org/wiki/List_of_works_by_Diego_Velzquez>. Acesso em: 18 jun. 2014.

30 LIST of paintings by Rembrandt. 2014. Disponível em: <http://en.wikipedia.org/ wiki/List_of_paintings_by_Rembrandt>. Acesso em: 18 jun. 2014.

31 WETERING, E. van de. The multiple functions of Rembrandt's self portraits. New Haven: Yale University Press, 1999.

32 WETERING, E. Van de. Rembrandt: the painter at work. Amsterdam: Amsterdam University Press, 1997.

33 LIST of paintings by Johannes Vermeer. 2014. Disponível em: <http://en . wikipedia. org/wiki/List_of_paintings_by_Johannes_Vermeer>. Acesso em: 18 jun. 2014.

34 WADUM, J. Johannes Vermeer (1632-1675) and his use of perspective. In: Historical painting techniques, materials, and studio practice: preprints of a symposium. The Getty Conservation Institute, 1995. p. 148-154. Disponível em: <http://www.getty.edu/ conservation/publications_resources/pdf_publications/pdf/historical_ paintings.pdf>. Acesso em: 10 jun. 2014.

35 KANDINSKY, W.; CABRAL, Á.; DANESI, A. d. P. Do espiritual na arte e na pintura em particular. São Paulo: Martins Fontes, 2000.

36 HULSKER, J. The complete Van Gogh: paintings, drawings, sketches. London: Phaidon, 1980 .

37 LOVEJOY, A. O. et al. Primitivism and related ideas in antiquity. Baltimore: Johns Hopkins University Press, 1997.

38 LIST of paintings by Vincent van Gogh. 2014. Disponível em: <http: //en. wikipedia. org/wiki/List_of_works_by_Vincent_van_Gogh>. Acesso em: 18 jun. 2014.

39 VAN GOGH, V.; VAN GOUGH, V. The complete letters of Vincent van Gogh. London: Thames and Hudson, 1958.

40 DUCHTING, H. Wassily Kandinsky 1866-1944: a revolution in painting. Köln: Taschen, 2000 .

41 WASSILY Kandinsky. 2014. Disponível em: <http://en.wikipedia.org/wiki/ Wassily_Kandinsky>. Acesso em: 18 jun. 2014.

42 IONE, A.; TYLER, C. Was Kandinsky a synesthete? Journal of the History of the Neurosciences, v. 12, n. 2, p. 223-226, 2003.

43 ELDERFIELD, J. et al. The "wild beasts": fauvism and its affinities. New York: Museum of Modern Art, 1976. 
44 FREEMAN, J.; BENJAMIN, R.; MATTISSE, H. The fauve landscape. Los Angeles: Los Angeles County Museum of Art, 1990.

45 LIST of works by Henri Matisse. 2014. Disponível em: <http://en . wikipedia .org/ wiki/List_of_works_by_Henri_Matisse>. Acesso em: 18 jun. 2014.

46 MATISSE, H. Matisse on art. California: University of California Press, 1995.

47 DAIX, P.; EMMET, O. Picasso: life and art. London: Thames and Hudson, 1994.

48 PABLO Picasso. 2014. Disponível em: <http://en.wikipedia.org/wiki/Pablo_ Picasso>. Acesso em: 18 jun. 2014.

49 RISHEL, J. J.; SACHS, K.; BERNSTEIN, R. Cézanne and beyond. New Haven: Yale University Press, 2009.

50 BARR, A. H. Cubism and abstract art: painting, sculpture, constructions, photography, architecture, industrial art, theatre, films, posters, typography. New York: Belknap Press of Harvard University Press, 1986.

51 GOLDING, J. Cubism: a history and an analysis, 1907-1914. Cambridge, Mass.: Belknap Press of Harvard University Press, 1988.

52 JOAN Miró. 2014. Disponível em: <http://en.wikipedia.org/wiki/Joan_Miro>. Acesso em: 18 jun. 2014.

53 MONTAGU, J. The surrealists: revolutionaries in art \& writing 1919-35. London: Tate Publishing, 2002.

54 STICH, S. Joan Miró, the development of a sign language. Washington: Washington University, 1980.

55 JACKSON Pollock. 2014. Disponível em: <http://en.wikipedia.org/wiki/ Jackson_Pollock>. Acesso em: 18 jun. 2014.

56 NAMUTH, H. Jackson Pollock. 1951. Disponível em: <https://www . youtube.com/ watch?v=6cgBvpjwOGo>. Acesso em: 05 jun. 2014.

57 WILliamS, H. Hegel, Heraclitus, and Marx's dialectic. New York: St. Martin's Press, 1989.

58 PRESS, W. H. Numerical recipes: the art of scientific computing. Cambridge: Cambridge University Press, 2007.

59 GONZALEZ, R. C.; WOODS, R. E. Processamento de imagens digitais. São Paulo: Edgard Blucher, 2000. 
60 ACHANTA, R. et al. SLIC superpixels compared to state-of-the-art superpixel methods. IEEE Transactions on Pattern Analysis and Machine Intelligence, v. 34, n. 11, p. 2274-2282, 2012. Disponível em: <http://ivrg.epfl.ch/research/superpixels>. Acesso em: 05 jun. 2014.

61 BILlMEYER, F. W.; SALTZMAN, M. Principles of color technology. New York: J. Wiley \& sons, 1981.

62 HOFFMANN, G. Cielab color space. 2007. Disponível em: <http://docs-hoffmann . de/cielab03022003 . pdf>. Acesso em: 10 jun. 2014.

63 ROMERO, J. et al. Using complexity estimates in aesthetic image classification. Journal of Mathematics and the Arts, v. 6, n. 2-3, p. 125-136, 2012. Disponível em: $<$ http://www.tandfonline.com/doi/abs/10.1080/17513472.2012.679514>. Acesso em: 05 jun. 2014.

64 MANOVICH, L. Style Space: how to compare image sets and follow their evolution (draft text). 2011. Disponível em: <http://lab.softwarestudies.com/2011/08/ style-space-how-to-compare-image-sets.html>. Acesso em: 05 jun. 2014.

65 MANOVICH, L. Mondrian vs Rothko: footprints and evolution in style space. 2011. Disponível em: <http://lab.softwarestudies.com/2011/06/ mondrian-vs-rothko-footprints-and.html>. Acesso em: 05 jun. 2014.

66 MANOVICH, L. ArtHistory.viz - visualizing modernism. 2008.

Disponível em: <http://lab.softwarestudies.com/2008/07/ arthistoryviz-mining-200000-images-of.html>. Acesso em: 05 jun. 2014.

67 HARALICK, R. M.; DINSTEIN, I.; SHANMUGAM, K. Textural features for image classification. IEEE Transactions On Systems Man And Cybernetics, v. 3, n. 6, p. 610-621, 1973. Disponível em: <http://ieeexplore. ieee.org/lpdocs/epic03/wrapper.htm? arnumber=4309314>. Acesso em: 05 jun. 2014.

68 PAPOULIS, A. The Fourier integral and its applications. New York: Mc Graw-Hill, 1962.

69 GOUVEIA, L. T. de; RODRIGUES, F. A.; FONTOURA COSTA, L. da. Multiscale curvature analysis of asphaltic aggregate particles. Journal of Computing in Civil Engineering, v. 24, n. 6 , p. 506-513, 2010.

70 JAIN, A.; ZONGKER, D. Feature selection: evaluation, application, and small sample performance. IEEE Transactions on Pattern Analysis and Machine Intelligence, v. 19, n. 2, p. 153-158, 1997.

71 DUNTEMAN, G. H. Principal components analysis. California: Sage, 1989.

72 LAMBERT, G.; NÉRET, G. Caravaggio. Ediz. tedesca. Berlin: Taschen Deutschland GmbH, 2000. (Basic Art Series). 



\section{APÊNDICE A - Tutorial para execução dos scripts Python desenvolvidos para análise}

Toda a análise realizada neste estudo foi implementada em linguagem Python, em sistema GNU/Linux Ubuntu, utilizando ferramentas de software livre. O código-fonte, assim como todo o conteúdo usado e gerado, encontra-se distribuído nos seguintes repositórios abertos:

- http://github.com/automata/dissertacao-ifsc: contém o código-fonte LTEX desta dissertação e pode ser compilado através do comando make, gerando um arquivo dissertacao.pdf como saída.

- http://github.com/automata/viz-paintings: aplicativo Web desenvolvido em JavaScript para visualização interativa da figura 3.14, onde o espaço de atributos pode ser "navegado" com panning e zoom, facilitando a identificação de cada pintura analisada e seu respectivo cluster. Essa mesma aplicação pode ser acessada on-line através do endereço http://automata.github.io/viz-paintings. Mais detalhes e capturas de tela do aplicativo no Apêndice C.

- http://gi thub. com/automata/tri-delaunay: código-fonte em Python para geração de pinturas generativas baseadas em figuras usadas neste estudo e triangulação de Delaunay. Estas pinturas foram exibidas em uma exposição em 2013 (Apêndice D). 
- http://github.com/automata/ana-pintores: scripts Python usados para obter os resultados discutidos nesse estudo, assim como a base de figuras das 240 pinturas utilizadas. A seguir, instruções para instalação e uso de tais scripts.

1. Certifique-se de ter instalado as dependências:

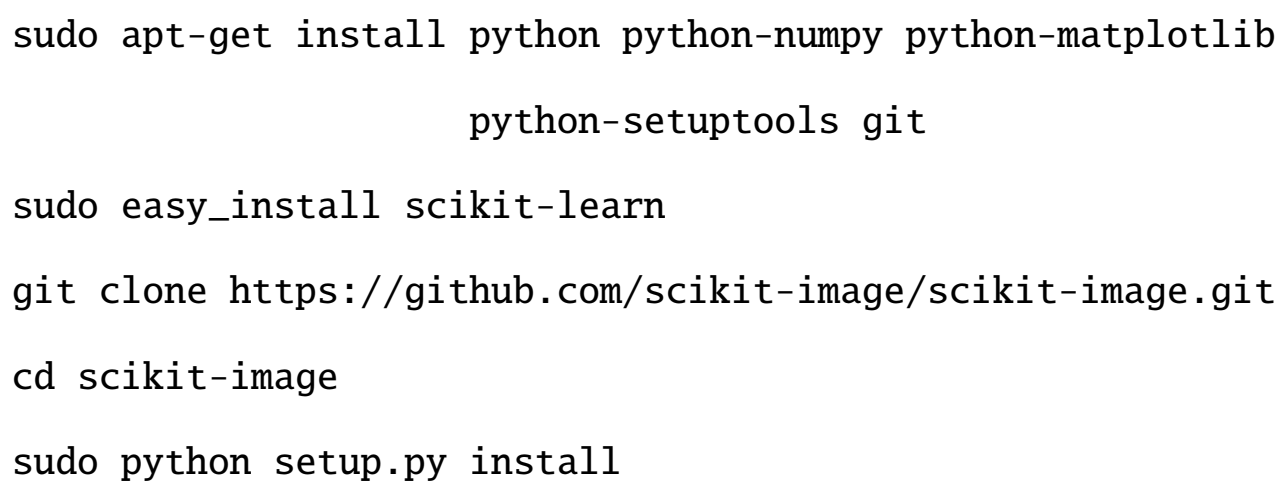

2. Clone o repositório Git da dissertação e scripts (o repositório inclui os arquivos de imagens das pinturas, portanto o tempo de download pode ser longo):

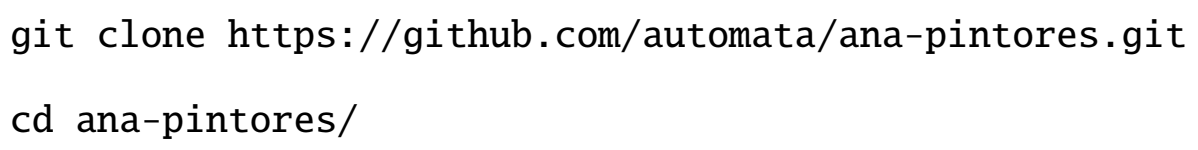

3. Para analisar as pinturas por processamento de imagens, execute:

python analise_pinturas.py

python analise_segs.py

4. Para gerar a matriz de atributos extraídos a partir da análise anterior:

$$
\text { python feature_matrix_gen.py }
$$

5. Para calcular as medidas de inovação, oposição e dialética, assim como plotar a série temporal considerando os dois melhores atributos e LDA, assim como uma versão alternativa que substitui os marcadores por miniaturas das pinturas: 


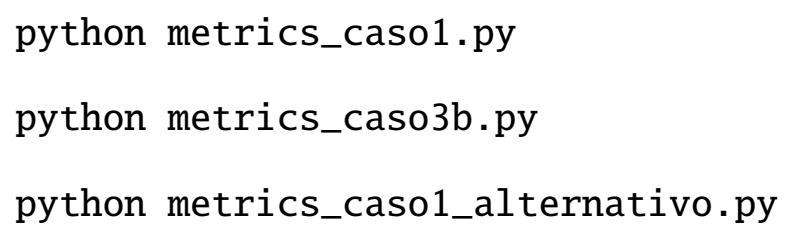

6. Para validar os resultados através do LDA:

python valida3_r.py

7. Para calcular as matrizes esparsas e o índice $\alpha$ de separação, listando e plotando os pares de atributos que apresentaram melhor separação:

python scatter_matrix_pintores.py

8. Para plotar o comparativo dos histogramas de níveis de cinza médio das pinturas:
python chiaroscuro.py
python chiaroscuro_modernos.py

Cada script produz arquivos de imagens e resultados de saída diversos. Seus respectivos códigos devem ser consultados para se compreender quais as saídas geradas. 



\section{APÊENICE B - Galeria de imagens das 240 pinturas analisadas}


Figura B.1 - Caravaggio
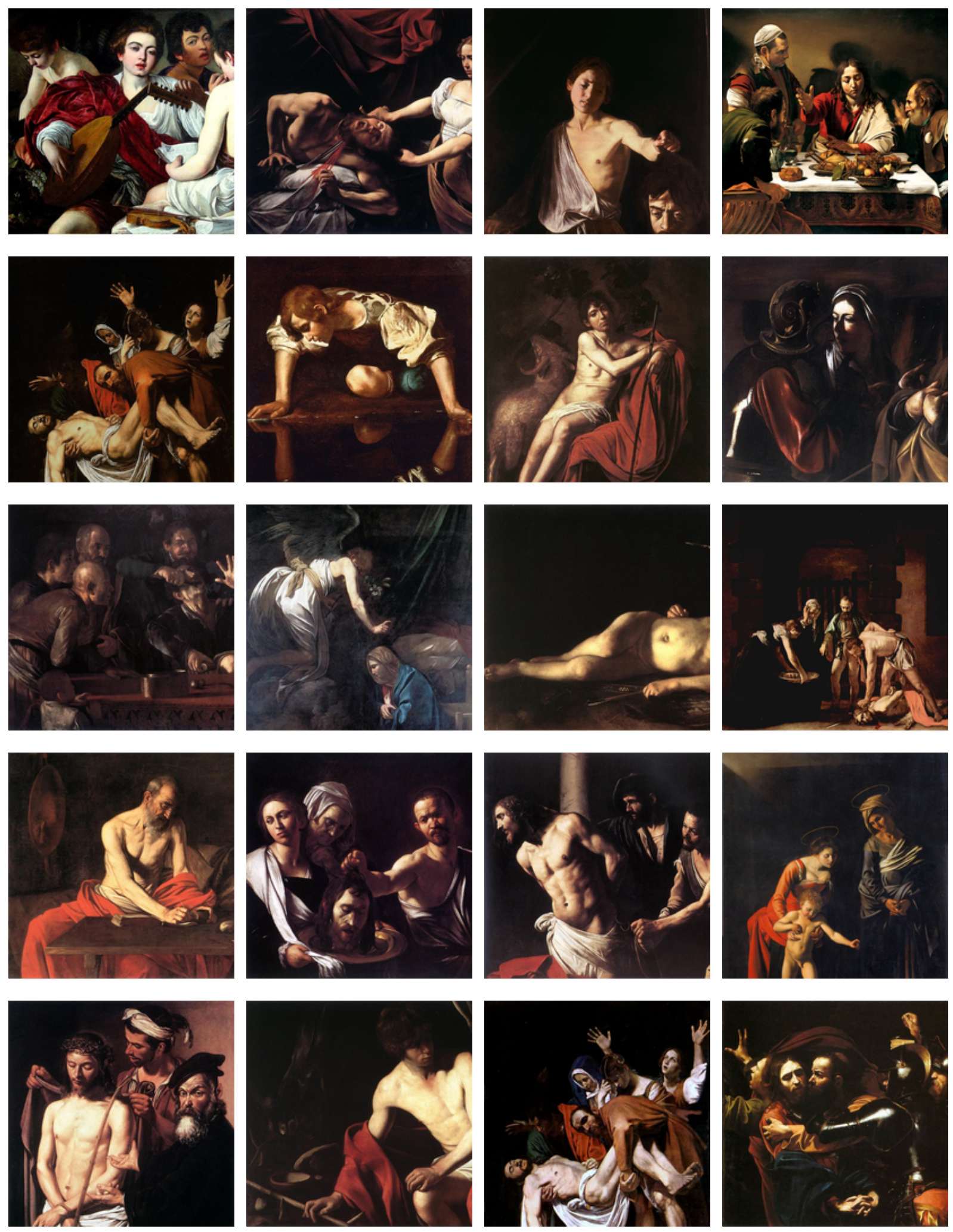

Fonte: CHRONOLOGY...(23) 
Figura B.2 - Frans Hals
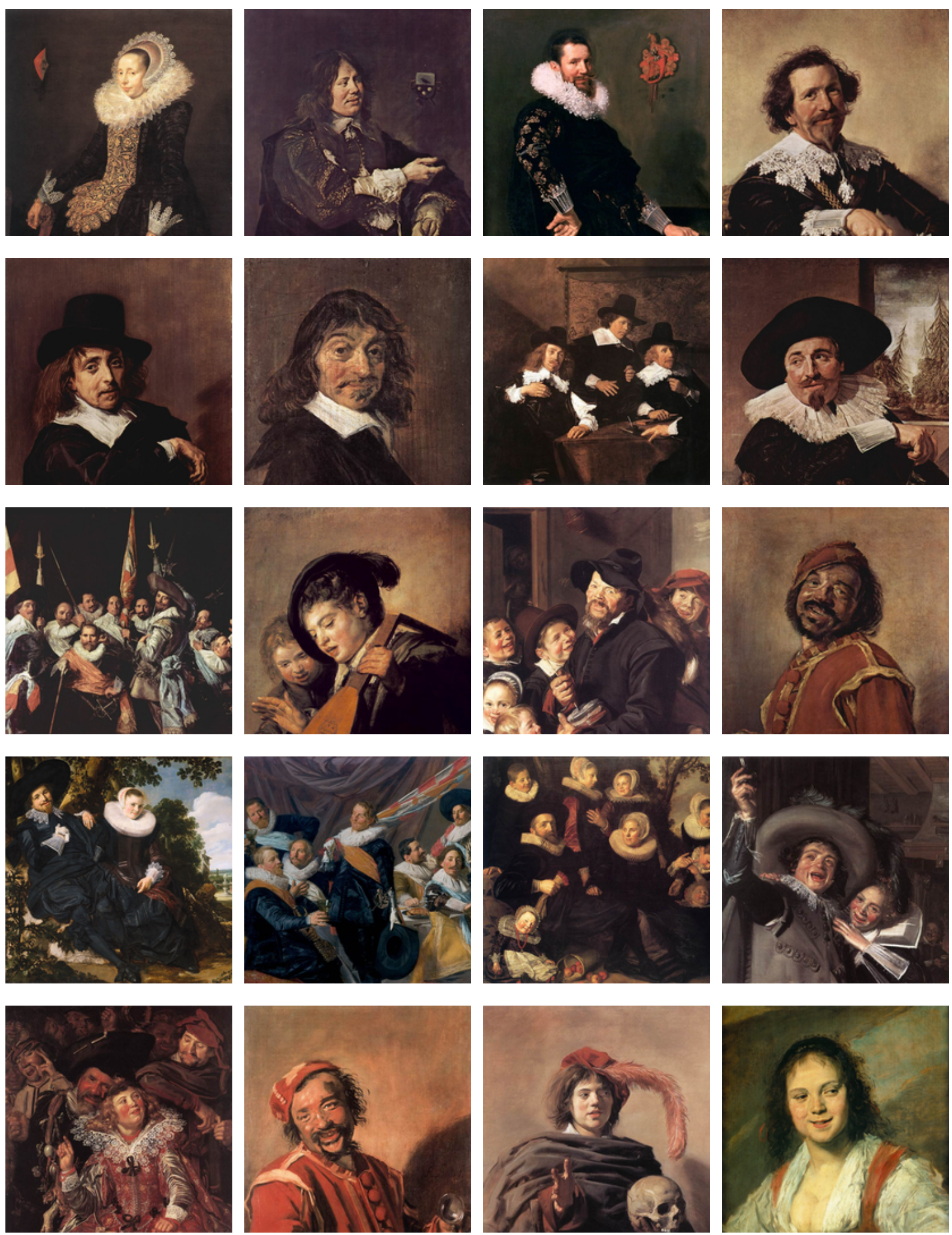

Fonte: LIST...(25) 
Figura B.3 - Nicolas Poussin
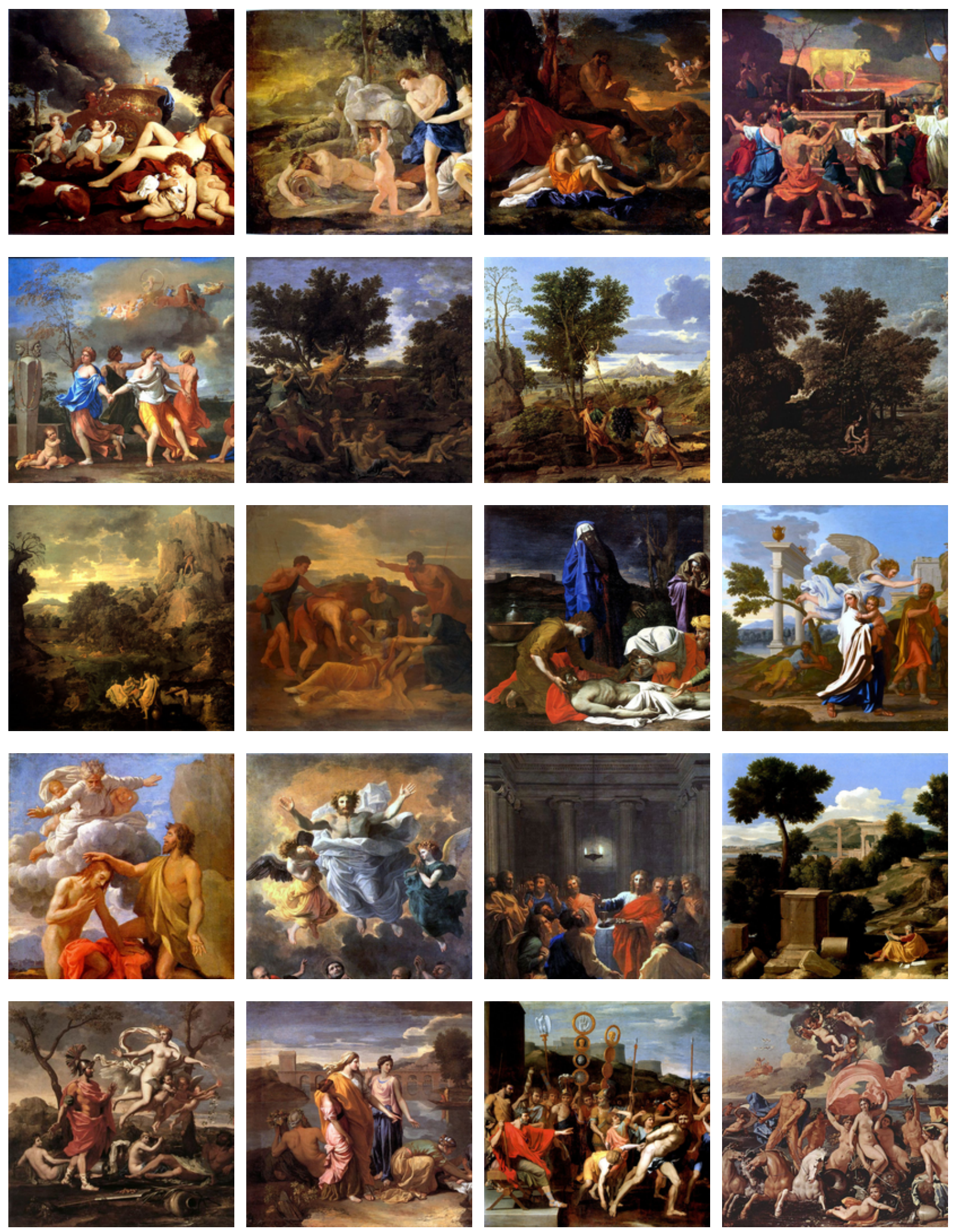

Fonte: LIST...(28) 
Figura B.4 - Diego Velázquez
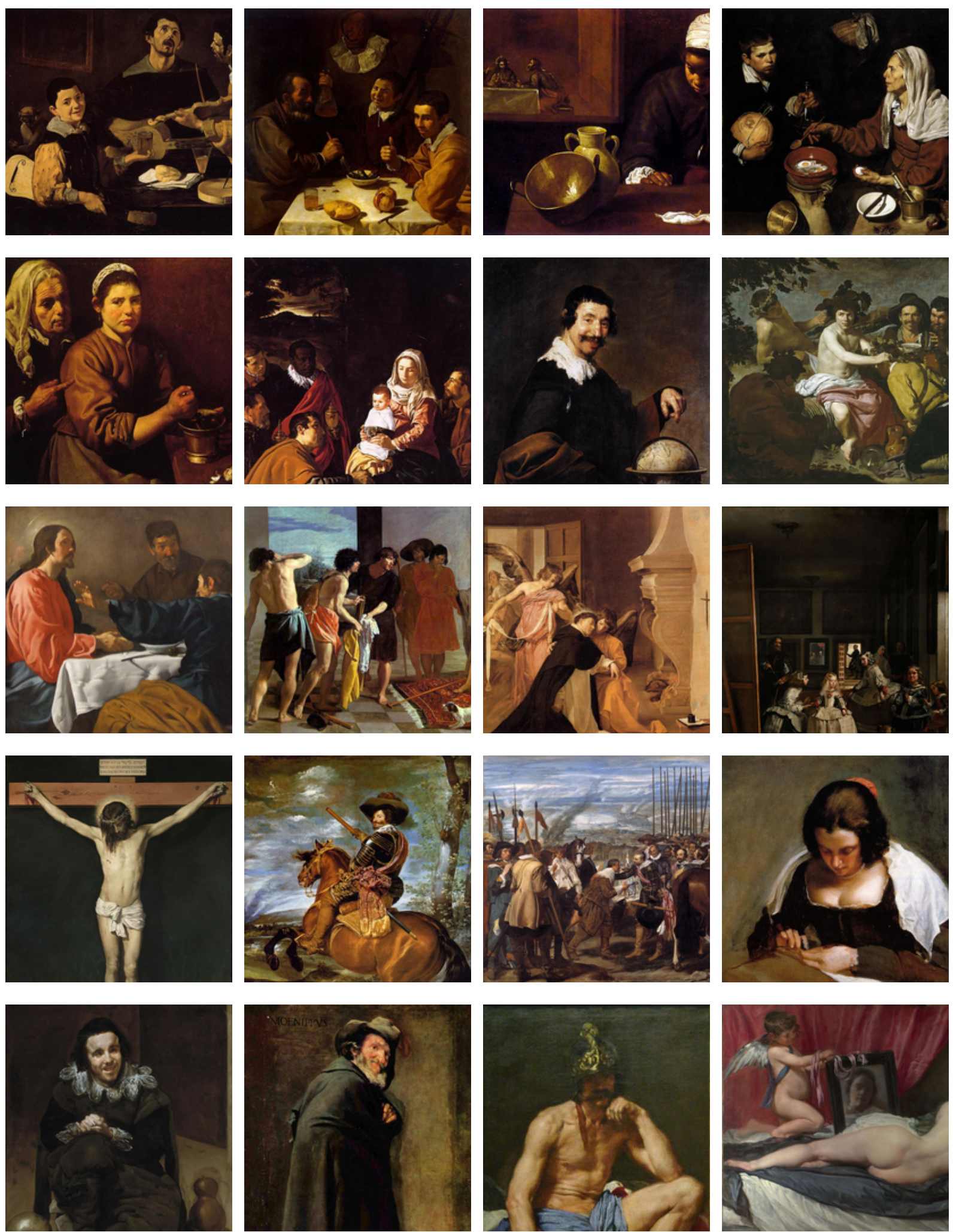

Fonte: LIST...(29) 
Figura B.5 - Rembrandt Harmenszoon van Rijn
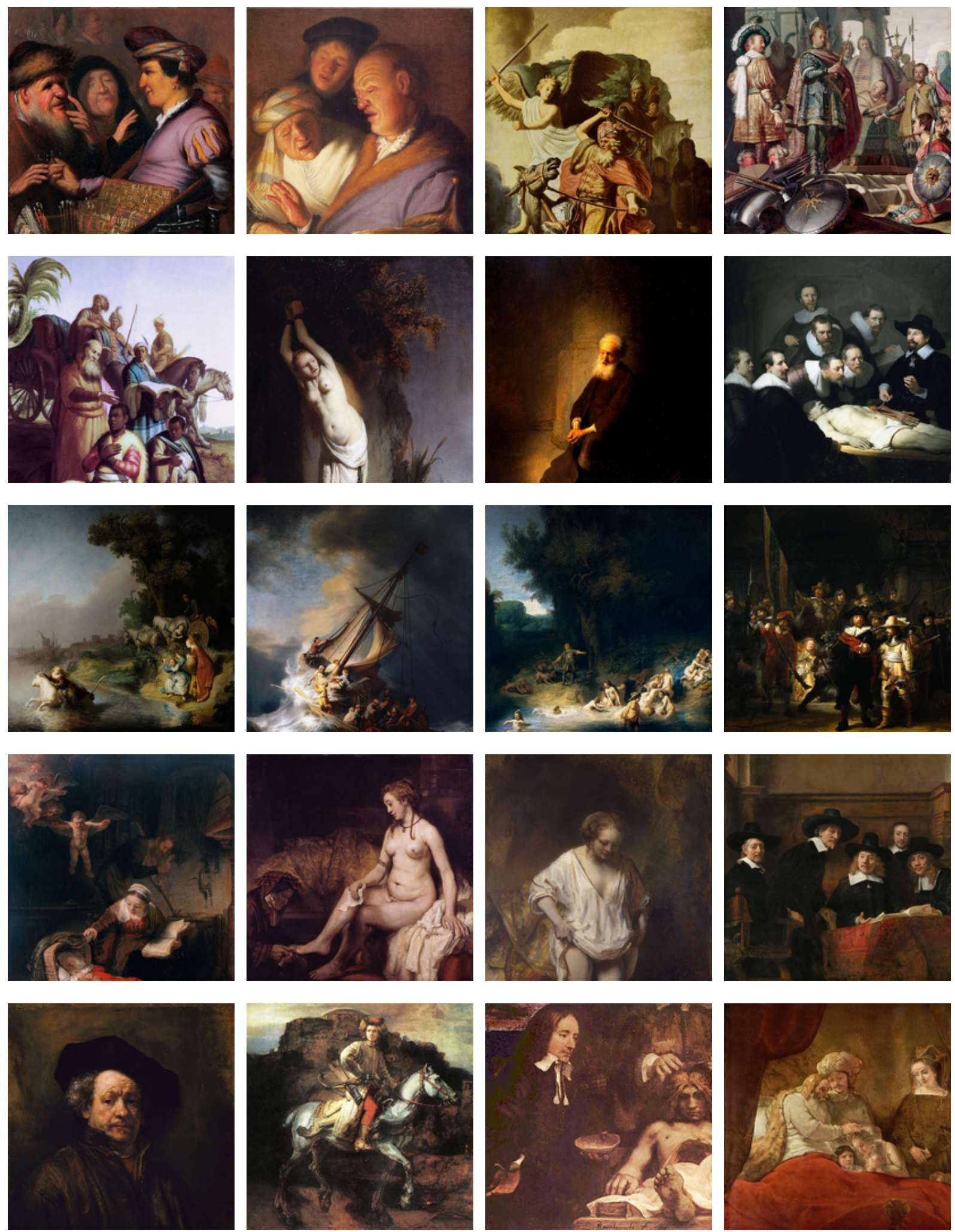

Fonte: LIST...(30) 
Figura B.6 - Johannes Vermeer
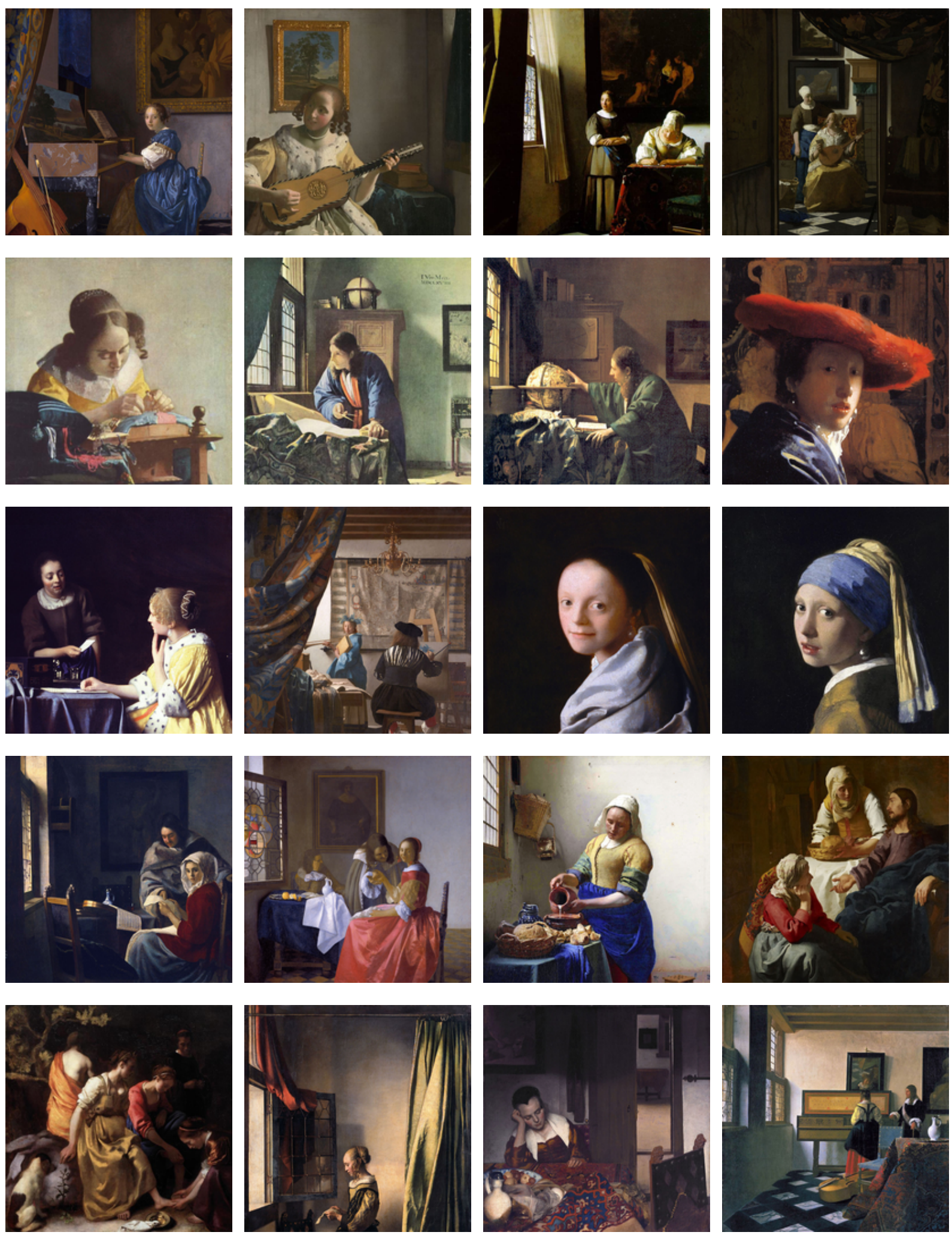

Fonte: LIST...(33) 
Figura B.7 - Vincent van Gogh
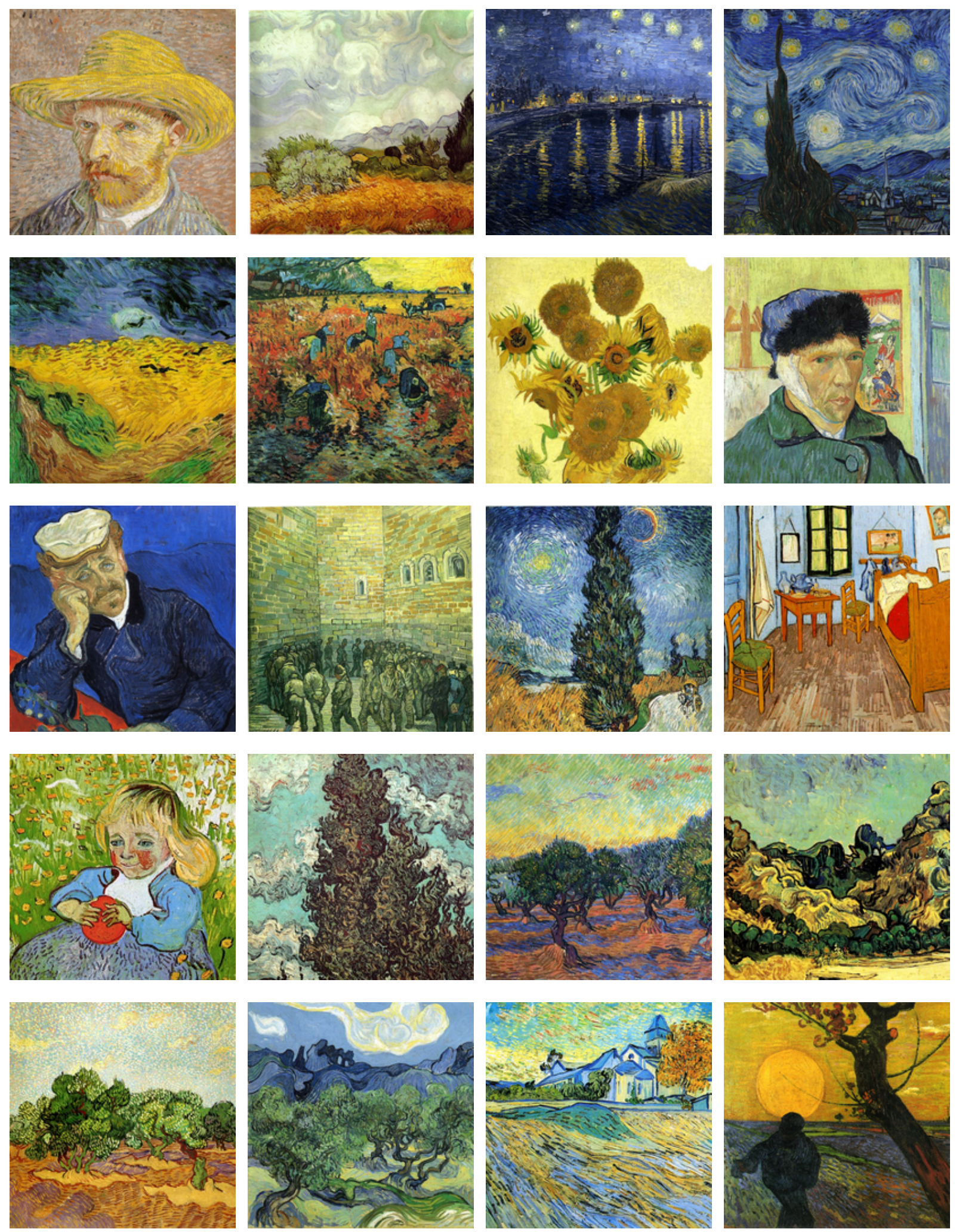

Fonte: LIST...(38) 
Figura B.8 - Wassilly Kandinsky
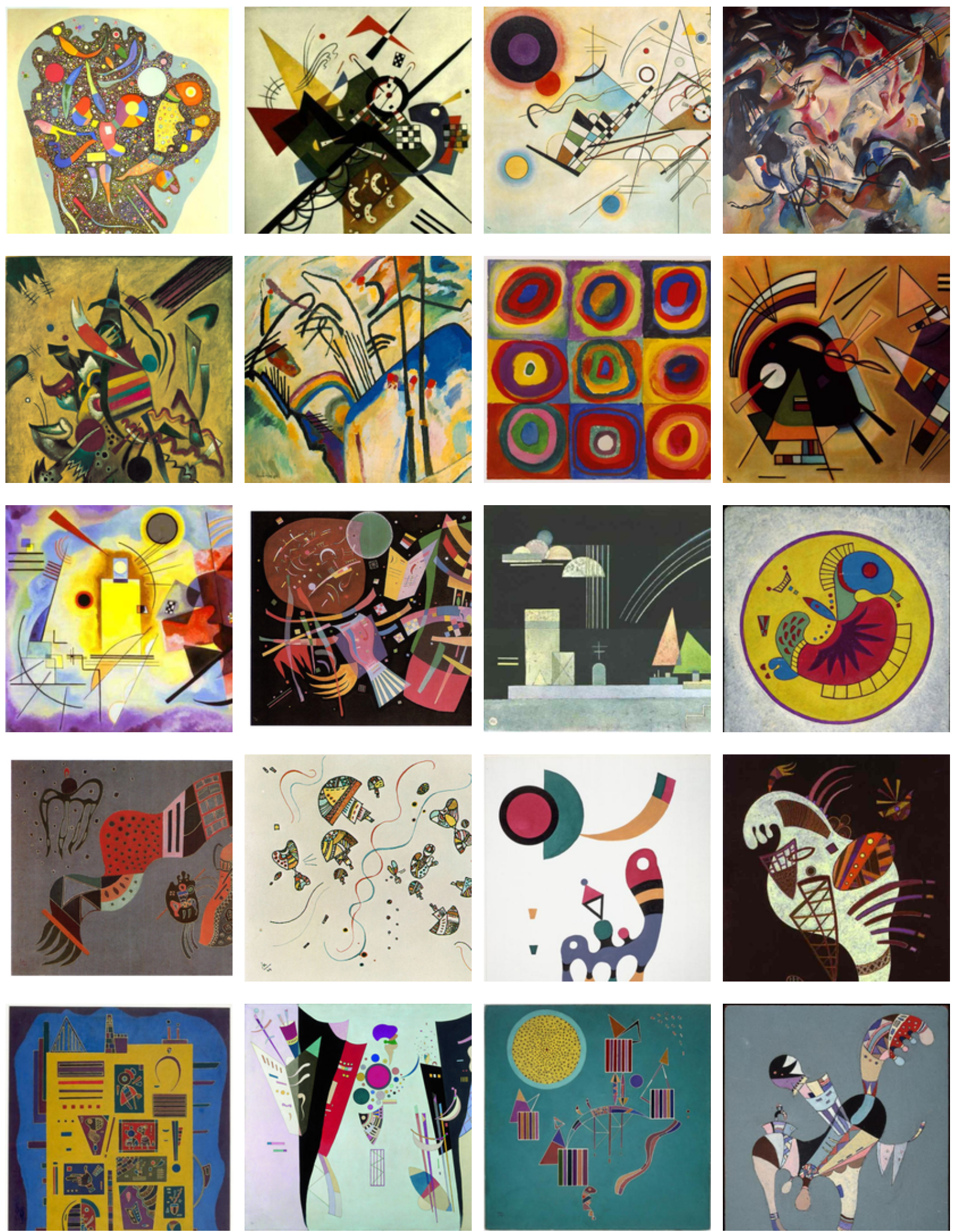

Fonte: WASSILY...(41) 
Figura B.9 - Henri Matisse
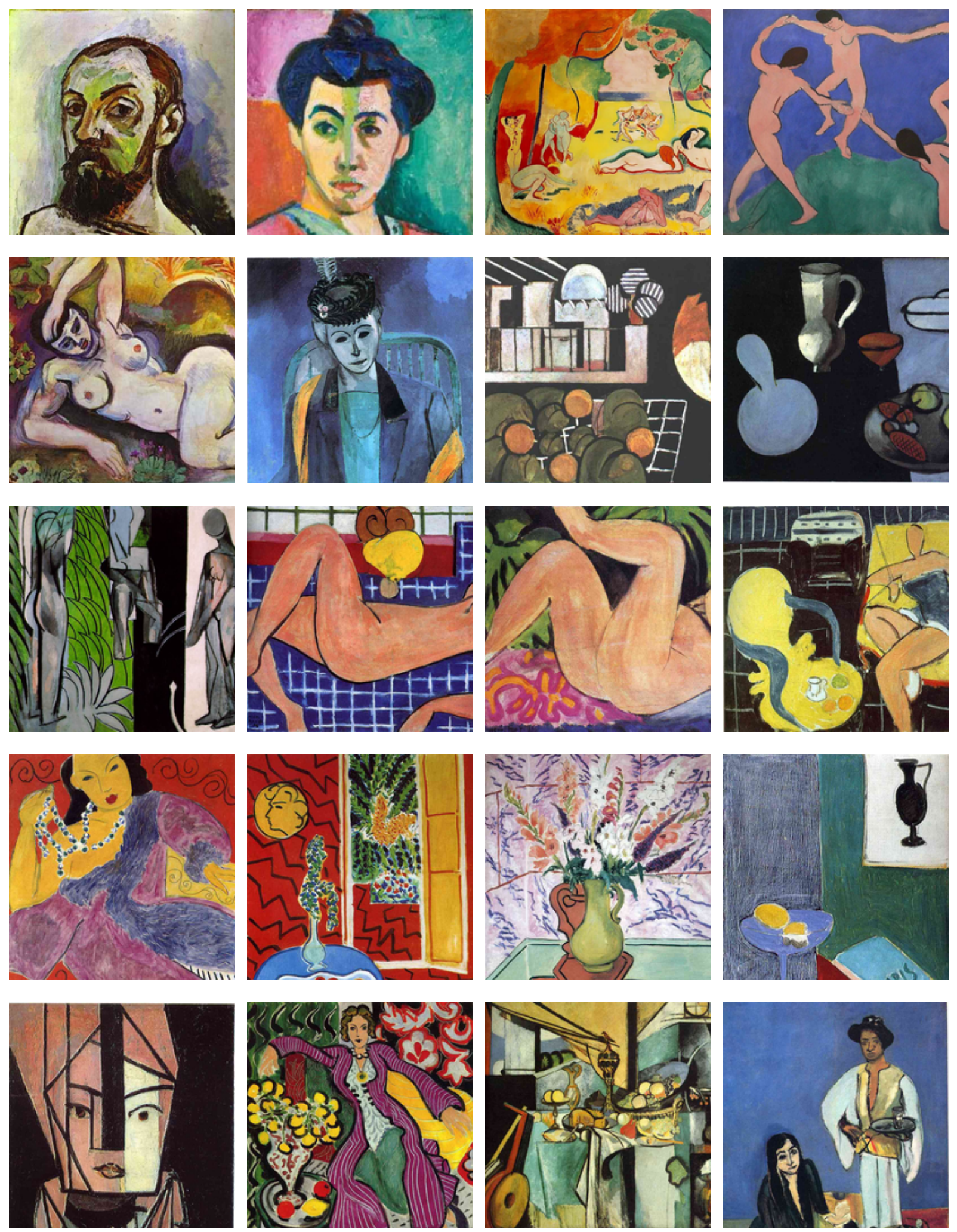

Fonte: LIST...(45) 
Figura B.10 - Pablo Picasso
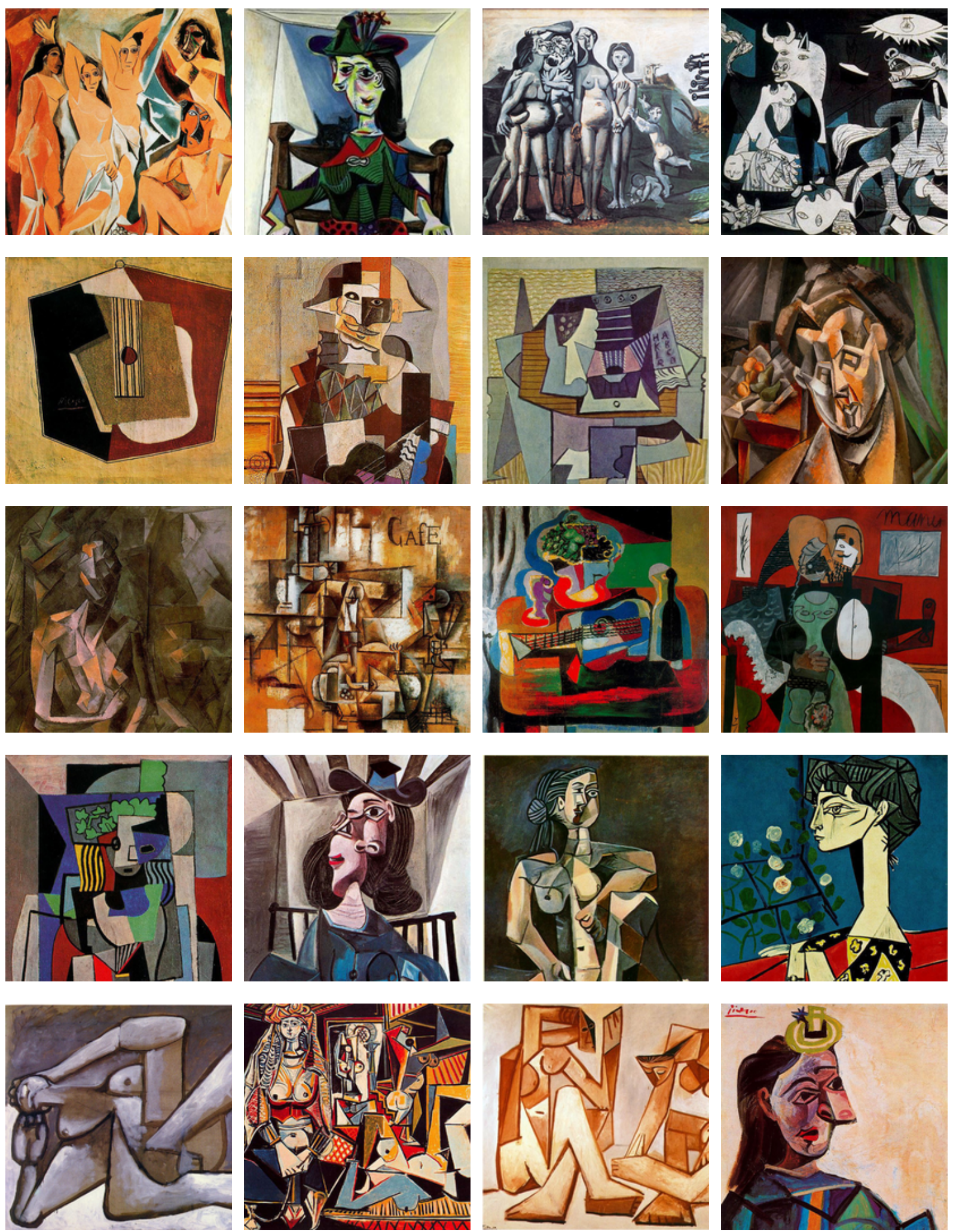

Fonte: PABLO...(48) 
Figura B.11 - Joan Miró
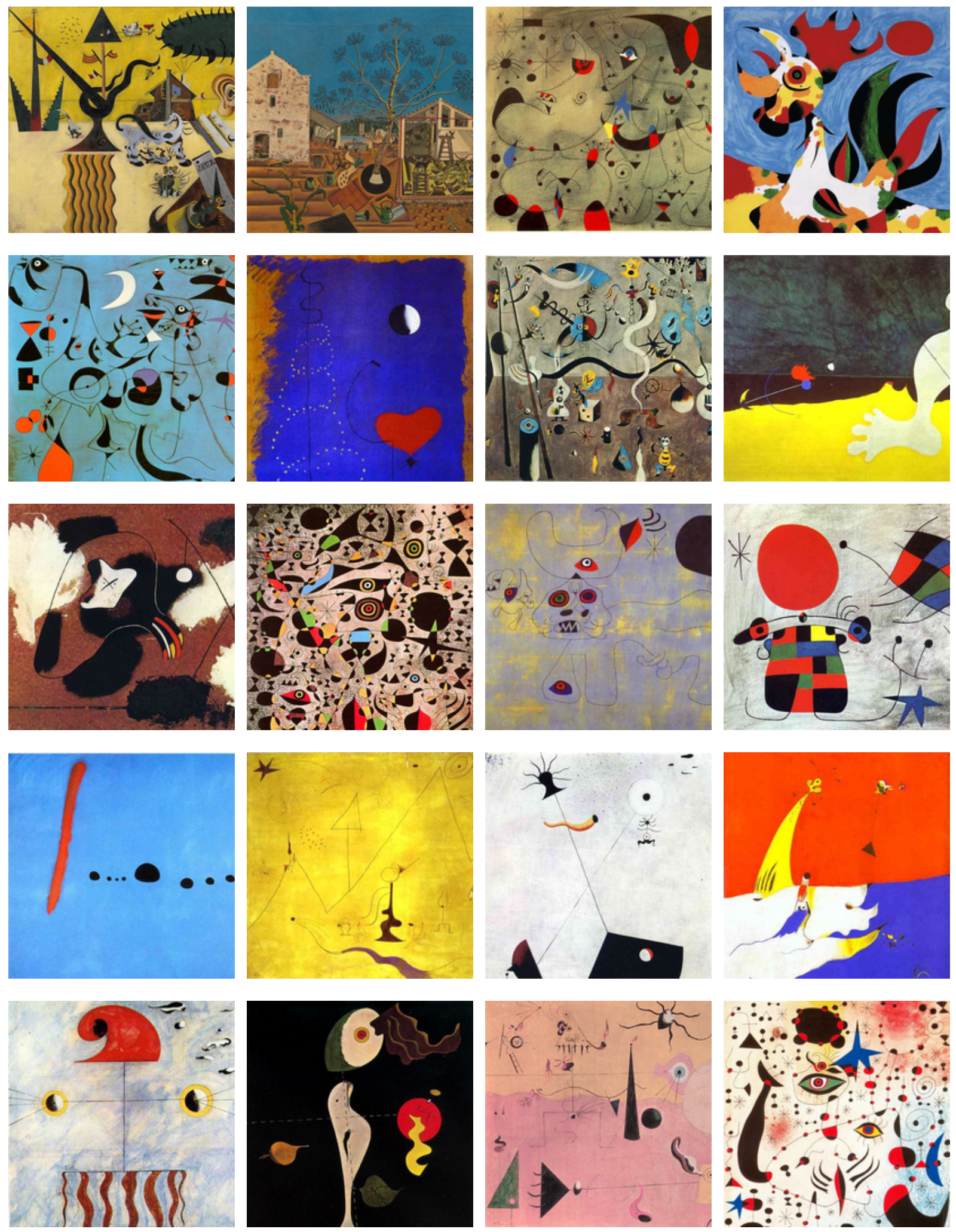

Fonte: JOAN...(52) 
Figura B.12 - Jackson Pollock
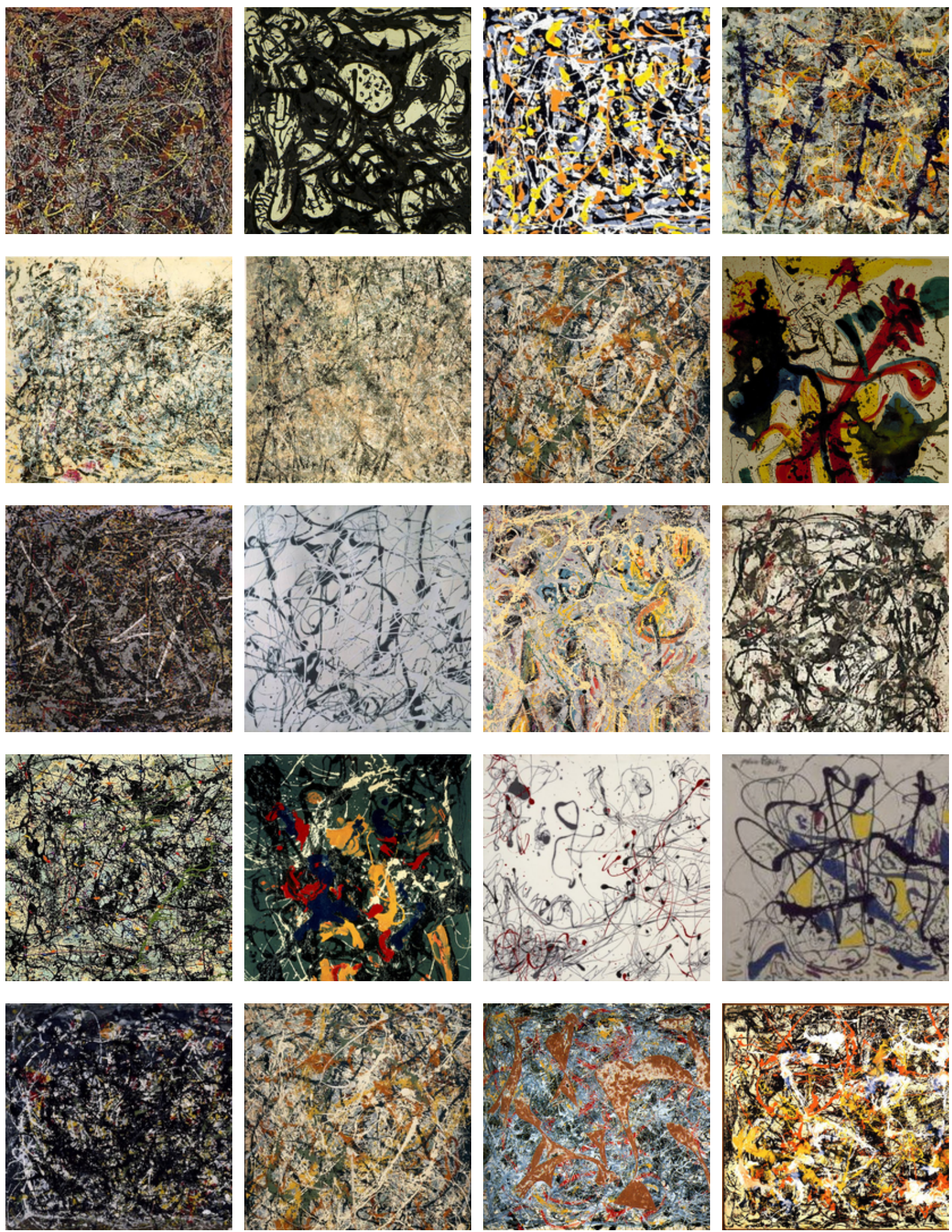

Fonte: JACKSON...(55) 



\section{APÊNDICE C - Visualizações complementares}

Ao se representar as projeções das figuras 3.14 e 3.15 usando miniaturas das pinturas ao invés de simples marcadores, tem-se uma visualização interessante onde detalhes de variações de contraste e cor podem ser observados (figura C.1, com detalhes destacados nas figuras C.2 e C.3).

Como a visualização fica comprometida em mídia impressa, optou-se pela implementação de um aplicativo Web que permite interagir com a projeção encontrada para as pinturas. O aplicativo está disponível em http://automata.github.io/viz-paintings e pode ser visitado por navegadores que suportem WebGL ${ }^{1}$. Há ainda um vídeo disponível em http://automata.cc/master-thesis que apresenta a gravação comentada do uso do aplicativo.

\footnotetext{
${ }^{1}$ Os navegadores Firefox 28.0 e Chrome 35, com suporte para WebGL devidamente configurado e habilitado, suportam tal aplicação
} 
Figura C.1 - Visualização alternativa das projeções das figuras3.14 e 3.15. É possível perceber detalhes de contraste e cor e sua influência no agrupamento e separação dos grupos de pintores.

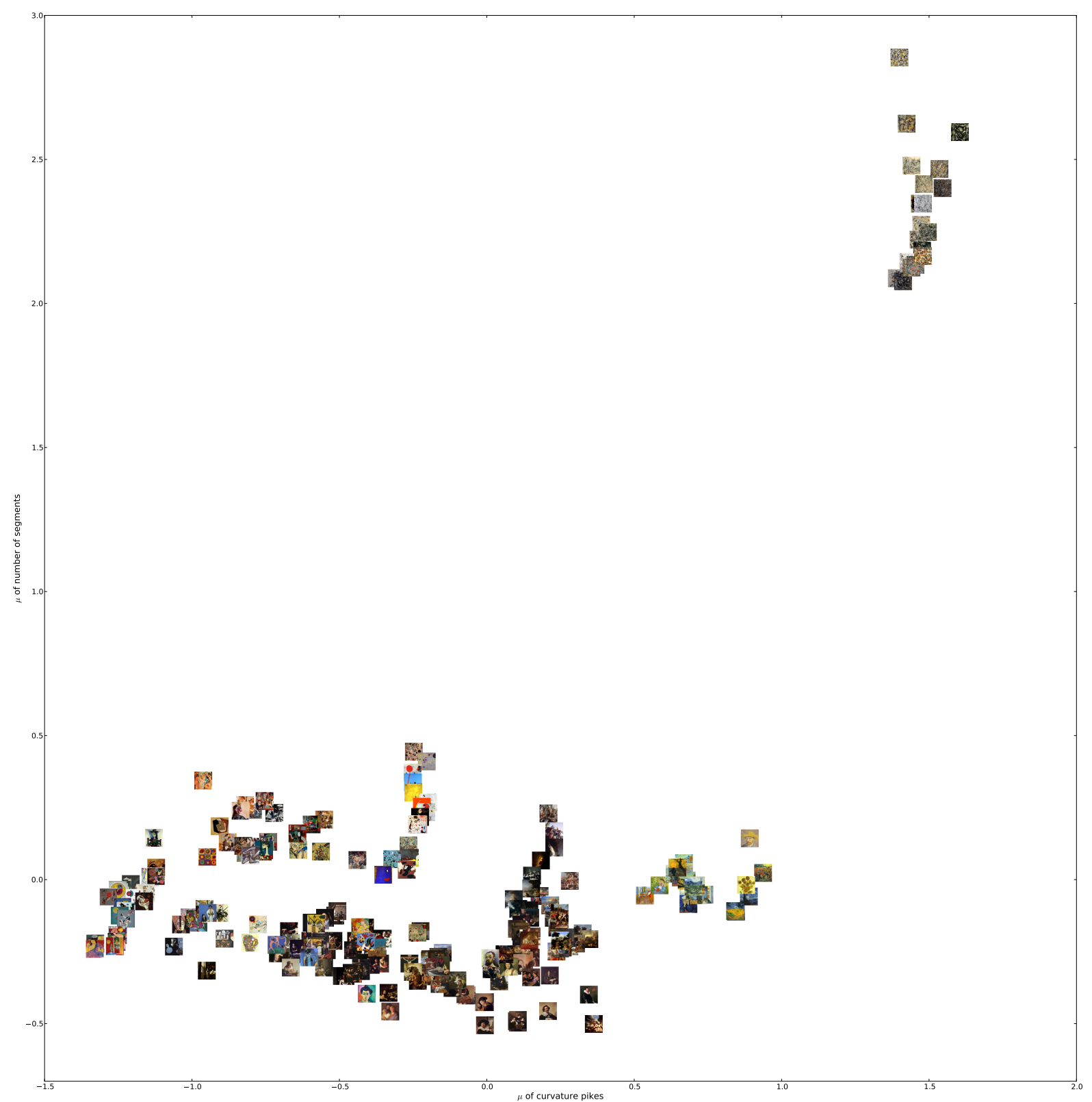

Fonte: Elaborado pelo autor. 
Figura C.2 - Detalhe da figura C.1 do grupo onde há maior concentração de pintores. Nota-se que alguns pintores, como van Gogh, apresentam uma classificação com nenhuma sobreposição, enquanto outros, principalmente aqueles do grupo Barroco, apresentam grande sobreposição.
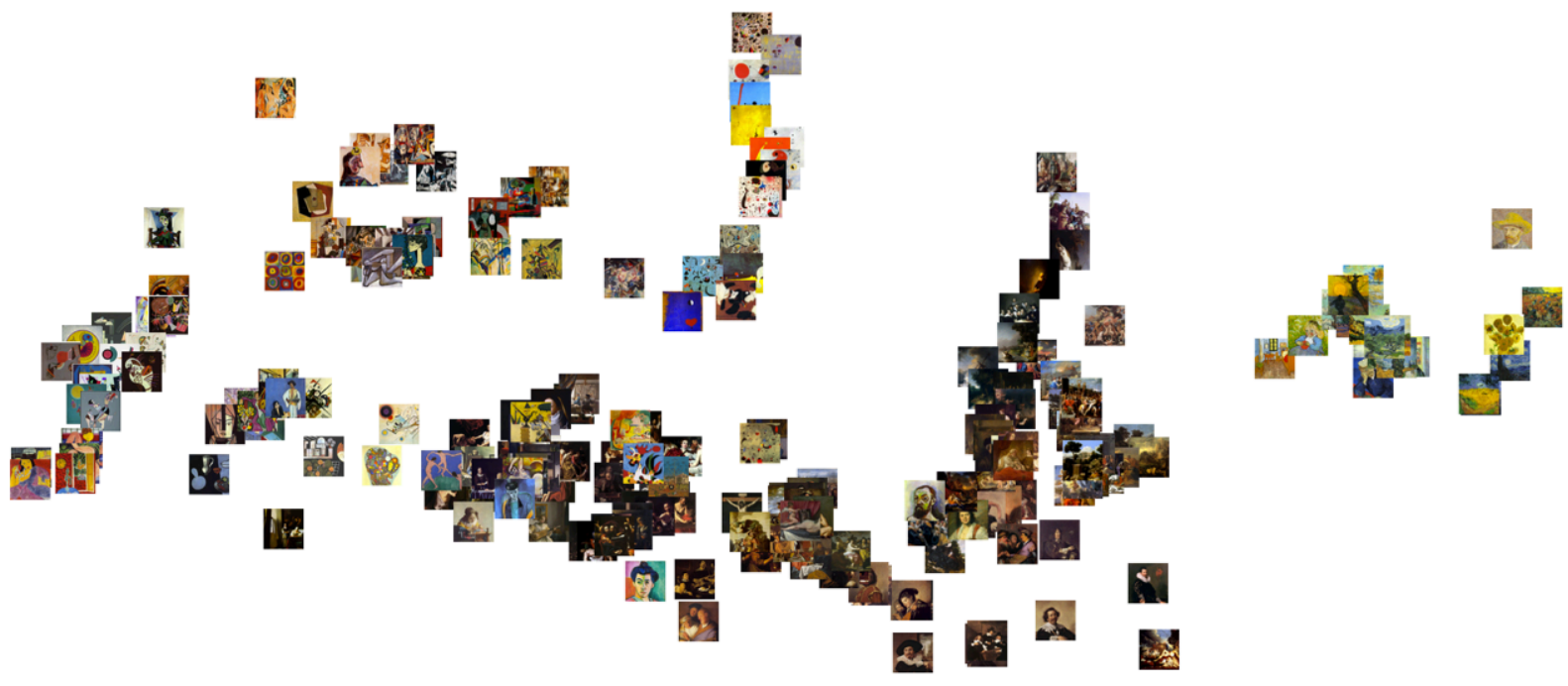

Fonte: Elaborado pelo autor. 
Figura C.3 - Detalhe da figura C.1 do grupo de pinturas pertencentes exclusivamente à Jackson Pollock. Por este pintor ter características que foge aos demais artistas, suas pinturas apresentam-se distribuídas afastadas consideravelmente dos outros pintores.

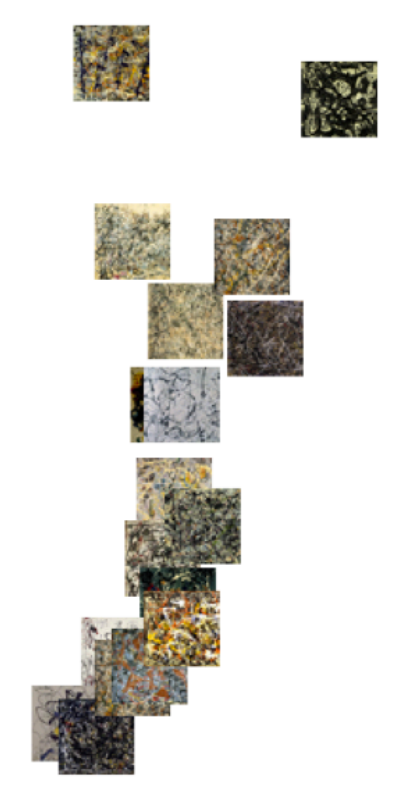

Fonte: Elaborado pelo autor. 


\section{APÊNDICE D - Contribuições artísticas}

Além da análise de pinturas e sua interpretação, este estudo pôde contribuir de maneira artística em algumas oportunidades aqui apresentadas. Tendo como base o processamento de imagens (principalmente as etapas de pré-processamento e segmentação) realizado para as 240 pinturas usadas nesse estudo, foram geradas 240 novas pinturas. Todas as 240 pinturas generativas estão disponíveis em http://www. flickr .com/photos/auto_mata/sets/72157634660390040/. Nos dias 30 de Setembro à 4 de Outubro de 2013, um conjunto destas pinturas foi aceito para exposição no espaço "Obra Artística” da $3^{a}$ Semana Integrada do Instituto de Física de São Carlos (SIFISC 3). Seguem os detalhes da obra, que também descreve o algoritmo implementado para a geração das pinturas:

Título Pinturas generativas por tesselação de Delaunay. Estudo 4

Tipo de obra Quadro

Altura $120 \mathrm{~cm}$

Profundidade $5 \mathrm{~cm}$

Largura $240 \mathrm{~cm}$

Descrição Imagens de pinturas originais dos movimentos Barroco e Moderno foram segmentadas. Coordenadas de pontos pertencentes a esses segmentos foram dadas como entrada 
para o algoritmo de tesselação de Delaunay. O algoritmo cria uma malha a partir da triangulação das coordenadas dadas, sem cruzamentos de arestas. A cor de cada triângulo da malha equivale à cor média do segmento da pintura original.

Todo o código-fonte assim como as pinturas geradas, e suas versões para impressão, encontramse em http://github. com/automata/tri-delaunay. A figura D.3 mostra fotos da exposição. O objetivo foi desmistificar o processo de geração das imagens, mostrando junto com a imagem final, cada passo do algoritmo, ilustrado com imagens explicativas — como visto nas figuras D.1 e D.2. Ainda, as instruções para o visitante acessar e executar o código-fonte, para gerar suas próximas versões remixadas com base em novas imagens, acompanhavam cada pintura. As pinturas expostas foram escolhidas através da consulta à preferência de pessoas em uma thread da lista de emails do labMacambira.sf.net ${ }^{1}$ e dos próprios autores deste estudo ${ }^{2}$

Há ainda uma proposta de publicação impressa destas imagens pela editora independente Quiosque, com editoração de Geraldo Magela de Castro Rocha Junior, curadoria de Leticia Palaria e texto de Renato Fabbri e integrantes do LabMacambira.sf.net. Uma prévia do conteúdo a ser publicado pode ser visto na figura D.4.

\footnotetext{
${ }^{1}$ http://labmacambira.sf.net

2 Em https://etherpad.mozilla.org/genpaintings encontra-se o pad com as sugestões levantadas, assim como um esboço de uma matéria sobre as pinturas que pretende-se publicar na revista aberta e independente Quiosque, em 2014.
} 
Figura D.1 - Pintura generativa, criada a partir de tesselação de Delaunay da obra original de Frans Hals.
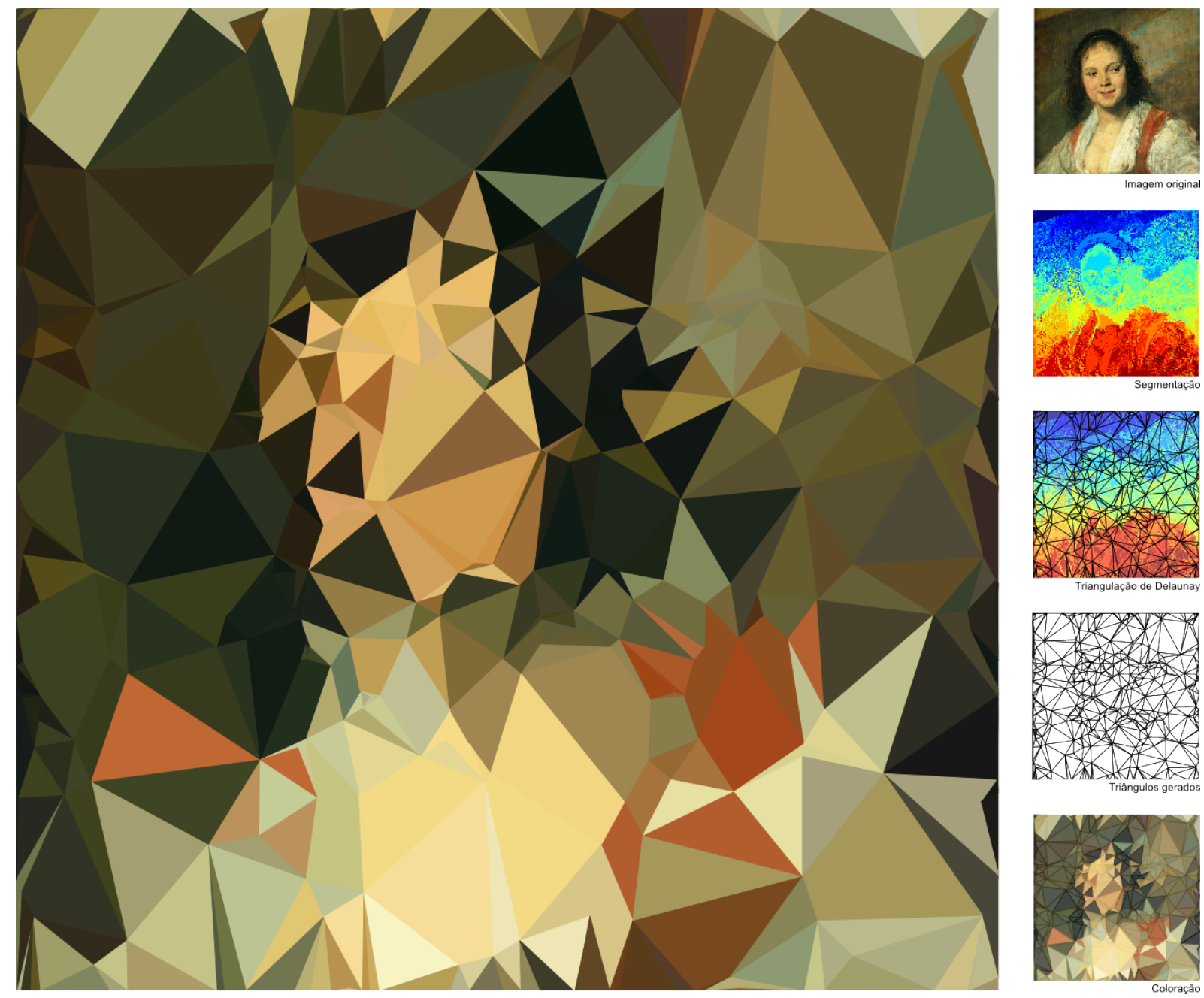

Fonte: Elaborado pelo autor. 
Figura D.2 - Pintura generativa, criada a partir de tesselação de Delaunay da obra original de Picasso.
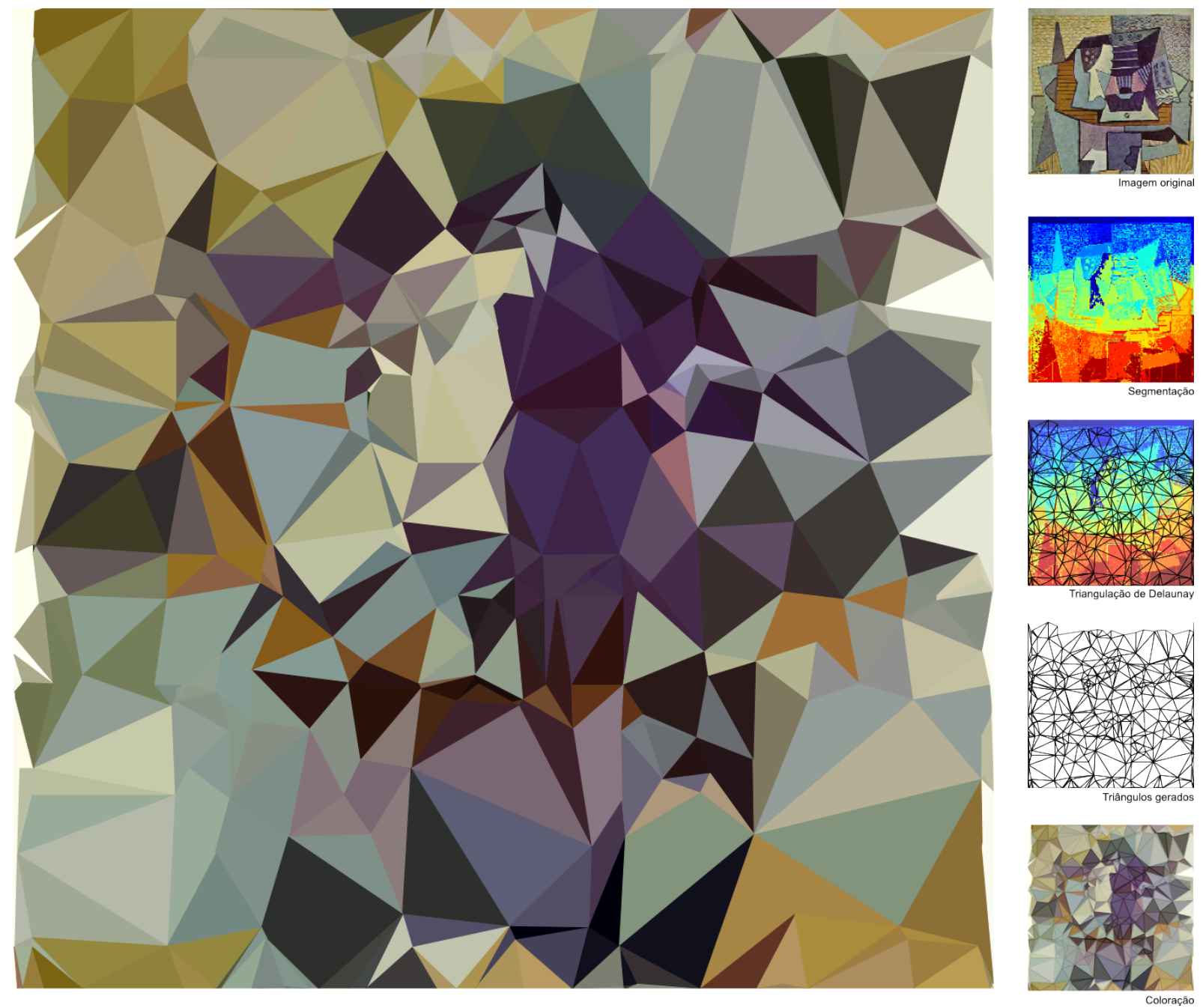

Fonte: Elaborado pelo autor. 
Figura D.3 - Fotos da exposição realizada no SIFISC 2013, no espaço "Obra Artística" com imagens geradas por algoritmo desenvolvido em paralelo a este estudo.
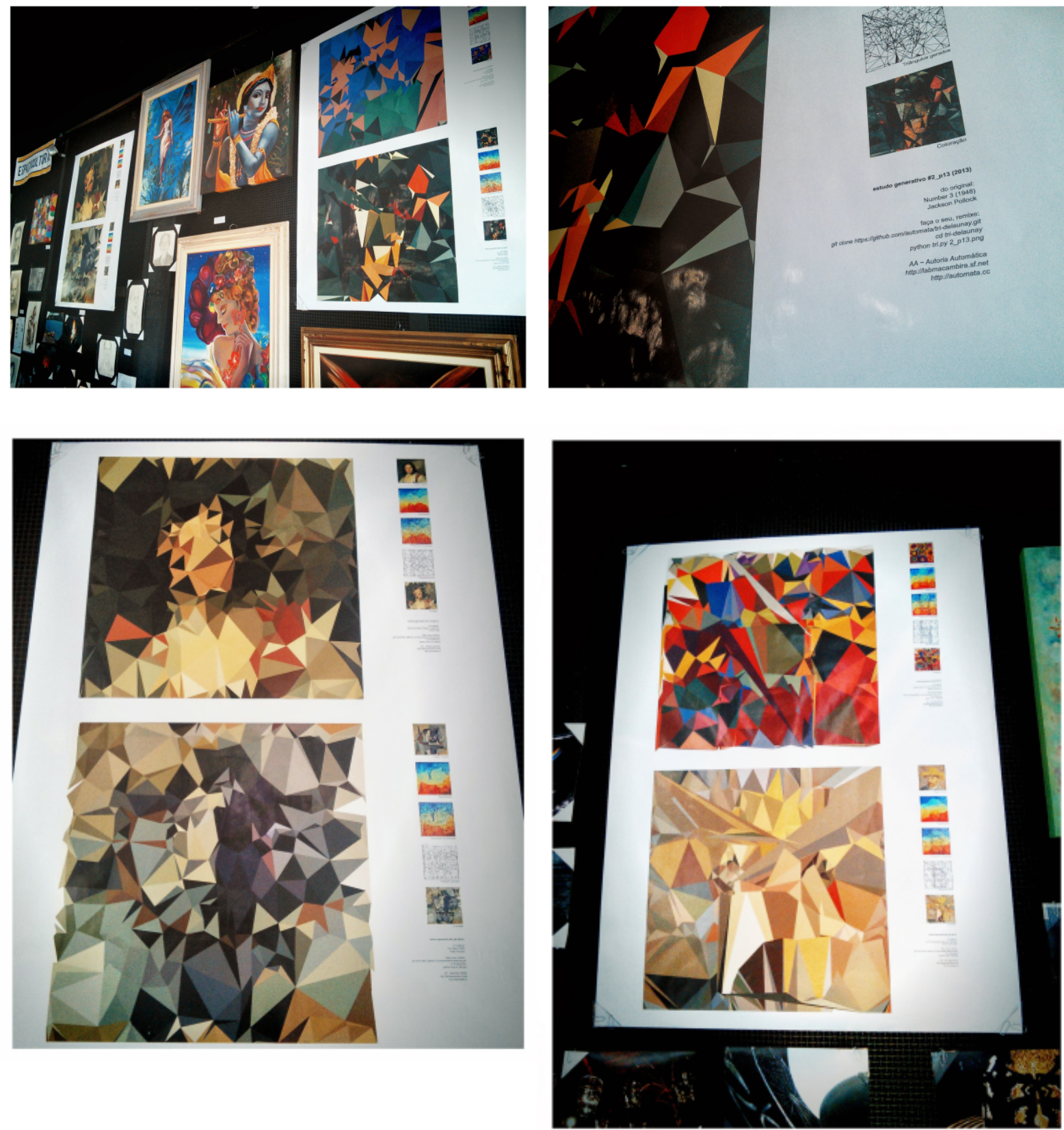

Fonte: Elaborado pelo autor. 
Figura D.4 - Prévia do conteúdo da publicação impressa intitulada "Pinturas generativas $\mathcal{F}$ Freakcoding” prevista para 2014, através da Editora independente Quiosque.

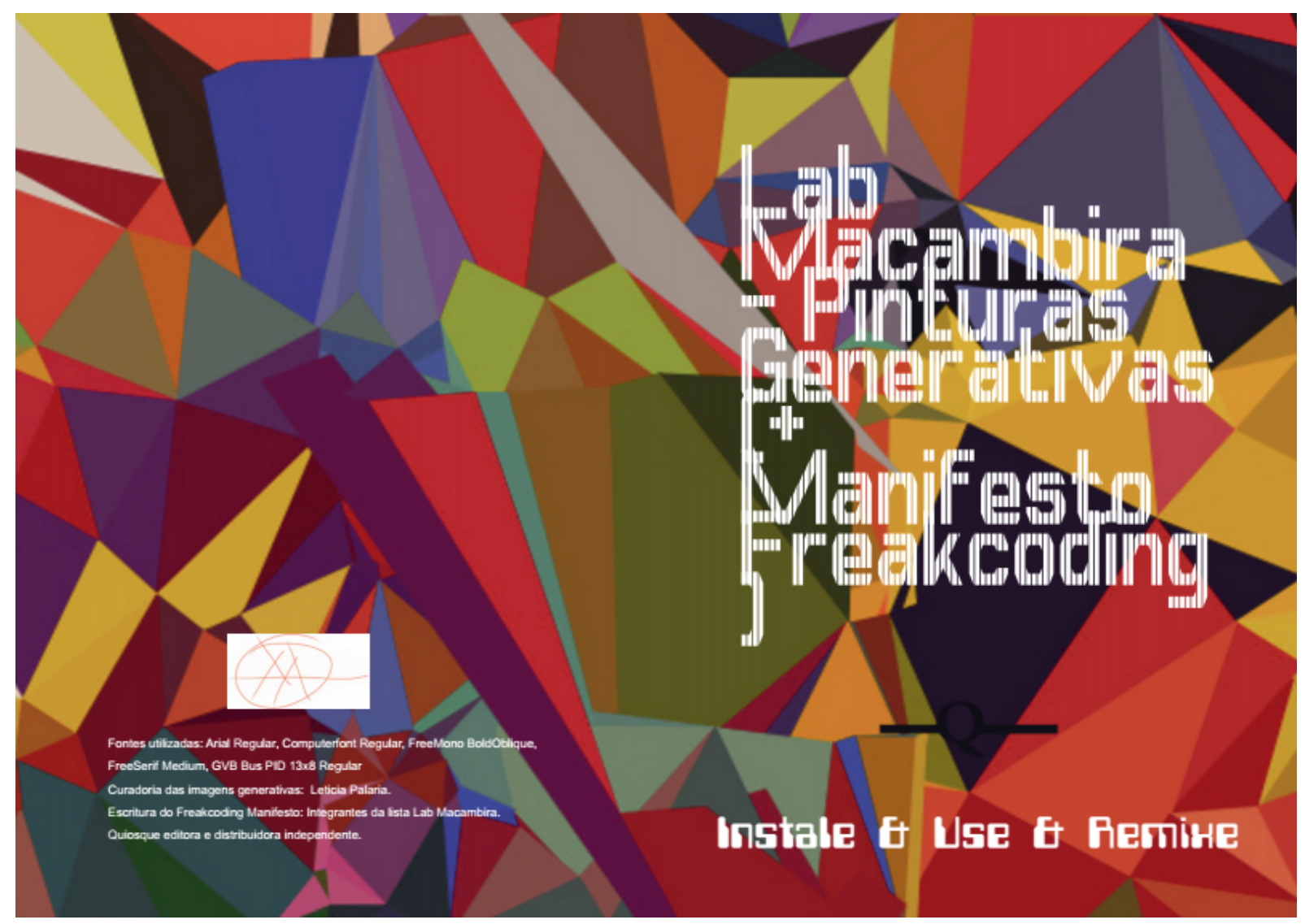

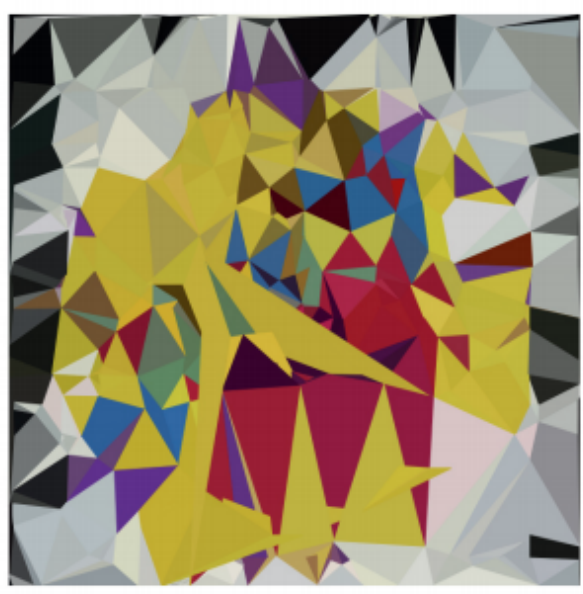

qaqsıaอก

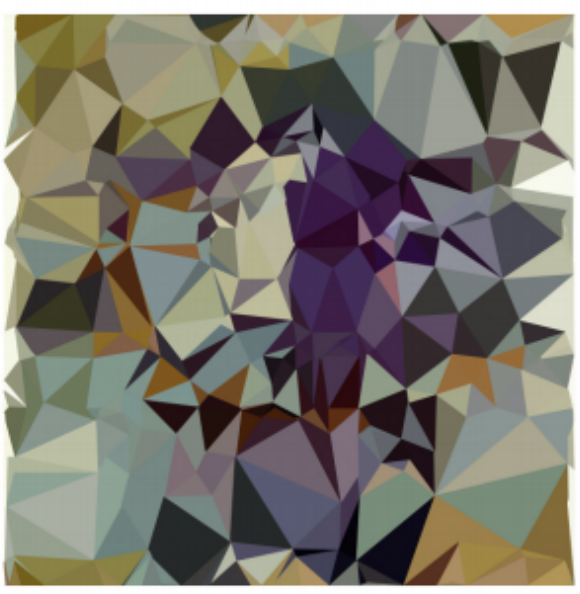

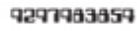

Pinturas

Generativas

Pinturas

Generativas 
